\title{
AN INVESTIGATION OF CORPORATE RESPONSIBILITY \& SUSTAINABILITY GOALS IN THE Canadian Commercial Real Estate and Construction SECtOR
}

BY

IRENA STANKOVIC

HONS. BA. YORK UNIVERSITY, TORONTO, 2007

A THESIS PRESENTED TO RYERSON UNIVERSITY

IN PARTIAL FULFILLMENT OF THE REQUIREMENTS FOR THE DEGREE OF

MASTER OF APPLIED SCIENCE

IN THE PROGRAM OF

ENVIRONMENTAL ApPlied SCIENCE AND MANAGEMENT

TORONTO, ONTARIO, CANADA, 2014

(C) IRENA STANKOVIC, LEED AP BD+C 2014 


\section{AUTHOR'S DECLARATION FOR ELECTRONIC SUBMISSION OF A THESIS}

I hereby declare that I am the sole author of this thesis. This is a true copy of the thesis, including any required final revisions, as accepted by my examiners.

I authorize Ryerson University to lend this thesis to other institutions or individuals for the purpose of scholarly research

I further authorize Ryerson University to reproduce this thesis by photocopying or by other means, in total or in part, at the request of other institutions or individuals for the purpose of scholarly research.

I understand that my thesis may be made electronically available to the public. 


\title{
Abstract \\ AN INVESTIGATION OF CORPORATE RESPONSIBILITY \& SUSTAINABILITY GOALS IN THE Canadian Commercial Real Estate and Construction SECtor
}

\author{
Master of Applied Science \\ 2014 \\ Irena Stankovic \\ Environmental Applied Science and Management \\ Ryerson University
}

This thesis investigates the potential integration of leading Corporate Responsibility and Sustainability (CR\&S) goals across selected Commercial Real Estate (CRE) firms, key anchor tenants, and construction companies within the Canadian market as they relate to office building assets. Current literature provides limited observations and analysis on CR\&S within the CRE sector, particularly for the Canadian market. In order to address this gap and advance the principles of CR\&S across the Canadian CRE sector, the research provides a comprehensive qualitative content analysis of publically available CR\&S reports, along with interviews conducted with subject matter experts in the sector. Reduction of energy, water and waste consumption, along with associated GHG emissions have been identified as leading elements driving environmental resource management, which in turn is identified as the founding base for integrating CR\&S goals across the Canadian CRE market. In addition to uncovering leading CR\&S goals, the study identified market differentiators and regulatory compliance as key CR\&S motivators, along with leading tracking and implementation measures for CR\&S goals, and their associated internal and external barriers to integrating CR\&S goals. Ultimately, the study provides an academic contribution in identifying environmental resource management as a base for CR\&S integration across the Canadian CRE sector. 


\section{Acknowledgments}

I would like to thank the following people for their continuous support and council through the entire thesis research process:

- Cory Searcy, the ideal supervisor who knew how and when to push my boundaries. Especially at crunch time.

- $\quad$ My mentors, for guiding my interests, developing my senses, and honing my energy.

- $\quad$ All of the industry and subject matter experts whose identities are concealed but their invaluable insights, directions and thirst for change have fuelled the research.

- My parents for their sacrifices, ongoing support and their words of encouragement delivered in the format of constant questioning. Thank you for teaching me perseverance by grounding me.

- $\quad$ My two younger sisters for teaching me the meaning of leadership.

- $\quad$ Captain Planet, and the green spirit of 90s cartoons.

"We are in an economy of control with which our intellectual inheritance fits but awkwardly. To make control really tolerable we need something more; something which is still in its infancy. We need an economics of responsibility, developed and embodied in our working business ethics."

J. Maurice Clark, University of Chicago 


\section{TABLE OF CONTENTS}

AUTHOR'S DECLARATION FOR ELECTRONIC SUBMISSION OF A THESIS ................II

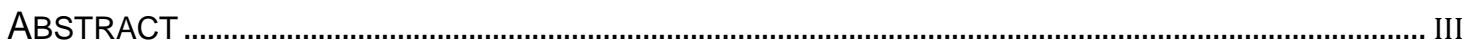

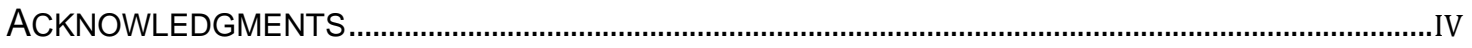

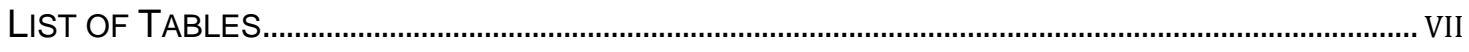

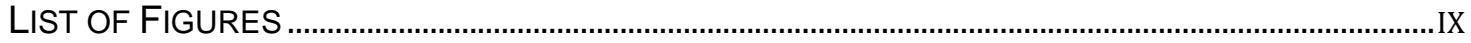

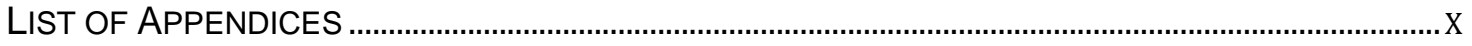

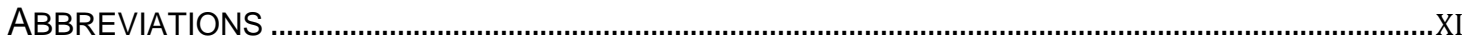

CHAPTER 1: INTRODUCTION

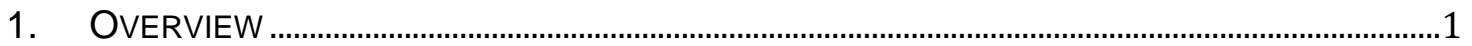

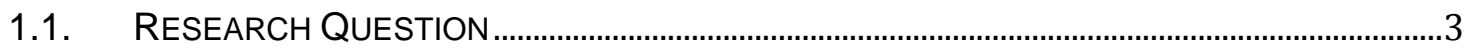

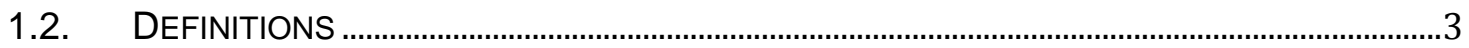

1.2.1. OFFICE BUILDING AND OFFICE BUILDING COMPLEX/SUBURBAN PARKS ..................4

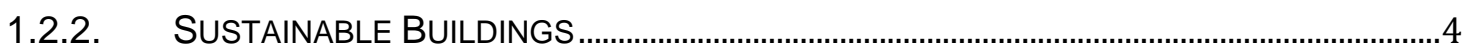

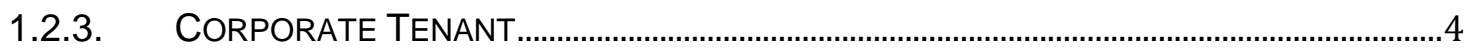

1.2.4. COMMERCIAL REAL ESTATE (CRE) FIRMS ...............................................................

1.2.5. CONSTRUCTION SECTOR ................................................................................................

1.2.6. CORPORATE RESPONSIBILITY \& SUSTAINABILITY .......................................................

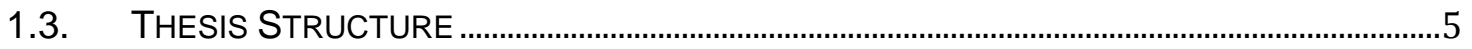

CHAPTER 2: LITERATURE REVIEW

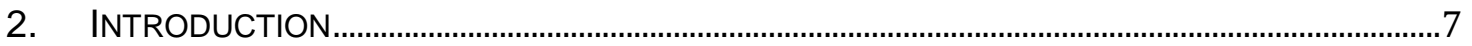

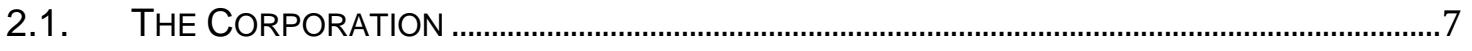

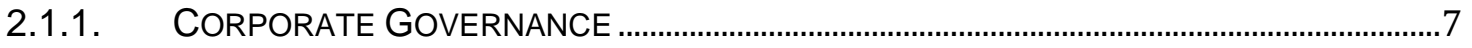

2.1.2. SHAREHOLDER AND STAKEHOLDER ACCOUNTABILITY .............................................

2.1.3. CORPORATE DECISION MAKING PROCESS...................................................................11

2.2. CORPORATE RESPONSIBILITY \& SUSTAINABILITY .......................................................11

2.2.1. DEFINING CORPORATE RESPONSIBILITY \& SUSTAINABILITY - GENERAL

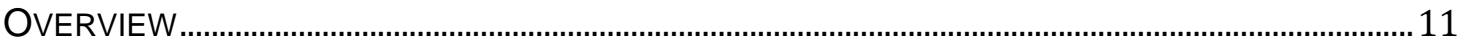

2.2.2. CORPORATE RESPONSIBILITY \& SUSTAINABILITY REPORTING ................................13

2.3. CORPORATE RESPONSIBILITY \& SUSTAINABILITY IN THE COMMERCIAL REAL

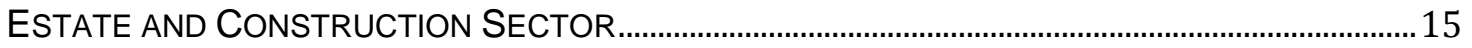

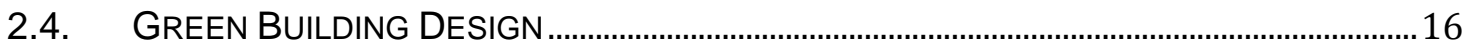

2.5. RESPONSIBLE PROPERTY INVESTMENT AND GREEN REAL ESTATE ...........................17

2.6. CORPORATE RESPONSIBILITY \& SUSTAINABILITY PERFORMANCE MEASURES -

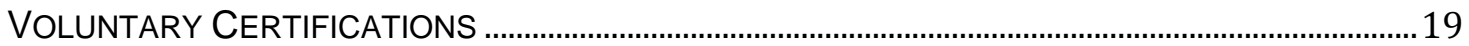

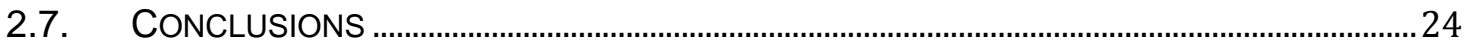

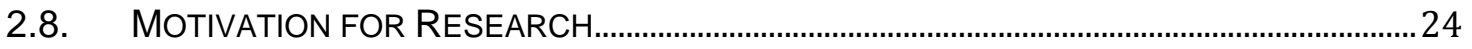

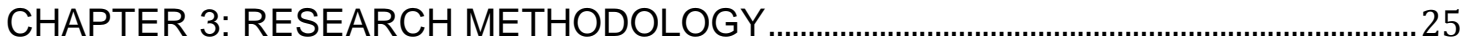

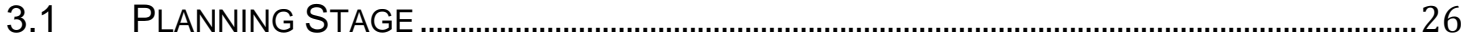

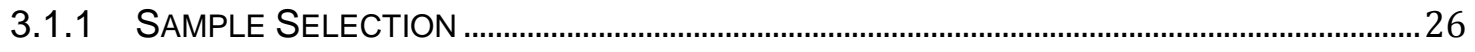

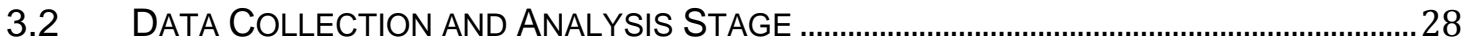

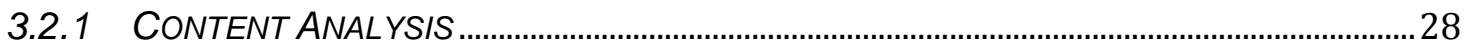

3.2.2 SEMI-STRUCTURED RESEARCH INTERVIEWS ..................................................................... 32

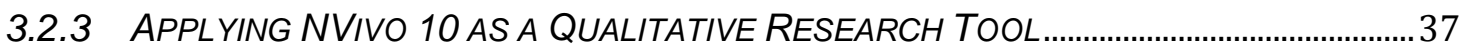

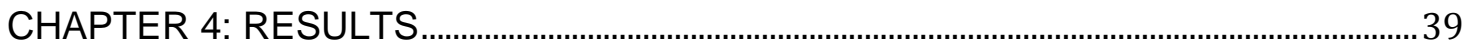

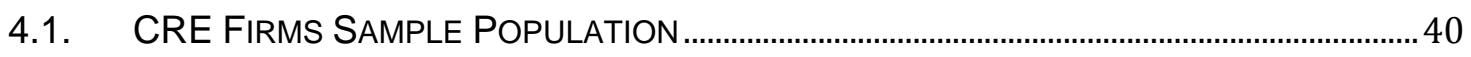

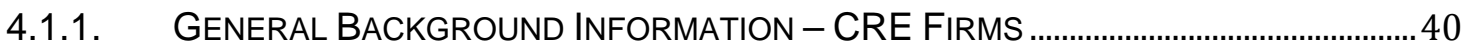

4.1.2. ASSESSING CR\&S ACROSS CRE FIRMS ............................................................... 41

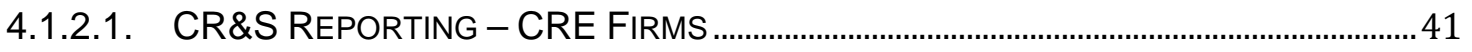


4.1.2.2. CR\&S DEFINITION - CRE FIRMS ……………........................................................ 42

4.1.3. LEADING CR\&S GOALS FOR CRE FIRMS ……….....................................................4

4.1.4. LEADING CR\&S MOTIVATORS FOR CRE FIRMS …………………………………...52

4.1.5. LEADING CR\&S IMPLEMENTATION AND TRACKING METHODS FOR CRE FIRMS 53

4.1.6. LEADING CR\&S BARRIERS FOR CRE FIRMS ……………..........................................56

4.2. CORPORATE TENANT SAMPLE POPULATION ...................................................................58

4.2.1. GENERAL BACKGROUND INFORMATION - CORPORATE TENANTS............................58

4.2.2. ASSESSING CR\&S ACROSS CORPORATE TENANTS .................................................59

4.2.2.1. CR\&S REPORTING - CORPORATE TENANTS............................................................59

4.2.2.2. CR\&S DEFINITION - CORPORATE TENANTS..............................................................6

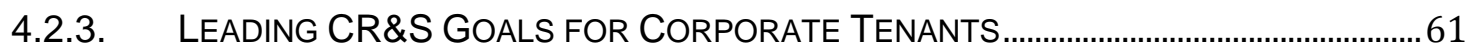

4.2.4. LEADING CR\&S MOTIVATORS FOR CORPORATE TENANTS .......................................67

4.2.5. LEADING CR\&S IMPLEMENTATION AND TRACKING METHODS FOR CORPORATE TENANTS 68

4.2.6. LEADING CR\&S BARRIERS FOR CORPORATE TENANTS ............................................72

4.3. CONSTRUCTION SAMPLE POPULATION...........................................................................75

4.3.1. GENERAL BACKGROUND INFORMATION - CONSTRUCTION FIRMS ............................75

4.3.2. ASSESSING CR\&S ACROSS CONSTRUCTION FIRMS...................................................76

4.3.2.1. CR\&S REPORTING - CONSTRUCTION FIRMS .............................................................76

4.3.2.2. CR\&S DEFINITION - CONSTRUCTION FIRMS ................................................................77

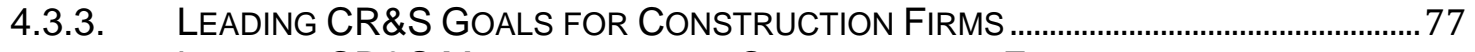

4.3.4. LEADING CR\&S MOTIVATORS FOR CONSTRUCTION FIRMS.......................................78

4.3.5. LEADING CR\&S IMPLEMENTATION AND TRACKING METHODS FOR CONSTRUCTION FIRMS ……………………………………………………………………………..79

4.3.6. LEADING CR\&S BARRIERS FOR CONSTRUCTION FIRMS............................................79

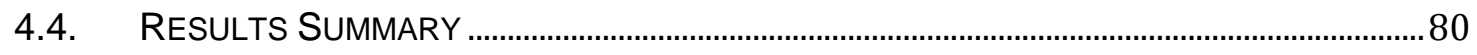

4.4.1. GENERAL BACKGROUND INFORMATION ………………………………………....81

4.4.2. ASSESSMENT OF CR\&S ACROSS CRE FIRMS, CORPORATE TENANTS AND

CONSTRUCTION FIRMS ………………………………………………………………………………....

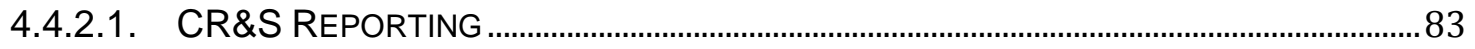

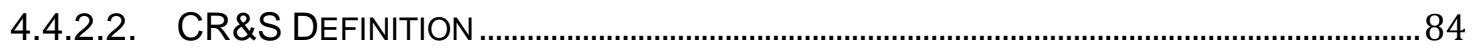

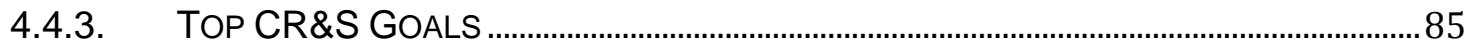

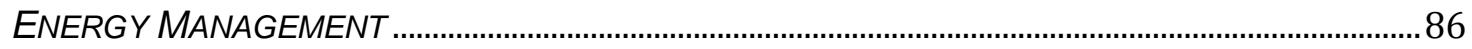

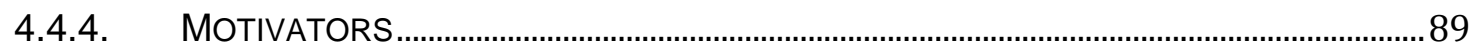

4.4.5. TRACKING AND IMPLEMENTATION ...............................................................................

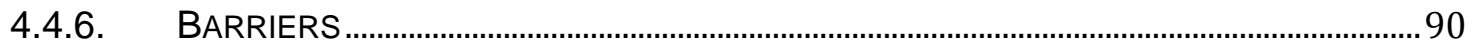

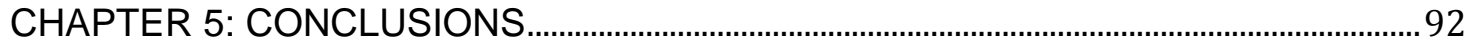

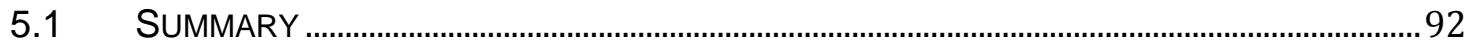

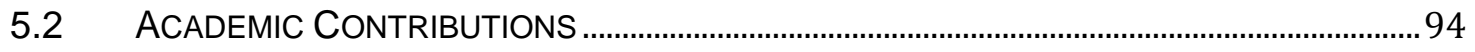

5.3 INDUSTRY RECOMMENDATIONS.....................................................................................95

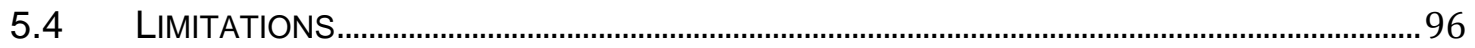

5.5 FUTURE RESEARCH.......................................................................................................97 


\section{List of Tables}

TABLE 1 ESG VALUES (PIVO, 2010)...

TABLE 2 CR\&S REPORTING AND CERTIFICATION REQUIREMENTS FOR VOLUNTARY CERTIFICATIONS, INDUSTRY BENCHMARKS AND REPORTING WITHIN THE CRE AND CONSTRUCTION SECTORS..........23

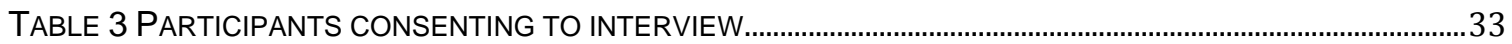

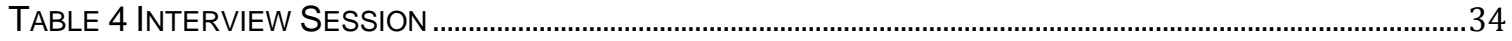

TABle 5 OfFice BuIlding SPACE (CANAdian PROPERTy ManAgement Vol. 26) .......................................40

TABLE 6 CR\&S BASED ROLES FOR SELECTED CRE FIRM SAMPLES ..............................................................41

TABLE 7 TOP ENVIRONMENTAL RESOURCE MANAGEMENT BASED CR\&S GOALS FOR CRE SECTOR -

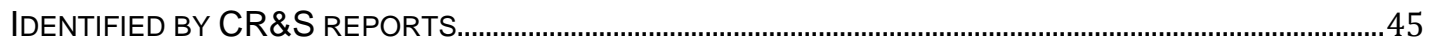

TABLE 8 TOP ENVIRONMENTAL ResOURCE MANAGEMENT BASED CR\&S gOALS FOR CRE SECTOR IDENTIFIED THROUGH INTERVIEW SEGMENTS .............................................................................................. 45

TABLE 9 CR\&S IMPLEMENTATION PROCESSES - CRE FIRMS ……………………….......................................54

TABLE 10 BARRIERS IN THE CRE SECTOR.................................................................................................56

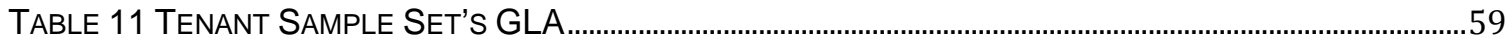

TABLE 12 - CR\&S BASEd RoleS FOR SELECTED TENANT SAMPLE PoPULATION .........................................59

TABLE 13 CORPORATE TENANTS' TOP CR\&S GOALS - CR\&S REPORTS ......................................................62

TABLE 14 IMPLEMENTATION STRATEGIES FOUND THROUGH TENANTS' CR\&S REPORTS .............................69

TABLE 15 INTERNAL VERSUS EXTERNAL BARRIERS - BASED ON TENANTS' INTERIEW SEGMENTS .............72

TABLE 16 CR\&S BASED ROLES FOR THE SELECTED CONSTRUCTION FIRMS .......................................................76

TABLE 17 OVERALl BUILDING SPACE AND ConStRUCTION PROJECT OVERVIEW............................................82

TABLE 18 OVERALL CR\&S BASED ROLES FOR SAMPLED CRE STAKEHOLDERS. ..............................................82

TABLE 19 TOP LEADING CR\&S GOALS IDENTIFIED ACROSS CRE SECTOR THROUGH AVAILABLE CR\&S

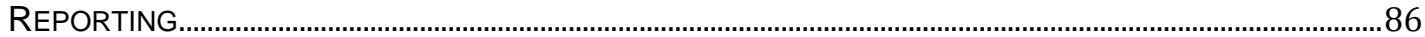

TABLE 20 NVIVO'S TOP 25 WORD FREQUENCY QUERY RESULTS FOR CR\&S DEFINITIONS - CRE FIRMS'

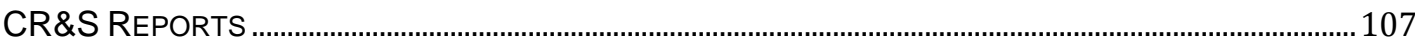

TABLE 21 NVIVO'S TOP 25 WORD FREQUENCY QUERY RESULTS FOR CR\&S DEFINITION - CRE FIRMS' INTERVIEW SEGMENTS ..........................................................................................................................108

TABLE 22 NVIVO'S TOP 25 WORd FREQUENCY QUERY RESULTS FOR CR\&S GOALS - CRE FIRMS'

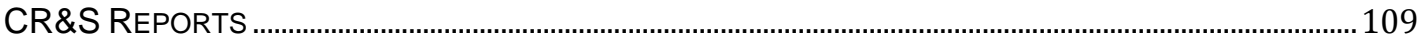

TABLE 23 NVIVO'S TOP 25 WORD FREQUENCY QUERY RESULTS FOR CR\&S GOALS - CRE FIRMS'

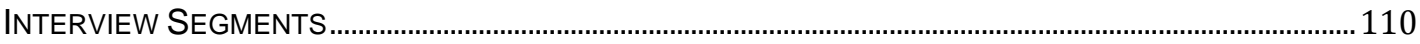

TABLE 24 NVIVO'S TOP 25 WORD FREQUENCY QUERY RESULTS FOR CR\&S MOTIVATORS - CRE

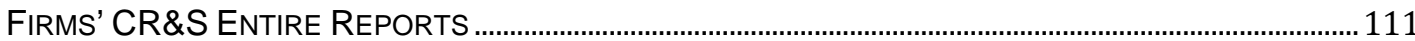

TABLE 25 NVIVO'S TOP 25 WORD FREQUENCY QUERY RESULTS FOR CR\&S MOTIVATORS - CRE FIRMS' INTERVIEW SEGMENTS

TABLE 26 NVIVO'S TOP 25 WORD FREQUENCY QUERY RESULTS FOR IMPLEMENTATION AND TRACKING METHODS- CRE FIRMS' CR\&S REPORTS..........................................................................................113

TABLE 27 NVIVO'S TOP 25 WORD FREQUENCY QUERY RESULTS FOR IMPLEMENTATION AND TRACKING METHODS - CRE FIRMS' INTERVIEW SEGMENTS.

TABLE 28 NVIVO'S TOP 25 WORD FREQUENCY QUERY RESULTS FOR BARRIERS ACROSS CRE FIRMS' INTERVIEW SEGMENTS

TABLE 29 NVIVO 10'S TOP 25 WORD FREQUENCY QUERY RESULTS FOR CR\&S DEFINITION CORPORATE TENANTS' CR\&S REPORT.

TABLE 30 NVIVO 10'S TOP 25 WORD FREQUENCY QUERY RESULTS FOR CR\&S DEFINITION CORPORATE TENANTS' INTERVIEW SEGMENTS

TABLE 31 NVIVO 10'S TOP 25 WORD FREQUENCY QUERY RESULTS FOR CR\&S GOALS -CORPORATE TENANT'S CR\&S REPORTS.

TABLE 32 NVIVO 10'S TOP 25 WORD FREQUENCY QUERY RESULTS FOR CR\&S GOALS - CORPORATE TENANTS' INTERVIEW SEGMENTS

TABLE 33 NVIVO 10'S TOP 25 WORD FREQUENCY QUERY RESULTS FOR CR\&S MOTIVATORS CORPORATE TENANTS' CR\&S REPORTS..

TABLE 34 NVIVO 10'S TOP 25 WORD FREQUENCY QUERY RESULTS FOR CR\&S MOTIVATORS CORPORATE TENANTS' INTERVIEW SEGMENTS 
TABLE 35 NVIVO 10'S TOP 25 WORD FREQUENCY QUERY RESULTS FOR CR\&S IMPLEMENTATION AND

TRACKING METHODS - CORPORATE TENANTS' CR\&S REPORTS

TABLE 36 NVIVO 10'S TOP 25 WORD FREQUENCY QUERY RESULTS CR\&S IMPLEMENTATION AND

TRACKING METHODS - CORPORATE TENANTS' INTERVIEW SEGMENTS ...............................................123

TABLE 37 NVIVO 10's TOP 25 Word FREQUENCY QueRY RESUlts CR\&S BARRIERS - CORPORATE

TENANTS' INTERVIEW SEGMENTS.........................................................................................................1 124

TABLE 38 NVIVO 10'S TOP 25 WORD FREQUENCY QUERY RESULTS CR\&S DEFINITIONS -

CONSTRUCTION FIRMS' CR\&S REPORTS.............................................................................................. 125

TABLE 39 NVIVO 10'S TOP 25 WORD FREQUENCY QUERY RESULTS CR\&S DEFINITIONS -

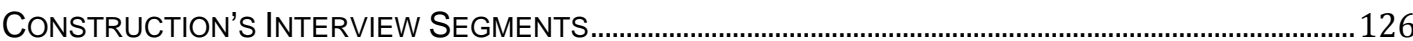

TABLE 40 NVIVO 10'S TOP 25 WORD FREQUENCY QUERY RESULTS CR\&S GOALS - CONSTRUCTION

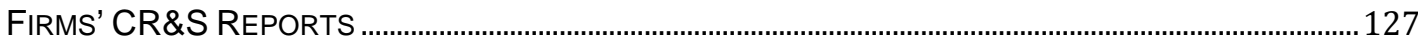

TABLE 41 NVIVO 10'S TOP 25 WORD FREQUENCY QUERY RESULTS CR\&S GOALS - CONSTRUCTION

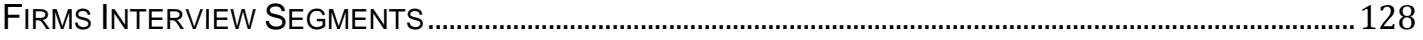

TABLE 42 NVIVO 10'S TOP 25 WORd FREQUENCY QUERY RESUltS CR\&S MOtIVATORS CONSTRUCTION FIRMS' CR\&S REPORTS...

TABLE 43 NVIVO 10'S TOP 25 WORD FREQUENCY QUERY RESULTS CR\&S MOTIVATORS CONSTRUCTION FIRMS' INTERVIEW SEGMENTS

TABLE 44 NVIVO 10'S TOP 25 WORD FREQUENCY QUERY RESULTS IMPLEMENTATION AND TRACKING METHODS - CONSTRUCTION FIRMS' CR\&S REPORTS....................................................................... 131

TABLE 45 NVIVO 10'S TOP 25 WORD FREQUENCY QUERY RESULTS IMPLEMENTATION AND TRACKING

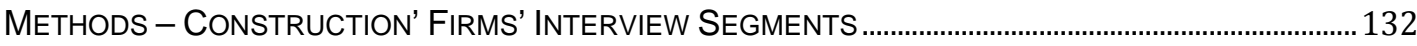

TABLE 46 NVIVO 10'S TOP 25 WORD FREQUENCY QUERY RESULTS FOR CR\&S BARRIERS CONSTRUCTION FIRMS' INTERVIEW SEGMENTS 


\section{List of Figures}

FigURE 1 PoWER RELATIONS IN MOdERn AMERICAN CORPORATIONS (DUNLAVY, 2006) ............................. 8

FIGURE 2 STAKEHOLDER ACCOUNTABILITY WITHIN THE CRE AND CONSTRUCTION INDUSTRY ....................10

Figure 3 THE TRIPLE BotTom Line (AdAPTED FROM CRANE AND MATTEN, 2008) .......................................12

FIGURE 4 RUSSIAN DOLL FRAMEWORK (SCHUMANN, 2010) ........................................................................12

FiguRE 5 THE PRINCIPLES OF RESPONSIBLE INVESTMENT, ANNUAL REPORT (2012) ..................................17

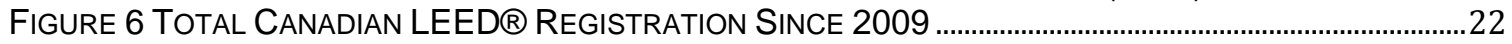

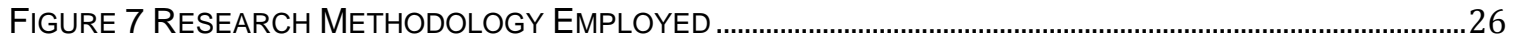

FiguRE 8 SAMPLE PoPULATION SELECTION PROCESS.......................................................................................28

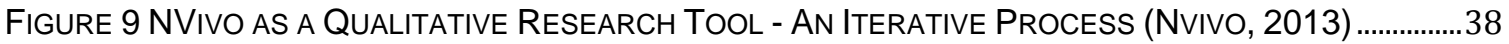

FIGURE 10 ORGANIZATIONAL OUTLINE .................................................................................................................39

FIgURE 11 NUMBER OF COMPANIES IN THE CRE SAMPLE REPORTING ON CR\&S .........................................42

FIGURE 12 ENERGY CONSUMPTION REDUCTION FOR CRE FIRMS .....................................................................4 48

FIGURE 13 WATER CONSUMPTION REDUCTION FOR CRE FIRMS ..................................................................49

FIGURE 14 GHG REDUCTION FOR CRE FIRMS .................................................................................................50

FIGURE 15 WASTE REDUCTION FOR CRE FIRMS........................................................................................ 51

FIGURE 16 ANCHOR TENANTS HISTORICAL CR\&S REPORTING ...................................................................6

FIGURE 17 TENANTS' ENERGY CONSUMPTION REDUCTION BENCHMARK ……................................................64

FIGURE 18 TENANTS' GHG REDUCTION 2011 - 2012 .........................................................................................66

FIGURE 19 CONSTRUCTION HISTORICAL CR\&S REPORTING............................................................................76

FIGURE 20 INTEGRATING CR\&S GOALS ACROSS CANADIAN CRE STAKEHOLDERS - SUMMARY ANALYSIS

FIGURE 21 OVERALL CR\&S REPORTING ACROSS CRE STAKEHOLDERS.......................................................84

FIGURE 22 LEADING CR\&S GOALS IDENTIFIED ACROSS CRE SECTOR THROUGH AVAILABLE CR\&S

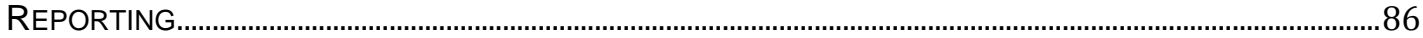


List of Appendices

APPENDIX A CANADA'S COMMERCIAL REAL ESTATE MARKET - GEOGRAPHICAL SPREAD $\quad 99$

APPENDIX B UNPRI CANADIAN SIGNATORIES

APPENDIX C DOCUMENTATION CHECKLIST - SOURCES USED ..................................102

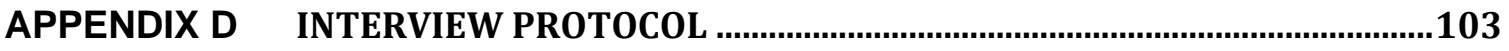

APPENDIX E - NVIVO 10 - MAPPING AND SCREEN SHOTS ............................................104

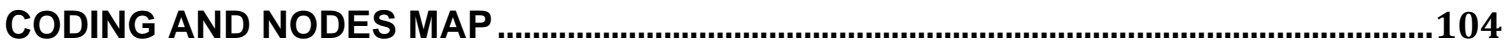

APPENDIX F - NVIVO 10'S WORD FREQUENCY QUERY RESULTS - CRS REPORTS

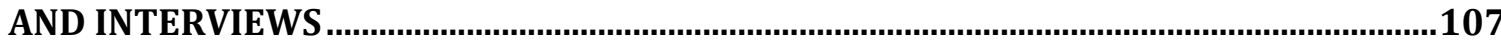

APPENDIX G ENVIRONMENTAL RESOURCE MANAGEMENT DATA- CRE FIRMS....134

APPENDIX H - ENVIRONMENTAL RESOURCE MANAGEMENT DATA- TENANTS .135 


\author{
Abbreviations \\ BOMA BEST: BUILDING OWNERS AND MANGERS ASSOCIATION, BUILDING ENVIRONMENT \\ STANDARD \\ CAGBC: CANADIAN GREEN BUILDING COUNCIL \\ CR\&S: CORPORATE RESPONSIBILITY \& SUSTAINABILITY \\ CRE: COMMERCIAL REAL ESTATE \\ CRESS: CONSTRUCTION AND REAL ESTATE SECTOR SUPPLEMENT \\ CSR: CORPORATE SOCIAL RESPONSIBILITY \\ ESG: ENVIRONMENTAL, SOCIAL AND GOVERNANCE \\ GJ: GIGAJOULES \\ GLA: GROSS LEASBLE AREA \\ GRESB: GREEN REAL ESTATE SUSTAINABILITY BENCHMARK \\ GRI: GLOBAL REPORTING INDEX \\ KPI: KEY PERFORMANCE INDICATORS \\ KWH: KILOWATTS AN HOUR \\ LEED: LEADERSHIP IN ENERGY AND ENVIRONMENTAL DESIGN \\ $M^{3}$ : CUBIC METERS \\ RPI: RESPONSIBLE PROPERTY INVESTMENT \\ $\mathrm{TCO}_{2} \mathrm{E}$ : TONNES PER $\mathrm{CO}_{2}$ EQUIVALENT
}




\section{CHAPTER 1: INTRODUCTION}

\section{OVERVIEW}

Estimates indicate that office buildings consume roughly $30 \%$ of all Canadian natural resources through construction, operation, and demolition. Additionally, $40 \%$ of Canada's overall energy consumption is directly tied to the management and operation of commercial real estate (CRE) (Schumann, 2010). A building's daily energy consumption through heating, cooling, lighting, and ventilation accounts for $80 \%$ to $90 \%$ of its life cycle carbon footprint (UNEP, 2010). Given the large shares of resources required in constructing, operating, and maintaining office occupancy in commercial buildings, all three CRE related areas hold significant opportunities in mitigating potential environmental risks, a key element of ESG (environmental, social and governance) risk mitigation, while responding to respective Corporate Responsibility and Sustainability (CR\&S) goals.

Consisting of approximately 45,415 buildings $^{1}$, the Canadian CRE market covers an aggregate of over 2.3 billion square feet $\left(\mathrm{ft}^{2}\right)$ (AltusInSite, 2013). Spread across Canada's 13 major markets ${ }^{2}$, the estimated total office space portfolio of $20,000 \mathrm{ft}^{2}$ or greater stands at 492.8 million $\mathrm{ft}^{2}$ and is represented by an estimated 4,600 class A, B and $C^{3}$ classified office buildings (Altus, 2013; and Jones Lang Lasalle, 2013). A large percentage of office building developments are concentrated in Toronto, Calgary, Vancouver, and Montreal (Jones Lang Lasalle, 2013). Currently, 16.2 million $\mathrm{ft}^{2}$ of office building developments are under construction across Canada, up from the estimated 8.9 million $\mathrm{ft}^{2}$ a year ago, with an estimated 1.0 million $\mathrm{ft}^{2}$ of the new supply expected to reach completion for the period ending in 2013 (Jones Lang Lasalle, 2013). Furthermore, Canada's CRE market enjoys a 92.3\% occupancy rate, compared to the aggregated global occupancy rate of $86.8 \%$ (Jones Lang Lasalle, 2013). Given the continuous rise in office space development and a healthy occupant activity, the Canadian CRE market faces significant opportunities and challenges as it relates to meeting respective CR\&S goals, particularly environmental resource management.

\footnotetext{
${ }^{1}$ Encompassing office and industrial buildings (Altus, 2013).

2 Canada's 13 major markets are include Vancouver, Edmonton, Calgary, Toronto, Ottawa, Montreal, Quebec City, Winnipeg, Charlottetown, Fredericton, Moncton, St. John's and Halifax. Please refer to Appendix A for further details.

${ }^{3}$ Relative measures for building classifications consist of a combination of factors, including rent, building finishes, system standards and efficiency, building amenities, location/accessibility and market perception (BOMA International, 2013). As per BOMAB International, (2013) Class A buildings are considered top tier office buildings, followed by Class B and Class C.
} 
Similar to the construction and CRE sectors, corporate tenants are increasingly realizing the importance of integrating elements of sustainability into the management of their corporate operations. With ninety-three percent (93\%) of Chief Executive Officers (CEOs) viewing sustainability as integral to their company's long-term success (Network for Business Sustainability. 2010), corporate tenants are determining ways to maintain their CR\&S commitments, while reducing operational costs without hindering levels of productivity (Brooks and Campanelli, 2011). As Canadian markets continue to mature and emphasis on efficiency and productivity gains further traction, the real estate footprint of corporate tenants will increasingly become an important factor for operational strategies (Jones Lang Lasalle, 2013). However, a noteworthy impediment to the expected expansion of Canada's office sector is that record corporate profits and 'cash in hand' are not currently being consistently reinvested with a longer-term or a growthoriented view (Jones Lang Lasalle, 2013). Corporate tenant innovation is currently focused on shorter-horizon efficiency (typically around 3 to 5 years return-on-investment $(\mathrm{ROI})$ ), and ongoing cost-saving measures may reduce the need for additional office space (AltusInSite, 2013 and Jones Lang Lasalle, 2013). Evidently, tenants' short-term ROI focus, particularly as it applies to their real estate footprint, poses potential challenges for incorporating elements of CR\&S across their office occupancy.

Uncovering common CR\&S goals between construction firms, CRE firms, and corporate tenants, can lead to mutually beneficial and lower-risk opportunities. The construction and CRE sectors need to develop strategies that will align their respective CR\&S goals so as to mitigate potential operational and investment risks, along with protecting respective long-term growth. Since occupant behaviour and operational management impact the performance of buildings, this thesis identifies corporate tenants, the CRE and construction sectors as key stakeholders to drive and administer the necessary industry change. Currently, there is no clear integration aligning respective $C R \& S$ strategies between construction, CRE firms, and corporate tenants. Therefore, the purpose of this thesis is to explore the integration of leading CR\&S goals across CRE firms, key anchor tenants, and the construction sector within the Canadian market, as it relates to their respective office space portfolios. Ultimately, in an attempt to mitigate potential corporate and investment risks by leveraging the environmental element of ESG, this thesis will aim to uncover and integrate top CR\&S goals among Canadian construction and CRE firms, along with leading corporate tenants. 


\subsection{RESEARCH QUESTION}

CR\&S is gaining an increasing profile across the CRE and construction sector. Therefore, this thesis seeks to identify opportunities to integrate CR\&S goals into the Canadian CRE sector that could maximize building performance and minimize the associated environmental risks for the built office environment. As such, the study's central research question is:

“How can tenants' CR\&S goals be integrated into the Canadian commercial real estate and construction sectors?"

The following four sub-questions have been designed to help address the central question:

1. What are the leading common CR\&S goals for Canada's leading CRE stakeholders $^{4}$ that can be cross-integrated?

2. What are the main motivators for engaging and implementing the identified CR\&S goals across the identified CRE stakeholders?

3. How are CR\&S goals currently implemented and tracked across the identified CRE stakeholders?

4. What are the main barriers impeding implementation of CR\&S goals across the identified CRE stakeholders?

Answering the central question through the help of the four aforementioned subquestions will facilitate the development of an integrated approach in addressing CR\&S goals across the Canadian CRE and construction stakeholders, while mitigating ESG risks to the Canadian office space environment. The research questions will be addressed through a qualitative content analysis of publicly available CR\&S reports (and applicable associated documentation) and interviews with subject matter experts in the Canadian CRE and construction sectors, as well as several major anchor tenants.

\subsection{DEFINITIONS}

The terminology used throughout this study was extracted from industry reports, including the Green Real Estate Sustainability Benchmark (GRESB), Canadian Green Building Council (CaGBC), Leadership in Energy and Environmental Design (LEED), Building Owners and Managers Association of Canada (BOMA), and Real Property Association of Canada (REALpac). The key definitions are outlined below.

\footnotetext{
${ }^{4}$ For the purposes of this thesis "CRE stakeholders" refer to anchor tenants, construction firms, and CRE firms.
} 


\subsubsection{OfFICE BUILDING ANd OfFICE BUILDING COMPLEXISUBURBAn PARKS}

The following general definition of an "office building" is adopted from the NAIOP Term \& Definition: U.S Office and Industrial Market. It is widely referenced across the CRE industry and characterizes office buildings as:

A property providing environments conducive to the performance of management and administrative activities, accounting, marketing, information processing, consulting, human resources management, financial and insurance services, educational and medical services and other professional services. At least 90 percent $(90 \%)$ of the interior space is designed and finished to accommodate office usage but the space may include other usage.

NAIOP (2013) segments office buildings as follows:

- Low-Rise: accounts for fewer than seven stories above ground.

- Mid-Rise: accounts between seven and 25 stories above ground level.

- High-Rise: accounts for higher than 25 stories above ground level.

The thesis also accounts for "office building complexes" and "suburban parks", defined by BOMA as a group of buildings that have common management personnel, common management practices, and a common central plant.

\subsubsection{SUSTAINABLE BUILDINGS}

According to the widely accepted industry definition, "green" buildings aim to improve occupant wellbeing, along with the environmental performance and economic returns of buildings through the use of established and innovative practices, standards and technologies $\left(\right.$ LEED ${ }^{\circledR}$ Canada - NC 1.0). Interchangeable and overlapping terms also include "energy-efficient building", "eco-building", "high-performance building" and "sustainable building" 5 . The research will refrain from referring to high performing office assets as "green" buildings, and will instead use "Sustainable Buildings". The focus of sustainable buildings is set on performance (e.g. energy, water and waste) and accounts for associated environmental elements of ESG that has the potential to influence longterm planning and investment strategies that can potentially minimize investment risk over time.

\subsubsection{CORPORATE TENANT}

The study will interchangeably refer to anchor tenants and occupants as corporate organizations leasing and occupying the majority of an office building's gross leasing area (GLA) or who are identified as major tenants by the study's identified CRE firms.

\footnotetext{
${ }^{5}$ Morrison Hershfield, (2005)
} 
Due established confidentiality over interview participants, a list of selected CRE firms will not be disclosed.

\subsubsection{COMmercial Real Estate (CRE) FiRmS}

Generally referring to a property that is owned for the purpose of generating income for an owner or a series of owners (NAOIP, 2013), Commercial Real Estate (CRE) is comprised of development, investment, management, brokerage firms, along with Real Estate Investment Trusts (REITs). As such, the study will include the above as Commercial Real Estate firms. The study will focus on CRE firms whose portfolio assets include office buildings. The sample population selection methodology employed will be detailed under Chapter 3.

\subsubsection{CONSTRUCTION SECTOR}

For the purpose of the study, the construction sector will comprise of firms whose construction projects are inclusive of office space buildings. The study will omit construction firms who focus on civic-based projects. Further details regarding the employed methodology for the selected construction sample population will be discussed under Chapter 3.

\subsubsection{CORPORATE RESPONSIBILITY \& SUSTAINABILITY}

Corporate Social Responsibility (CSR) is commonly associated with the triple bottom line that accounts for social, environmental, and economic initiatives undertaken by corporations. An example definition of CSR is "consideration of issues beyond the narrow economic, technical, and legal requirements of the firm" (Crane et al., 2008). Aiming to drive CRE stakeholders to consider long-term investment strategies that will mitigate potential risks to their real estate assets and projects, while responsibly conducting elements environmental management, this thesis will use the term "Corporate Responsibility \& Sustainability (CR\&S)" instead of CSR. A detailed explanation for choosing CR\&S over CSR will be provided in Chapter 2.

\subsection{THESIS STRUCTURE}

The thesis is structured into five remaining chapters as follows. The second chapter provides a detailed literature review consisting of academic, industry, and government publications that have assessed the field of CR\&S and its implications on the CRE and construction sectors. It covers the history of corporations and stakeholders, definitions of CSR, and examines the current state of the Canadian sustainable real estate and construction market. The third chapter describes the research methodology undertaken 
to answer the central research question and associated sub-questions. The chapter begins by defining qualitative content analysis and semi-structured interviews as the two chosen methodologies, and draws on industry reports, such as REALpac, JantziSustainalytics, Corporate Knights, and The Leaders to purposively select the sample population across all three stakeholders. The fourth chapter of the thesis presents the key findings, which are organized by the three key stakeholders and research subquestions. Finally, the fifth section includes an overview of the overall analysis and its implications for the CRE stakeholders, discusses the research limitations, and concludes with recommended industry action plans and possible future academic research. 


\section{CHAPTER 2: LITERATURE REVIEW}

\section{INTRODUCTION}

There is little academic research that focuses on the application of CR\&S in the Canadian CRE and construction sector. Consequently, a large part of the literature review will focus on American, Australian, and UK based research where CR\&S trends within these sectors are found to be more developed and established. Industry and governmental based reports both at the federal and international level will also be discussed.

\subsection{THE CORPORATION}

\subsubsection{CORPORATE GOVERnANCE}

Peopled by individuals (consisting of shareholders, managers and employees) Dunlavy (2006) characterizes corporations both as political and strong economic institutions. A conventional model since the mid-nineteenth century, Figure 1 illustrates the hierarchical power relation between shareholders, managers and employees (Dunlavy, 2006). Dunlavy describes shareholder relations as being the quintessential "black box" of business history. According to Dunlavy, in order to conceptualize the relationships between shareholders it is important to note that every "body politic" (defined as the corporation) has a constitutional structure embedded in statue law and in the company's bylaws, granting them the title of a "little republic". As illustrated in Figure 1, shareholders hold a horizontal power relation that is passed down through a vertical power relation that requires management. In essence, this relates to the fiduciary obligation of executive management teams who are held accountable toward ensuring profit earnings to their shareholders. 


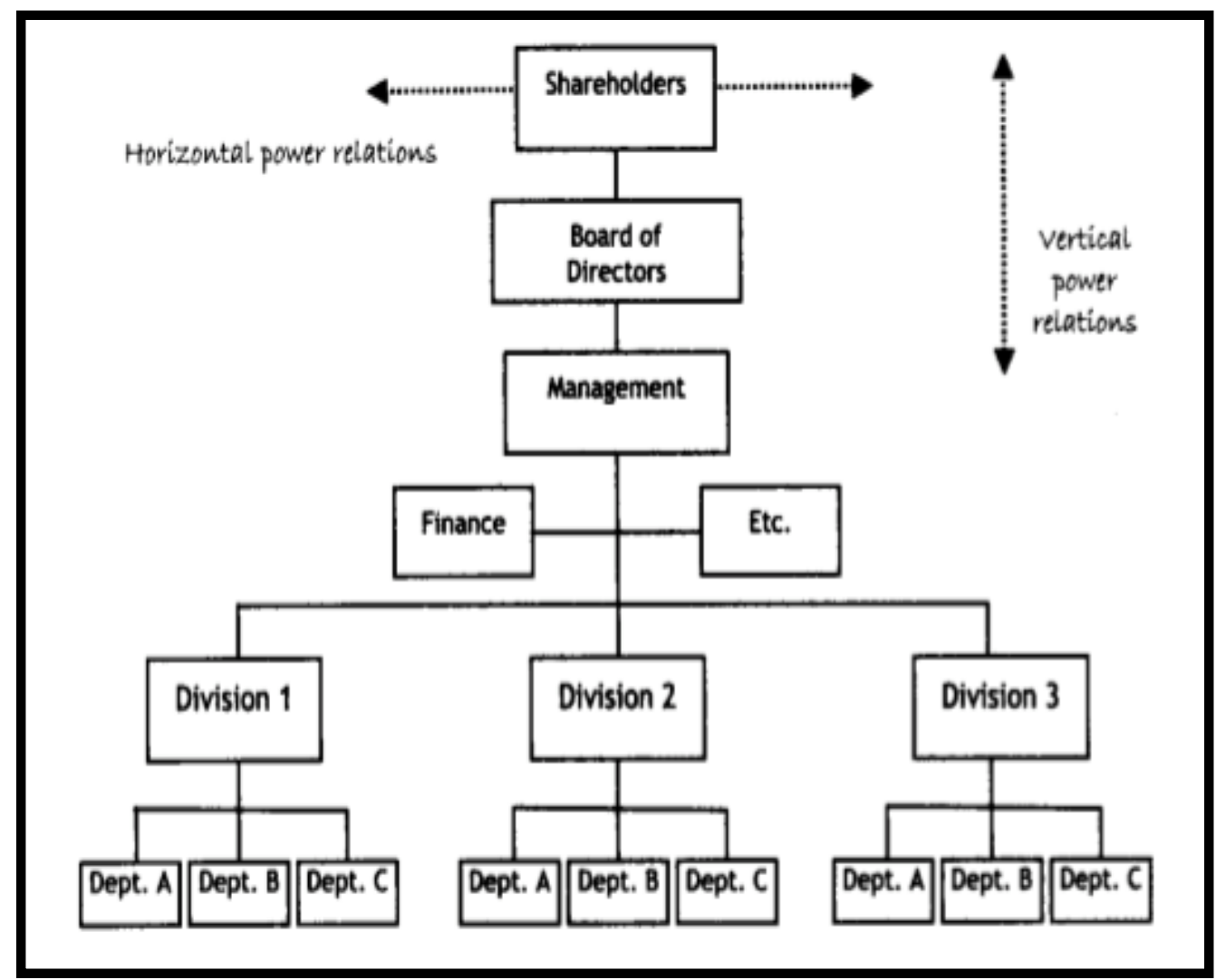

Figure 1 Power Relations in Modern American Corporations (Dunlavy, 2006)

In 1932, E. Merrick Dodd Jr. conceived a notion that was later reinforced by economist Milton Freidman (1970), that the sole function of the corporation is to create profit for its stockholder-members, such that they are the ultimate beneficiaries of the outcomes and activities resulting from the business' operation. Shareholder profit maximization as defined by Dodd and Freidman, dismisses two possible impediments to shareholder profit maximization. First, devaluing the embedment of ESG as a corporate risk mitigating strategy poses the potential to increase business costs that could impact the value of shares. Given customers' generally high perception and intolerance toward risk (Kolluru, 1996), it is the executive management's obligation to ensure that trust and confidence remains strong, in order to avoid distrust among customers, which could hinder corporate profits and share value. Second, both Dodd and Freidman presume that profit maximization is the sole focus to all shareholders, and that they are uninterested in aspects concerning ESG.

Through their purchasing power, Dodd (1932) also held the notion that public opinion dictates and formulates governing laws that are able to shape corporations into social and environmental institutions, while also upholding a profit-making function. In essence, purchasing power increases the influential role stakeholders (which in addition to customers, includes clients, employees, suppliers, governments and communities) 
hold over corporate management decision. However, the responsibility of such sound corporate governance ultimately falls on the executive management team's ability to integrate their accountability toward both shareholders and stakeholders in their decision making process. Ultimately, uncovering the main CR\&S goals, processes and current state of sustainability within the CRE market, will determine if environmental resource management is perceived as a critical goal of the three key stakeholders studied in this thesis.

\subsubsection{SHAREHOLDER AND STAKEHOLDER ACCOUNTABILITY}

In order to mitigate environmental risks resulting from operational activities, Socially Responsible Investment (SRI) is increasingly playing a leading role in shareholder accountability and activism (Monks et al., 2004). Shareholder democracy is a corporate management theory that emerged following World War II as a popular movement meant to empower corporate shareholders, and seeks to increase the accountability of corporate management toward its shareholders (Dunlavy, 2006). In order to stabilize trust and confidence among investors and consumers alike, new mechanisms will need to be aligned and implemented across corporate management (Dahir, 2006). Transparency and accountability through the principles of SRI is one such mechanism identified by Monks et al. and Dunlavy that is meant to protect the rights and interests of all parties. Ultimately, both investors and consumers (identified as tenants for the purpose of this thesis) have the ability to influence and shift corporate decision-making processes across the CRE and construction sector toward achieving and implementing CR\&S goals. Figure 2 explains the shareholder accountability shared between both the CRE and construction industries. 


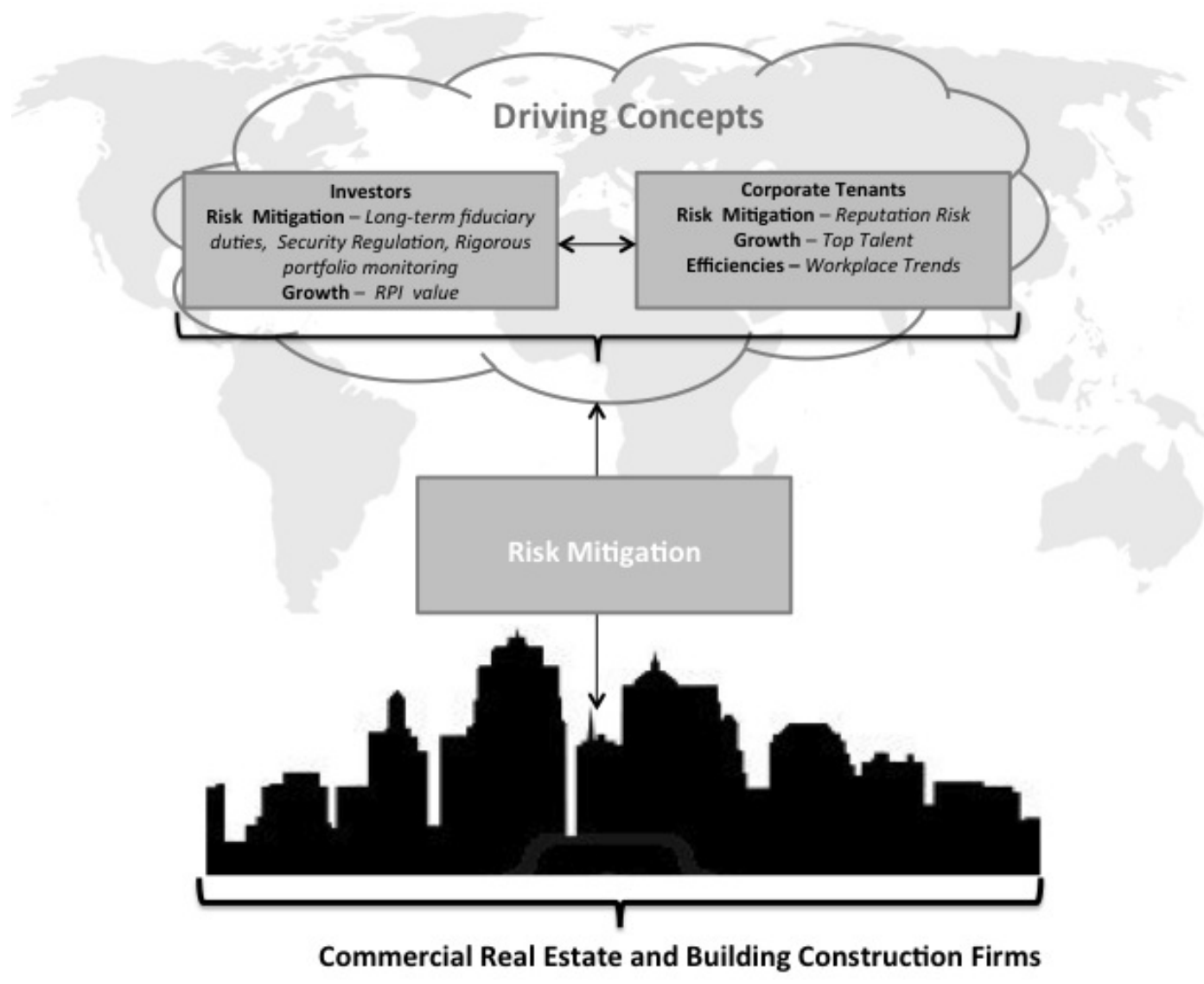

Figure 2 Stakeholder Accountability within the CRE and Construction Industry

Figure 2 illustrates the driving concepts for both investors as shareholders and corporate tenants as stakeholders. Their ESG based risks are managed by CRE and building construction firms and included as part of their corporate decision making process. The details pertaining to the driving concepts, such as risk mitigation, growth and efficiencies, will be further analyzed in the data characterization section of Chapter 4: Results, to determine the main driving concepts for the Canadian market.

Fiduciary accountability is the characteristic base for directors' duties and discretion as it relates to corporate governance, however it is an argument that is hard to assert in the court of law (Hawley and Waitzer, 2011). As legislated by the Canadian Business Corporation Act (CBCA) and Ontario Business Corporation Act (OBCA), corporate decision makers have the "... where the corporation is an ongoing concern, [the fiduciary duty] look(s) to the long-term interests of the corporation" (Waitzer and Jaswal, 2009). In the Canadian context, Canadian legislation supports a convergence inclusive of identifying long-term approach to value and wealth maximization, which views cooperate obligations toward a variety of beneficiaries as being equally or more significant to an organization than their obligation toward shareholders (Waitzer and Jaswal, 2009). As 
such, directors' duties and mandates in the Canadian business context are geared toward mitigating potential risks (therefore committing to providing long-term business strategies) as it relates to both associated shareholders and stakeholders.

\subsubsection{Corporate Decision MaKing Process}

Balancing the pillars of ESG, while meeting the needs of both shareholders and stakeholders, presents serious challenges all around. Understanding the complexity of such a decision making process is necessary when assessing CR\&S, and can prove beneficial for the complex framework under which the CRE and construction sectors operate. Azapagic and Perdan's (2005) review of an integrated sustainability decisionsupport framework offers a rudimentary direction in identifying and addressing the ESG challenges faced by all stakeholders. As exemplified by Azpagic and Pardan (2005), the first stage involves problem structuring, followed by developing a model to analyze the problem, which finally leads to a problem resolution. Employing Multi Criteria Decision Analysis (MCDA), Azpagic and Pardan offer a framework through which to maximize available alternatives and develop a unified goal. Their integrated sustainability decision-support framework will help identify the sample set in Section 3.2.

\subsection{CORPORATE RESPONSIBILITY \& SUSTAINABILITY}

\subsubsection{Defining Corporate Responsibility \& Sustainability - General OVERVIEW}

Originating in the late 1920s through the work of leading economist J.M. Clark, the study of Corporate Social Responsibility (CSR) views business as having intrinsic societal obligations toward the communities it serves (Freeman and Hasnaoui, 2010). In response to rising economic and environmental calamities over the last few decades, principles of economics and environmental concerns grew to reshape the definition of CSR into the classical tri-circular model shown in Figure 3, which the thesis will be referring to as CR\&S. Based on the triple bottom line, the three pillars of CR\&S center on sustainability as a by-product of a balanced ecosystem between economic enterprise and growth, rising social welfare and increased environmental protection (Crane and Matten, 2008). 


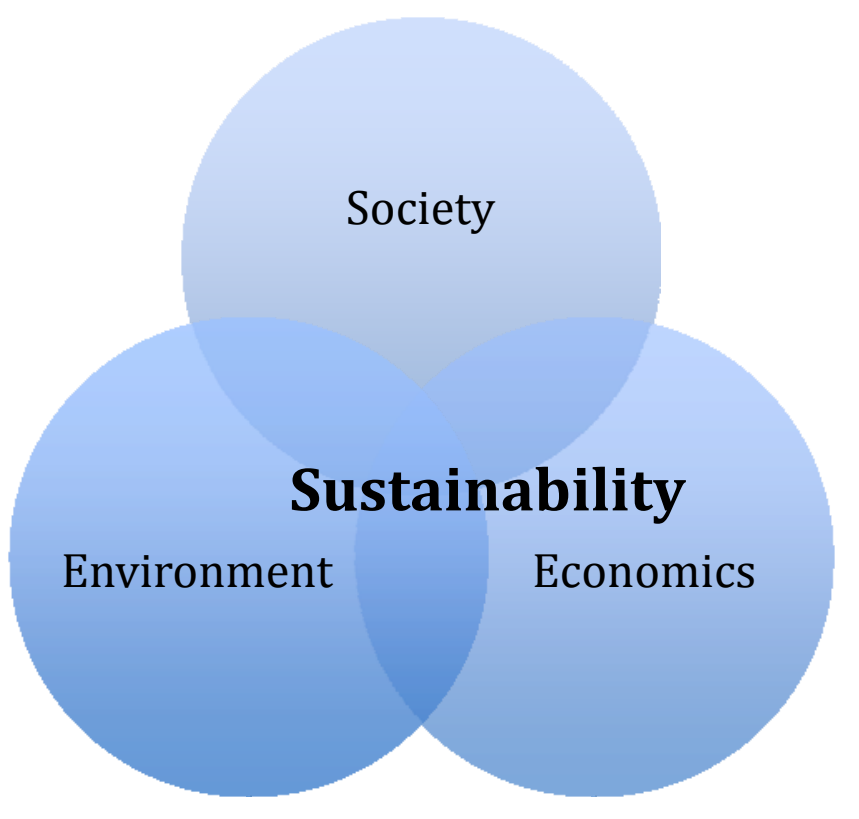

Figure 3 The Triple Bottom Line (Adapted from Crane and Matten, 2008)

However, given the core definition of economics as the study of coordinating processes, the science of managing individual choices along with the study of human behaviour and their effects on scarcity (Backhouse and Medema, 2009), it is evident that the management of environmental scarcity and societal behaviour constitute part of the study of economics. As such, sustainability is intrinsically embedded within the principals of wealth creation (economics) that drives the development engine, while being constrained by environmental and social considerations (Schumann, 2010). This alternative concept is exemplified through the Russian Doll framework, modeled by Schumann (2010) in Figure 4.

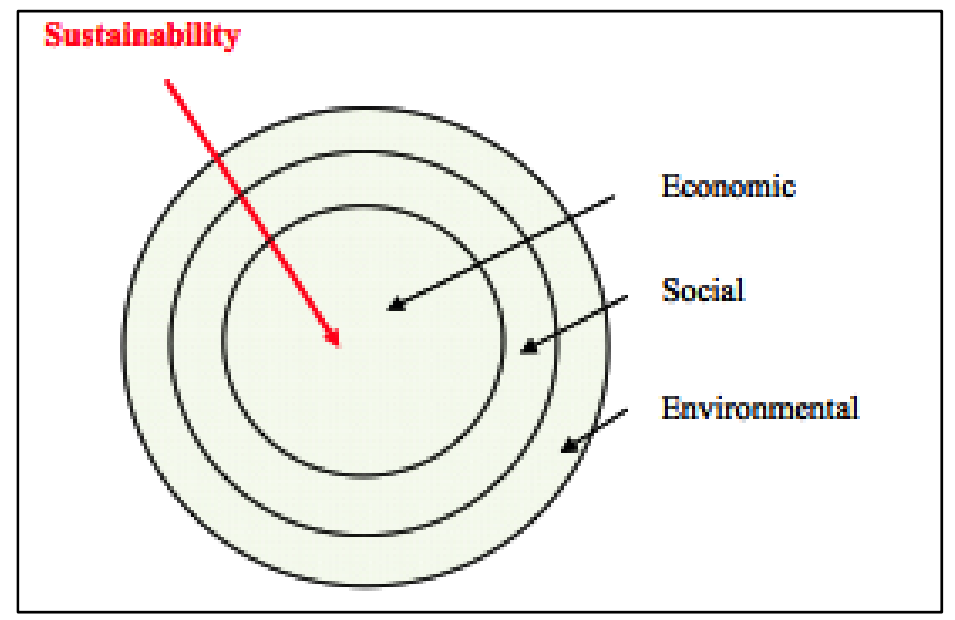

Figure 4 Russian Doll Framework (Schumann, 2010) 
Rearranging the classic CR\&S model into one that conceptualizes sustainability as part of a ripple effect stemming from the framework of economics, offers executive decisionmakers a stronger business case to develop and implement CR\&S mandates. The thesis will also argue that the framework of sustainability in Figure 4 holds for the real estate market, as it aims to protect the interests of shareholders, while meeting the needs of the tenants, communities and the environment in which it operates.

\subsubsection{CORPORATE RESPONSIBILITY \& SUSTAINABILITY REPORTING}

The concept of CR\&S reporting, as defined by Buhr (2007), is a communication medium through which companies advocate their ESG strategies. CR\&S efforts are communicated either through advertising, such as print, radio, billboard and TV; public relations and presses; securities filings; or the publication of voluntary environmental or sustainability reports (Buhr, 2007). Although CR\&S reporting remains voluntary across most industries; with the exception of financial institutions (i.e. banks, insurance companies, trust and loan companies) who are required to produce "Public Accountability Statements" as per the requirements of SOR - 2002 - 133 (Government of Canada, 2002), mounting social pressures to address the triple bottom line by prudent corporate management, particularly reporting on elements of ESG, have risen since the mid-1990s (Krumwiede et al., 2012, Freeman and Hasnaoui, 2010, Searcy and Buslovich, 2013; O'Conner and Spangenberg, 2007). Varying levels of CR\&S reporting and standards have emerged as a result of rising societal pressures. The Global Reporting Index (GRI) is one such reporting standard that provides industry specific reporting guidelines. Wenhao, and Kaufman (2011) have identified social outreach, employees, environment, integrity and energy/sustainability as the top 5 CSR practices for Fortune Top 50 companies. Previous studies have identified ethical or economically practical business strategies as key motivators for companies to report on CR\&S (Searcy and Buslovich, 2013; Adams, 2002). Building a business case supporting the implementation of elements of ESG within operational management is a common major motivator, in addition to rising public pressure, enhancing corporate legitimacy and pursuing a market differentiating strategy (Searcy and Buslovich, 2013).

Created to provide a transparent and credible framework for sustainability reporting that can be used by varying organizations and sectors, the GRI offers participants effective tools to manage stakeholder relations, investment decisions, and other market relations (GRI, 2012). The GRI's Construction and Real Estate Sector Supplement (CRESS) is intended directly for companies that invest in, develop, 
construct or manage buildings and infrastructure projects. It covers the lifecycle stage activities associated with construction and real estate markets; inclusive of new construction, management and occupation, along with demolition and redevelopment (CRESS, 2011). Elements of ESG reporting are embedded within CRESS's reporting system.

Environmental concerns embedded within ESG typically focus on pollution control, recycling, waste treatment, green initiatives, energy efficiency, emission reductions and the use of fewer resources through manufacturing and distribution channels (Krumwiede et al., 2012). Alternatively, social concerns center on business ethics, relationships with stakeholders, workers and external customers. Finally, the principles of governance target investor relations, and ensure a healthy and sustainable economic environment. Establishing and understanding CR\&S goals provides a baseline under which firms can set specific ESG targets that will not only reduce possible negative ESG impacts (Krumwiede et al., 2012) but reduce operational costs as well. Ultimately, recognizing that each real estate stakeholder (be it tenant, CRE and construction based firms) hold respective CR\&S commitments, it is important to uncover and align their targets so as to minimize the overall ESG costs attributed to their operational footprint.

A comparative study on the CR\&S reporting of Fortune Magazine's Top 50 companies conducted by Wenhao and Kaufman (2011) identifies the financial sector (34\%) as the industry most likely to report on their CSR performance, followed by the oil and gas producers (18\%) and automobile and parts (10\%). No mention was made to the real estate and construction sectors throughout their analysis. Given the aforementioned breakdown of CR\&S reporting, the thesis seeks to uncover if similar motivators and goals as identified in previous studies also affect the Canadian CRE stakeholders' behaviour toward CR\&S. It is also important to note that reporting requirements influence overall behaviour and performance, a notion supported by information inductance which identifies the connection between reporting and actual performance. Referring to the complex process through which the behaviour of an information sender is influenced by the information that is required to communicate, information inductance asses the behaviour of a decision making entity influenced by information in two ways: first as an information recipient receiving communications from other elements or making its own observation on them; and second, as an information sender, by communicating information to some other elements or being open to observation (Prakash and Rappaport, 1977). Both Prakash and Rappaport (1977) view 
the possible use of information as an important instrument for changing or controlling the behaviour of the recipient. Although this research does not focus on assessing actual CR\&S performance, it does discuss the identified connection between CR\&S reporting and building performance.

\subsection{CORPORATE RESPONSIBILITY \& SUSTAINABILITY IN THE COMMERCIAL REAL ESTATE AND CONSTRUCTION SECTOR}

According to the Dow Jones Sustainability Indices (DJSI, 2013), real estate is a heterogeneous industry for which climate change and energy efficiency bears great importance as buildings account for one third of global GHG emissions. Increased attentiveness to keep asset values high, reduce the impact of volatile energy prices on costs related to management and ownership of a property and to remain preferred proprietor for corporate tenants, the CRE industry is experiencing a growing demand for asset portfolios holding high building performance (DJSI, 2013). International research and documentation reveal that the global "office market" has come a long way in a relatively short period of time in embracing the sustainability agenda (Jones Lang Lasalle, 2013, Warren, 2009, Chen et al., 2009). However, given the novelty of the concept of sustainability within the real estate sector, there are plenty of opportunities to be uncovered; particularly as it relates to CR\&S reporting. Stockland, an Australia based diversified property group engaged in the development and management of real estate projects across Australia, the UK, and New Zealand, is an example of an industry leader identified by DJSI in 2013 for initiating reporting on their combined financial, social and environmental performance. Mirrored through its sustainability achievements, Stockland's strategy strives to achieve a balanced performance on all three dimensions, and identifies issues central to the company's business by following three sustainability indicators centered on capture, prioritization, and response (DJSI, 2013).

Several research papers based out of the United Kingdom (UK) and Australia have aimed at establishing a common framework for measuring and reporting sustainability for their respective commercial property assets. Generally, research indicates that CR\&S reports have strong tendencies toward policy reporting; while demonstrating weaker practices on their implementation strategies (Warren, 2009; and Ellison and Brown, 2011). Interestingly, a limited number of respondents in the UK based research were able to provide data on their energy and water use, waste, and carbon emissions (Elllison and Brown, 2011), which is also an area that this thesis will aim to research for the Canadian sample market. Comparably, Warren's (2009) research, which examines the growth of building rating systems in Australia and issues facing developers, owners 
and real estate asset valuers in establishing the viability of environmental sustainable development (ESD), found that there is a growing need to design a consistent rating tool that will enable valuers to evaluate buildings on a like for like basis.

Data are being gathered at the asset or portfolio level to support the policies and strategies being developed by both industry and regulators but is limited, relatively inaccessible for the purposes of objective analysis and has no common format (Warren (2009).

What is more, both industry reports and academic research point toward the global real estate market's "circle of blame" between constructors, developers, investors and tenants in which no party takes accountability for the lack of sustainable practices in the CRE industry. This thesis will also attempt to uncover if a similar behaviour applies across the Canadian CRE's industry with regards to CR\&S, and will aim to develop recommended measures needed to sustainably manage buildings that are designed, built, operated, and occupied. Given the lack of available Canadian research addressing these specific objectives, the thesis will be making an original contribution for the Canadian CRE and construction industry.

\subsection{GREEN BUILDING DESIGN}

The Hannover Principles presented by leading architect, William McDonough aim to inspire designs that meet the needs and aspirations of the present without compromising the ability of the planet to sustain an equally supporting future (McDonough, 1992). Echoing the 1987 Brundtland Commission of the United Nations, McDonough's first key principle is representative of a healthy, supportive, diverse, and sustainable co-existence between what is understood as human rights and nature. Other design principles seek to recognize interdependence, respect spirit and matter based relationships, accept responsibility resulting from possible design consequences, the creation of safe objects intended for long-term value, eliminate the concept of waste, rely on natural energy flows, understand and be cognisant toward the limitations of design, and to constantly seek improvement by encouraging direct and open communication between varying stakeholders (McDonough, 1992; Bonda and Sosnowchik, 2007).

As such, an integrated and well-developed sustainable design will be able to address economic, environmental and social concerns. Ricardo Mateus and Luís Bragança (2011) view sustainable buildings as an intricate relationship between built, natural and social systems requiring consideration at each life-cycle stage. Morrison and Hershfield (2005) demonstrate the widespread benefits CRE stakeholders gain, ranging from economic, occupant health and risk reduction, which provides sound comparative 
grounds for this thesis. However, designing and creating a building that reflects the balance between all of the varying sustainability levels (economic, environmental and social) as well as remaining true to the undertones of design through practicality, transparency and flexibility pose real challenges (Bonda and Sosnowchik, 2007; Mateus and Bragança, 2011). Economic issues, such as property appraisals and potential rent revenues are of higher concern to landlords; whereas occupant health and comfort are paramount to corporate tenants (Mateus and Bragança, 2011). As such, these complex issues need to be addressed cohesively into the design of a high performance building.

\subsection{Responsible Property InVestment and Green Real Estate}

As of 2013, Canada's institutional investment industry committed 49 signatories (see Appendix B for all UNPRI Canadian signatories) toward the Principles for Responsible Investment (PRI) initiative, a partnership set by the United Nations Environmental Program Finance (UNEP Finance) and the UN Global Compact designed to lead asset owners, investment managers and professional service partners to form commitments toward responsible ownership and long-term sustainable financial returns (UNPRI, Annual report 2012). Similar to the 1214 global signatories, Canada's PRI signatories (where consistent with their fiduciary responsibilities) have committed to the following six (6) principles (Figure 5):

\begin{tabular}{|c|c|}
\hline 2 & $\begin{array}{l}\text { - We will incorporate ESG issues into investment analysis and } \\
\text { decision-making processes. }\end{array}$ \\
\hline 3 & $\begin{array}{l}\text { - We will be active owners and incorporate ESG issues into our } \\
\text { ownership policies and practices. }\end{array}$ \\
\hline 5 & $\begin{array}{l}\text { - We will seek appropriate disclosure on ESG issues by the entities } \\
\text { in which we invest. }\end{array}$ \\
\hline $\begin{array}{l}\text { - We will promote acceptance and implementation of the Principles } \\
\text { within the investment industry. }\end{array}$ \\
\hline $\begin{array}{l}\text { - We will work together to enhance our effectiveness in } \\
\text { implementing the Principles. }\end{array}$ \\
\hline $\begin{array}{l}\text { - We will each report on our activities and progress towards } \\
\text { implementing the Principles. }\end{array}$ \\
\hline
\end{tabular}

Figure 5 The Principles of Responsible Investment, Annual Report (2012)

Tailored to fit each organization's investment strategy approach and resources, PRI offers guidance and action plans which allow signatories to incorporate and address 
specific ESG challenges into their investment practices across all asset classes (PRI, 2012). Seen as "extra-financial determinants" by a growing number of institutional investors, ESG factors are increasingly influencing investors' decision-making process as they impact investment risk and share value over time (Hebb et al., 2010). Responsible property investment (RPI) is defined as one of such determinant, which aims to reduce the ESG impacts of building construction and operations through responsible real estate investment and management (Pivo 2008; and Hebb et al. 2010).

Leading RPI research argues that tenants exercise a preference for occupying more "sustainable" properties, which would in turn prove that the income growth of investing in a sustainable building will hold superior value versus a less sustainable investment, and in turn a less desirable stock (Hebb et al., 2010, and Pivo, 2010). Similarly, it is argued that if investors exercise the same preference, then less sustainable assets will prove less liquid, more risky and potentially hold less value than a stock with higher sustainable values (Hebb et al. 2010; Pivo, 2010). However, as argued by Hebb et al. (2010), addressing the materiality of ESG issues as it relates to real estate investment will be mainly felt over a longer-term horizon, which will lead investors to adopt investment practices extending beyond the average $3-5$ year investment strategies. The sustainable values that will improve an investor's asset performance will require CRE firms managing investors' assets to consider the following (Table 1): 
Table 1 ESG values (Pivo, 2010)

\begin{tabular}{|c|c|}
\hline Targets & Description \\
\hline Energy co & $\begin{array}{l}\text { Green power generation and purchasing, energy efficient } \\
\text { design or conservation retrofitting. }\end{array}$ \\
\hline Environmental protection & $\begin{array}{l}\text { Water conservation, solid waste recycling, habitat } \\
\text { protection. }\end{array}$ \\
\hline Voluntary C & $\begin{array}{l}\text { Green building certification, certified sustainable wood } \\
\text { finishes }\end{array}$ \\
\hline $\begin{array}{l}\text { Public transport oriented } \\
\text { developments }\end{array}$ & $\begin{array}{l}\text { Transit oriented development, walk able communities, } \\
\text { mixed-use development }\end{array}$ \\
\hline $\begin{array}{l}\text { Urban revitalization and } \\
\text { adaptability }\end{array}$ & $\begin{array}{l}\text { Infill development, flexible interiors, brownfield } \\
\text { redevelopment; }\end{array}$ \\
\hline Health and safety & $\begin{array}{l}\text { Site security, avoidance of natural hazards, fist aid } \\
\text { readiness, }\end{array}$ \\
\hline Worker wellbeing & $\begin{array}{l}\text { Plazas, childcare on premises, indoor environmental } \\
\text { quality, barrier-free design }\end{array}$ \\
\hline $\begin{array}{l}\text { Social equity and } \\
\text { community } \\
\text { development }\end{array}$ & $\begin{array}{l}\text { Regulatory compliance, sustainability disclosure and } \\
\text { reporting, independent boards, adoption of voluntary } \\
\text { codes of ethical conduct, stakeholder engagement }\end{array}$ \\
\hline Corporate Citizenship & $\begin{array}{l}\text { Fair labor practices, affordable social housing, community } \\
\text { hiring and training }\end{array}$ \\
\hline $\begin{array}{l}\text { Social equity and } \\
\text { community } \\
\text { development }\end{array}$ & $\begin{array}{c}\text { Quality design, minimum neighbourhood impacts, } \\
\text { considerate construction outreach, historic } \\
\text { preservation, no undue influence on local governments }\end{array}$ \\
\hline
\end{tabular}

Given the above-mentioned ESG values and commitments listed under the UNPRI, this thesis will attempt to examine the current state of the Canadian CRE and construction industry in meeting and integrating them across its portfolio and projects.

\subsection{Corporate Responsibility \& Sustainability Performance Measures - VOLUNTARY CERTIFICATIONS}

Fulfilling the elements of $C R \& S$ requires the adoption and reporting of target indicators that can track sustainable business performance. O'Connor and Spangenberg (2008) discuss the importance of creating a dialog which addresses the spectrum of sustainability across all parties through the implementation of solid CR\&S reporting. The adoption and reporting of specific indicators and their measurement helps identify 
targets of improvement and develop common strategies across all real estate stakeholders. Most notably, numerous industry reports and academic research have found a direct correlation between increased sustainability performance and enhanced financial performance as a result of reduced operational costs and portfolio risk (Eichholtz et al., 2012). The leading industry based voluntary certifications and performance measures specific for the Canadian CRE market include: Green Real Estate Sustainability Benchmark (GRESB), Canadian Green Building Council (CaGBC)'s Leadership in Energy and Environmental Design (LEED $\left.{ }^{\circledR}\right)$ green building rating system, Building Owners and Managers Association Building Environmental Standards (BOMA BESt) and the Global Reporting Initiative's (GRI) Construction and Real Estate Sector Supplement (CRESS), which was addressed earlier. The reporting guidelines and prerequisites of these reporting measures and voluntary certifications will guiding the thesis to identify and analyze the framework which influences the development of CR\&S goals across the Canadian CRE and construction market.

\section{GRESB}

A global and industry-led organization providing independent evaluation of sustainable performance for real estate portfolios, GRESB works in tandem with institutional investors and their portfolio managers to identify and implement sustainable benchmarks and industry best practices set to protect and maximise shareholder value (GRESB, 2012). Representing close to 450 property companies and funds across 36,000 properties; with the European market leading the response participation at $37.4 \%$ followed by the North American sector at 37.0\%, the GRESB survey results illustrate real estate investors and managers' commitment to sharpening their focus on the challenges their asset investments face with regards to sustainability (GRESB, 2012). The assessment is based on two dimensions (management \& policy with a weight of $34 \%$ and implementation and measurement with a weight of $66 \%$ ) and sustainability aspects with varying weights.

Based on the data accrued from the scorecard results, GRESB (2012) develops a Four-Quadrant Model of sustainability performance which provides participants with an overview and a comparative sustainability performance rating against that of their global peers. GRESB's four quadrants illustrate percentage scores as they relate to the dimensions of Management \& Policy and Implementation \& Measurement by dividing the results into Green Starters, Green Talk, Green Walk and Green Stars. 
$C a G B C-\angle E E D \circledast$

Originally developed by the United States Green Building Council (USGBC), Leadership in Energy and Environmental Design (LEED $\left.{ }^{\circledR}\right)$ is a licensed green building rating system administered through the Canadian Green Building Council (CaGBC). As a North American based rating system, the CRE industry views $L E E D \otimes$ as holding significant and positive impacts on tenant companies' ability to attract and retain top talent, along with meeting their sustainability goals, and improving general brand image for investors and surrounding communities (Persram et al. 2007). There are five key rating systems that are applicable to office space development projects: New Construction (NC), Core \& Shell (CS), Commercial Interior (Cl), Existing Buildings and Operations and Maintenance (EB:OM) and Neighbourhood Development (ND).

Designed to certify the sustainability of ongoing operations of existing commercial buildings, $L E E D \circledast E B: O M$ assists building owners and operators of existing buildings to measure operations, improvements and maintenance on a consistent scale, with the goal of maximizing operational efficiency, while minimizing environmental impacts (LEED ${ }^{\circ}$ Canada EB:OM 2009). Hence LEED ${ }^{\circ}$ EB:OM applies to the operation and management of existing office buildings.. LEED ${ }^{\circ} N C$ applies to new construction and major renovations of commercial buildings, while $L E E D \AA C S$; a derivative of $L E E D ® N C$, applies to buildings where less than fifty percent (50\%) of the building area will be fit-up to LEED ${ }^{\circ}$ NC requirements prior to certification (LEED® Canada NC, 2009). LEED ${ }^{\circledR}$ NC and LEED ${ }^{\circ}$ CS are geared toward the construction sector and their projects. Applicable to tenant improvement of new or existing office space, $L E E D \otimes C l$ is characterized as the green benchmark for the tenant improvement market that is used for certifying highperformance green interiors that are: healthy, productive places to work; are considered less costly to operate and maintain; and have an overall reduced environmental footprint (LEED® Canada $\mathrm{Cl}, 2009)$

Based on a maximum of 110 possible points, LEED® projects receive "Certified" levels for achieving forty to forty nine points (40-49 points), "Silver" level for fifty to fifty nine points (50-59 points), "Gold" levels for sixty to seventy nine points (60 - 79 points) and Platinum level for achieving over eighty points (80 points) Since 2001, Canada has registered over 4,100 projects, out of which 1,600 are commercial in nature and 699 are directly related to office-project based registrations (CaGBC, 2013). The following data (Figure 6) represents $L E E D \otimes$ registration and certification across Canada from 2001 to the first quarter of 2013. 
Figure 6 Total Canadian LEED $®$ Registration Since 2009

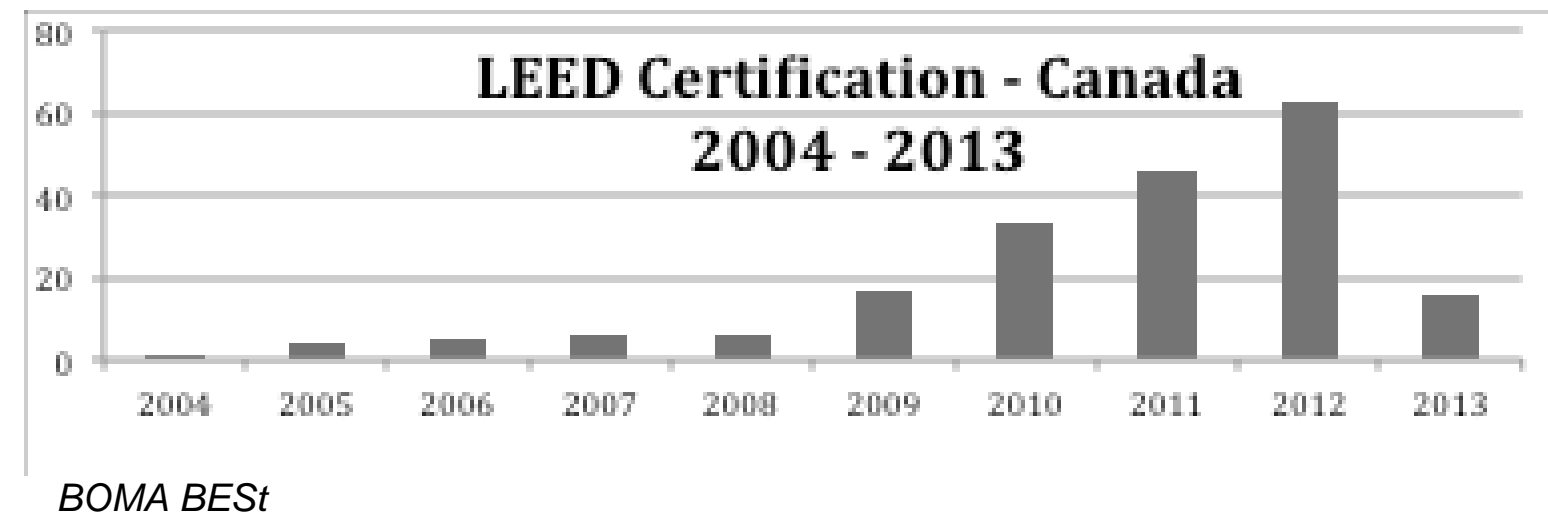

Based on the internationally accepted Green Globes environmental platform, BOMA BESt is another Canadian industry standard for commercial building sustainability certification. The voluntary national program is designed to assess environmental performance and management of buildings for commercial building owners and managers by providing a consistent framework to critically assess six (6) key areas of environmental performance and management. It includes four (4) levels of certifications, ranging from Level 1, where a minimum of fourteen (14) BOMA BESt Practices must be achieved, to Level 4 BOMA BESt Assessment requiring a score of over ninety (90) percent. According to a 2011 BOMA BESt Energy and Environmental Report (BBEER), buildings over 100,000 sqft and under 250,000 sqft represented the largest segments of office buildings by size, each representing $37 \%$ and $36 \%$ of the buildings respectively. Buildings covering over 500,000 sqft in size made up 11\% of Level 2 through Level 4 of BOMA BESt certified buildings for 2011 (BOMA BESt, 2013). Assessing the six (6) key performance and management metrics, BOMA BESt buildings tend to outperform conventional buildings in terms of energy intensity (per $\mathrm{ft}^{2}$ ) at $30.8 \mathrm{ekWh} / \mathrm{ft}^{2} / \mathrm{yr}$ compared to the national average of $36.65 \mathrm{ekWh} / \mathrm{ft}^{2} / \mathrm{yr}$ (BBEER, 2011).

Table 2 summarizes the requirements under voluntary certifications, industry benchmarks and voluntary reporting. These requirements include: building performance indicators (such as energy, water, waste and GHG emission), along with indoor environment, environmental management systems, management and strategy, policy disclosure, risk and opportunities, building certification, social factors, and new development and innovations. Through the listed sub questions in section 1.1, the thesis aims to uncover how the Canadian CRE and construction sectors, inclusive of corporate tenants, report on the CR\&S requirements outlined in Table 2. 
Table 2 CR\&S Reporting and Certification Requirements for Voluntary Certifications, Industry Benchmarks and Reporting within the CRE and Construction Sectors

\begin{tabular}{|c|c|c|c|c|c|}
\hline \multirow{2}{*}{\multicolumn{2}{|c|}{$\begin{array}{c}\text { CR\&S Reporting/Certification } \\
\text { Requirements }\end{array}$}} & \multicolumn{4}{|c|}{ Voluntary Certifications \& Industry Benchmarks } \\
\hline & & \multirow{2}{*}{$\begin{array}{c}\text { BOMA BESt } \\
35 \%\end{array}$} & \multirow{2}{*}{$\begin{array}{l}\text { LEED } \\
31 \%\end{array}$} & \multirow{4}{*}{$\begin{array}{c}\text { GRESB } \\
\\
25 \%\end{array}$} & \multirow{2}{*}{$\begin{array}{c}\text { GRI CRESS } \\
x\end{array}$} \\
\hline \multirow{4}{*}{ 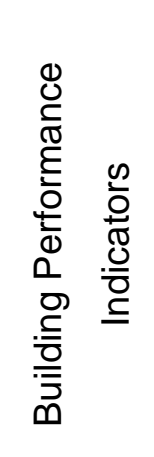 } & Energy & & & & \\
\hline & Water & $8 \%$ & $12 \%$ & & - \\
\hline & Waste & $11 \%$ & $3 \%$ & & - \\
\hline & $\begin{array}{l}\text { Green House } \\
\text { Gas Emissions }\end{array}$ & $17 \%$ & $13 \%$ & & - \\
\hline \multicolumn{2}{|c|}{ Indoor Environment } & $18 \%$ & $13 \%$ & ‘- & - \\
\hline \multicolumn{2}{|c|}{$\begin{array}{l}\text { Environmental Management } \\
\text { Systems }\end{array}$} & $11 \%$ & $8 \%$ & $11 \%$ & - \\
\hline \multicolumn{2}{|c|}{ Management \& Strategy } & - & '- & $13 \%$ & - \\
\hline \multicolumn{2}{|c|}{ Policy Disclosure } & - & $10 \%$ & $9 \%$ & - \\
\hline \multicolumn{2}{|c|}{ Risk \& Opportunities } & - & & $15 \%$ & - \\
\hline \multicolumn{2}{|c|}{ Building Certification } & - & $3 \%$ & $11 \%$ & - \\
\hline \multicolumn{2}{|c|}{ Social Factors } & - & & $16 \%$ & - \\
\hline \multicolumn{2}{|c|}{ New Developments \& Innovations } & - & $5 \%$ & - & - \\
\hline & TOTAL & $100 \%$ & $100 \%$ & $100 \%$ & - \\
\hline
\end{tabular}

Upon further analysis of the given voluntary certifications, available industry benchmarks, and reporting guidelines, it is clear that there is significant potential for improving sustainability performance across all three CRE stakeholders. As the use of these instruments across CRE stakeholders continues to rise and is increasingly becoming a measurement to evaluate portfolio performance and building selection, the Canadian CRE and construction market will also need to start incorporating the 
necessary dimensions to maintain competitive grounds amid domestic and global markets.

\subsection{CONCLUSIONS}

Providing a brief historic overview on corporations summarizes the founding fiduciary principles that guide business decision-making process across the three identified CRE stakeholders. As explained, corporate fiduciary responsibility ultimately shapes and influences corporate commitments toward the integration of sustainability across their operational footprint. Although much research has been generally conducted on CR\&S and its varying frameworks, this thesis' literature review reveals a lack of sufficient academic research and industry reports addressing CR\&S as it relates directly to the CRE and construction sector, particularly for the Canadian market. The adoption of specific metrics set to measure ESG across the CRE and construction markets are relatively new, and consequently inconsistent particularly for the Canadian market. Therefore, the thesis seeks to investigate how to initiate CR\&S integration across corporate tenants, and the Canadian CRE and construction sector.

\subsection{MOTIVATION FOR RESEARCH}

The principles of responsible investment and the green real estate movement are gaining momentum in Canada and provide the founding base that can assist CRE stakeholders to integrate their respective CR\&S goals. However, given that no significant academic advancements have been made in the field, particularly as it relates to the Canadian market, this thesis will focus on uncovering the top CR\&S goals, motivators, implementation and tracking measures and barriers across the identified CRE stakeholders and provide direction on possible means of integration. 


\section{CHAPTER 3: RESEARCH METHODOLOGY}

A qualitative research methodology is employed to address the research questions. A qualitative research approach is more applicable than a quantitative approach given the exploratory nature of this research. Encompassing a variety of scientific tools, which include report and document analysis, and in-depth research interviews with subject matter experts, this research seeks to develop a broad understanding of the decision making processes involved in the everyday corporate operations related to CR\&S of the chosen sample population (Van den Hoonaard, 2012). The coding of trends, links and commonalities found in reports, documents and research interviews are facilitated through the use of NVivo, a qualitative research software. A synopsis of the research methodology is highlighted in Figure 7 and details pertaining to each methodology stage

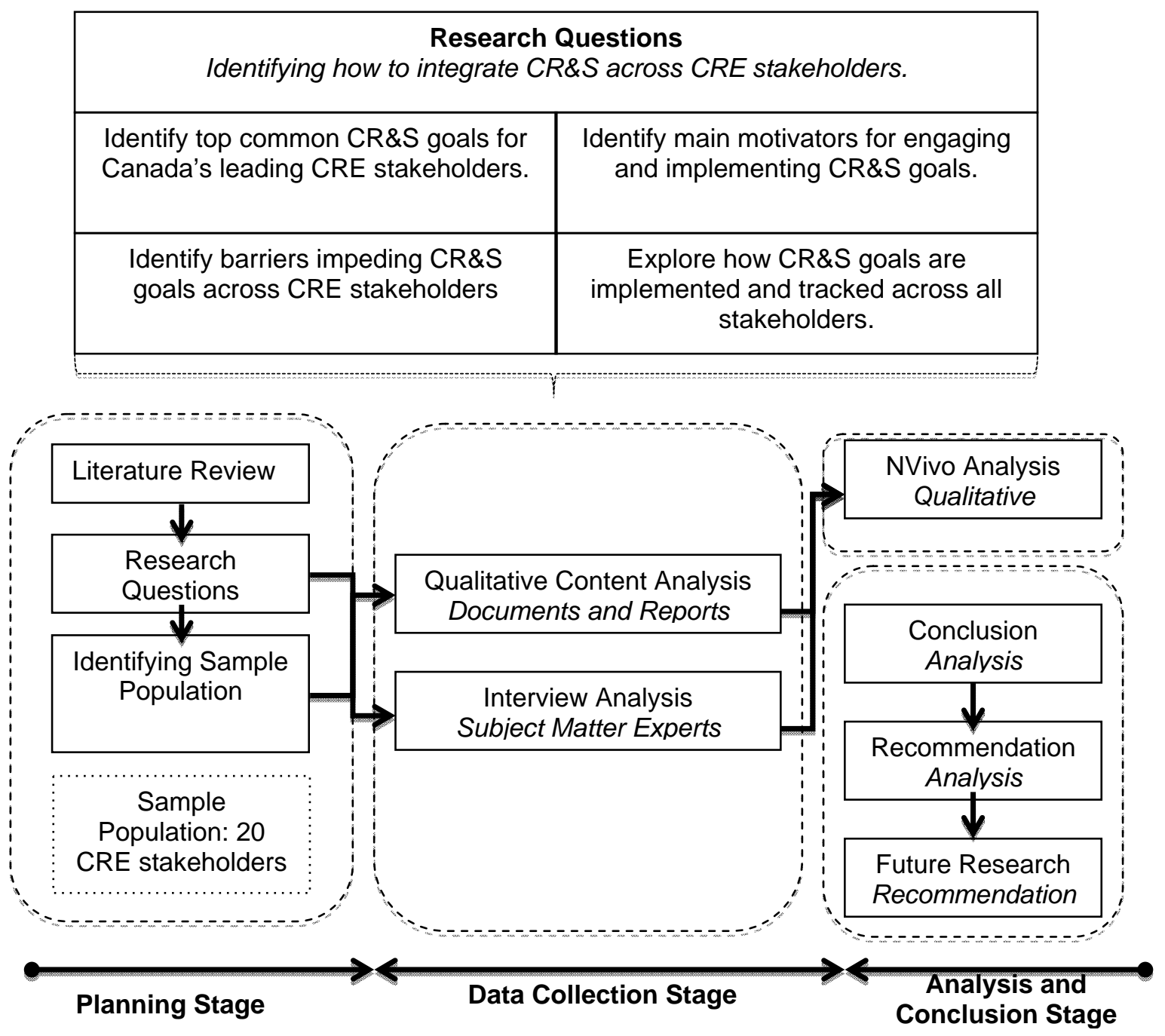

are explained in the ensuing sections. 


\section{Figure 7 Research Methodology Employed}

Although Warren's study addresses similar research questions, in terms of examining issues facing developers, owners and valuers in establishing the viability of ESD, his research offers an Australian perspective. Given the nature of Canada's CRE industry, the difference in markets, and the genesis of CR\&S across the CRE sector, this research is intended to provide exploratory strides, instead of conducting a comparative analysis. Although conducting a comparative study holds significant value, examining the state of CR\&S within the Canadian CRE market offers an initial step toward a comparative direction. Therefore, employing the following listed methodology holds the possibility to conduct further research that could in turn implement Warren's design and methodology in order to grant comparable results.

\subsection{Planning Stage}

\subsubsection{SAmple Selection}

The sample population draws on Canadian firms that have at a minimum published sustainability reports and related documentation as of 2012. Key CRE and construction firms, and anchor tenants were identified though cross-referencing leading industry reports.

This thesis relied on purposive sampling. The sample populations for CRE firms was pulled from a leading industry report conducted by REALpac and Jantzi Sustainalytics (2010) who identified eighteen (18) Canadian real estate companies demonstrating considerable efforts in ESG management across their portfolio. A questionnaire was sent out to the eighteen (18) identified CRE firms, and six (6) out of eighteen (18) firms agreed to participate and discuss their results with REALpac and Jantzi-Sustainalytics's. Coincidentally, the six (6) consenting firms also scored highly on REALpac and Jantzi Sustainalytics' ESG scorecard. In order to further qualify the 6 firms identified by the REALpac and Jantzi-Sustainalytics report, it was affirmed that their portfolio holdings included commercial office buildings. An additional CRE firm was also added to the selected CRE participant list due to GRESB's (2012) recognition for their adoption of progressive environmental standards and implementing industry leading CR\&S practices across their commercial portfolio (inclusive of office buildings). Two (2) out of the six (6) firms identified in the REALpac and Jantzi-Sustainalytics report were also recognized by GRESB for their CR\&S based efforts. For the purpose of meeting the objective of this research, the selected CRE sample firms are required to hold 
portfolios that are inclusive of office space and who operate across Canada. A total of seven (7) CRE firms were therefore included in the study.

Once the commercial real estate participants were identified, their office portfolio holdings were analyzed in order to identify top tenants leasing office space. Generally, CRE firms publically disclosed their portfolio holdings, along with a list of their largest tenants based on either the percentage of rental revenue represented by each tenant or their associated GLA. Some CRE firms disclosed their key tenants during their interview sessions. Following the identification of anchor tenants, they were cross-referenced against leading CR\&S publications and indices, such as Corporate Knights' 2012 Best 50 Corporate Citizens in Canada and Maclean's Top 50 Socially Responsible Corporations 2012 (in partnership with Sustainalytics). The sample tenant population was selected based on their overall performance across a broad range of ESG indicators listed under the identified CR\&S indices and published industry reports (Corporate Knights, 2012; and Macleans, 2012). The identified sample tenant population demonstrated strong sustainability performance and commitment across their industry groupings (such as diversified financials; banks; energy, oil and gas; insurance and professional services), and were identified as top rankings among their group. What is more, the selected tenant population listed under the CR\&S publications and indices are either Canadian-listed, or wholly owned subsidiary of a foreign-listed company holding significant operations across Canada (Macleans, 2012) and listed on the Financial Post 500 (Corporate Knights, 2012; Macleans, 2012). As a result, six (6) anchor tenants with strong CR\&S mandates were identified. Three (3) remaining companies were identified as anchor tenants during interview responses with representatives of the CRE sample set, who exhibited and were awarded for their industry leadership in corporate citizenship. Therefore, a total of nine (9) anchor tenants were selected for the purpose of this research.

Similarly to the above-mentioned stakeholders, the Canadian building construction sample population was derived from The Leaders, 2012, an industry leading report that highlights Canada's leading general contractors based on their selfreported 2011 gross revenue from Canadian operations and verified by company officials (The Leaders, 2012). Once Canada's largest construction firms had been identified, their available online reports and publications were assessed. Since no CR\&S based rankings nor assessments for the Canadian construction industry were made available as of 2013 , the study found that only four (4) out of a list of fifty (50) construction firms were identified as suitable candidates who promote sustainable and 
environmental building construction initiatives and whose construction projects focus on commercial office space.

Therefore, a total of twenty (20) companies that hold significant market share and influence for the Canadian CRE sector were included in the study. Figure 8 demonstrates the sample population selection process undertaken. The methodology employed to identify the subject matter experts for the interview sessions are outlined in section 3.2.2.

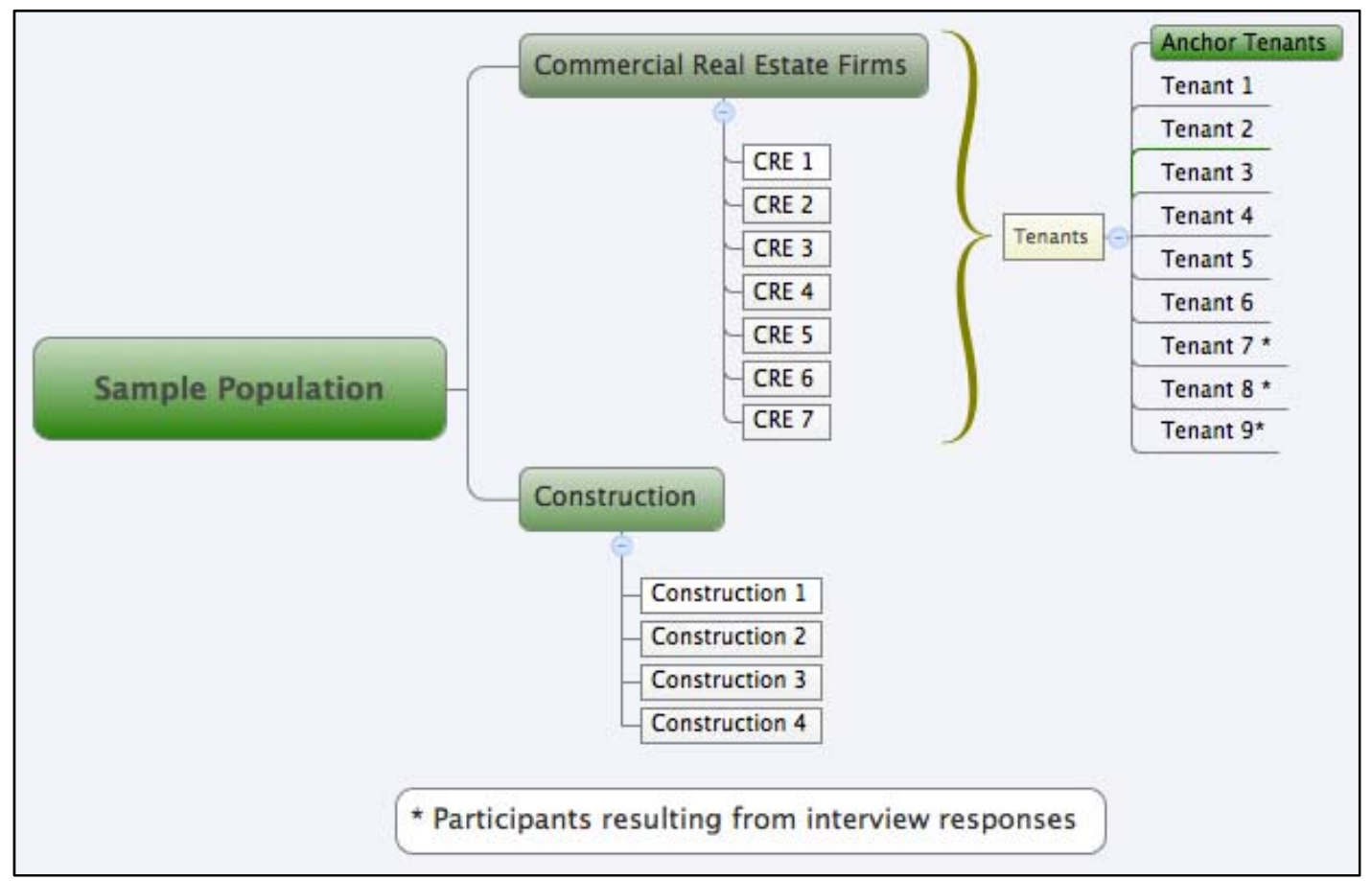

\section{Figure 8 Sample Population Selection Process}

\subsection{Data Collection and Analysis Stage}

\subsubsection{CONTENT ANALYSIS}

Intended to record and interpret written communication, qualitative content analysis is defined as an empirical and methodologically controlled analysis approach set to analyze the context in which documents are communicated, by following content analytic rules and step-by-step models without resorting to the use of quantitative methodology (Schilling 2006; Mayring, 2000). In preparation of conducting qualitative content analysis, Krippendorff (1980) identifies the following six key questions that need to be addressed throughout the initial process:

1. Which data are analyzed?

The study analyzes sustainability reports published by anchor tenants, leading Canadian 
CRE firms, and construction companies. In order to ensure consistency, the analysis will focus on the most recently published report as of 2012. Appendix C summarizes the available documentation that was analyzed throughout the thesis. In order to help answer the research's main question and sub questions, the data analysis focuses on identifying and exploring the following six categories:

- General Background Information: assessing the overall market trends across all three stakeholders, their asset holdings, leading industry tenants and current office development statistics. This category is intended to assist in understanding the general market background across the selected sample population so as to address the central research question in identifying possible CR\&S integration strategies

- Assessing CR\&S: identifying definitions of CR\&S, published mission statements and commitment levels, along with details on each stakeholder's reporting and general CR\&S programs, The aim of this data analysis is to uncover how CR\&S is understood, defined and supported by executive teams across all three identified CRE stakeholders.

- Leading CR\&S Goals: identifying and listing the CR\&S objectives and goals, the reasons they have been chosen, the metrics that are used to track the implementation measures and their associated success rates, and the current status of the goal. The intent under this category is to uncover which CR\&S goal holds the most relevance across the selected CRE sample population.

- Leading CR\&S Motivators: uncovering the driving motivators for committing to the leading identified CR\&S goals. The study sets out to identify common motivators across the identified CRE stakeholders that will facilitate with cross CR\&S integration.

- Implementation and Tracking Methods: determining methods and processes for tracking CR\&S goals and commitments, along with their results and impacts on meeting identified CR\&S goals and commitments. This final category allows addressing the main research question, along with supporting sub-questions.

- Leading CR\&S Barriers: identify the associated barriers to implementing CR\&S goals, along with their implementation and tracking methods. The identified barriers will also help set common trends that will facilitate with cross CR\&S integration.

2. How are they defined? 
Stakeholders' CR\&S performance is qualitatively analyzed through their publically available CR\&S reports and their applicable documentation. CR\&S reports from all three stakeholders were reviewed to identify their CR\&S goals, which included their commitments and statements on ESG conformity and performance. Due to the CR\&S reporting inconsistency throughout the varying stakeholders, the document analysis will focus specifically on the most recently available report as of 2012 .

3. What is the population from which they are drawn?

The population from which the data are drawn consists of Canadian firms who have either publicly available CR\&S reports or alternative documentation made available through their websites disclosing their CR\&S strategies. As previously noted, the selected sample population includes commercial real estate and construction firms, along with anchor tenants, which were drawn from their respective industry ranking reports. For the purpose of this research, a Canadian firm is identified as either Canadian-listed or holding operations within Canada.

4. What is the context relative to which the data are analyzed?

As previously explained in Section 1.2, the objective of this research is to identify a cohesive approach of integrating CR\&S goals across the Canadian CRE stakeholders, (inclusive of CRE firms, anchor tenants, and construction firms), that will ultimately maximizing building performance and minimizing CR\&S risks associated with the built office environment. Ultimately, the objective of the research will guide the direction in which all reports and documentation will have their contents collected and qualitatively analyzed.

\section{What are the boundaries of the analysis?}

Several limitations bind the structure of the analysis. First, a geographical criterion binds the analysis by focusing directly on the Canadian market. As such, the selected sample population is required to have a Canadian based presence and operation. The second criterion requires that each selected sample population publishes or makes publically available their commitment to CR\&S for the reporting period of 2011-2012, or most recent reports. The third criterion limits the analysis solely to assessing occupancy, asset management and development projects as they relate to office assets. Therefore, industrial and retail assets are excluded from the analysis. In turn, given the study's sustainability and office based focus, self-selection to downtown office class A buildings is an uncontrolled boundary that may persist through the analysis. 


\section{What is the target of the inferences?}

Referring to the conclusive results researchers aim to reveal from their analyzed data, Krippendorf (1980) defines inference as a deduction, or a conclusion drawn from facts. The target of inferences in the given content analysis framework are the links and conclusions that are driven from analyzing the identified data sets. The main objective of this thesis is to identify how to integrate CR\&S goals across all CRE stakeholders. In order to address the main objective, the four sub-questions identified in Section 1.2 guide the development of the data collection and analysis.

Where available ${ }^{6}$, published CR\&S reports or publically available online documents (inclusive of websites or CR\&S associated documentation), were analyzed through the use of the research software NVivo 10 (2013). The content analysis of available CR\&S reports and other documents sought to first uncover common CR\&S definitions, goals, certifications and tracking metrics used across the selected population sample. Through the use of NVivo 10, the research also coded for corporate interpretations of CR\&S and ESG practices. Once basic commonalities were formulated, word counts associated with goals, metrics, and processes were tabulated in NVivo's database. A manual Excel data spreadsheet was also used to numerically identify and track certification labels, along with disclosed environmental management data. Charts, tables, graphs and overall conclusions were developed to support the conclusive remarks.

Krippendorff's six theoretical key steps in content analysis preparation, as identified above, need to be pilot tested. Mayring (2000) introduces inductive category development as a process to identify keyword definitions for content analysis. The research questions identified in Section 1.2 defined the nature of keywords and phrases to be searched in NVivo 10 across the content analysis. A two-fold theoretical verification process was employed: First, a pilot test and "formative check" was conducted during the early stages of the research so as to help refine the list of keywords. In order to verify the efficiency and accuracy of the analysis, three reports where tested. Second, a "summative check" was employed to ensure that all occurrences of keywords were counted. In practice, results with no or few occurrence were manually screened so as to identify the highest reporting percentages.

\footnotetext{
${ }^{6}$ This applies to supplementary documentation that is provided by CRE stakeholders and listed under Appendix C. The study found that corporate tenants from the financial sector provided supplementary documentation relating to their environmental performance outside their CR\&S reporting.
} 


\subsubsection{SEMI-STRUCTURED RESEARCH INTERVIEWS}

Conveying perspectives that would otherwise not be made available in reports, semistructured research interviews capture the subject matter experts' central views and experience (Kvale, 1996). The purpose of conducting qualitative research interviews is to gain deeper insights from the sample's point of view and to further uncover central thematic meanings (Kvale, 1996) that would otherwise not be available through content analysis alone. In order to successfully extract the required information during the research interview process, Kvale (1996) proposes that the following seven stages are followed:

\section{Thematizing}

Formulating the purpose of the investigation and describing the concept of the investigative topic prior to the start of the interviews (Kvale, 1996) structures the potential results and directs the interview toward the research objectives. Building on the previously stated objectives, the subject matter experts were therefore interviewed with respect to their insights relating to CR\&S within the Canadian CRE and construction sector as it relates to the office environment.

\section{Designing}

Effective design that accounts for all seven stages prior to the start of the interview is necessary (Kvale, 1996) to ensure the proper follow-through of research objectives. Similar to the structure followed for content analysis, the design stage of the interview analysis aimed to code general definitions relating to CR\&S, leading CR\&S goals and corporate commitments, building certifications and reporting mechanisms, along with an overview of their office portfolio. Focusing on the research objectives and the subquestions identified in Section 1.2, the study devised 16 interview questions, which are identified under Appendix C.

The semi-structured interview questions were designed for approximately 30 to 60 minute telephone or in-person sessions. Following Ryerson University Research Ethics board's approval, each selected sample was invited to participate in the research interview session via e-mail. The participating interviewees for each firm were identified as subject matter experts listed either on public corporate websites, CR\&S reports or identified as main point of contact through Linkedln ${ }^{7}$. Participation response rates were

\footnotetext{
${ }^{7}$ LinkedIn is a global professional social network (LinkedIn, 2013).
} 
manually tracked through the use of an Excel spread sheet and the 14 consenting participants (representing $70 \%$ of the selected sample population) are listed in Table 3.

Table 3 Participants consenting to interview

\begin{tabular}{|c|c|c|c|c|}
\hline Actor & Stakeholder & Type of Interview & $\begin{array}{c}\text { Approximate } \\
\text { Length of interview }\end{array}$ & $\begin{array}{c}\text { How Data was } \\
\text { Recorded }\end{array}$ \\
\hline Participant 1 & CRE & Phone Interview & 45 minutes & Recording \\
\hline Participant 2 & CRE & Phone Interview & 30 minutes & Recording \\
\hline Participant 3 & CRE & In-person & 1 hour & Recording \\
\hline Participant 4 & CRE & In-person & 30 minutes & Recording \\
\hline Participant 5 & Construction & In-person & 1 hour & Recording \\
\hline Participant 6 & Construction & In-person & 1 hour & Recording \\
\hline Participant 7 & Construction & In-person & 1 hour & Recording \\
\hline Participant 8 & Tenant & In-person & 1 hour & Recording \\
\hline Participant 9 & Tenant & In-person & 30 minutes & Recording \\
\hline Participant 10 & Tenant & In-person & 1 hour & Recording \\
\hline Participant 11 & Tenant & In-person & 1 hour & Recording \\
\hline Participant 12 & Tenant & In-person & 1 hour & Recording \\
\hline Participant 13 & Tenant & In-person & 30 minutes & Recording \\
\hline Participant 14 & Tenant & In-person & 45 minutes & Recording \\
\hline
\end{tabular}

The interviews were conducted between the months of December 2012 and April 2013. Consenting interview participants' titles ranged from Directors of Sustainability to Senior Vice President of Enterprise Real Estate (each interviewee's role and title is listed in the Results section). As listed under Table 4, tenants had the highest interview consents seventy-seven $(77 \%)$ of the selected tenant sample population consented to 
participate in the interview sessions), followed by the construction sector with seventy percent $(70 \%)$ consenting to partake in the interviews, and the CRE firms standing at the lowest participating consent of fifty-seven percent (57\%).

Two (2) out of the nine (9) tenants were unable to participate due to lack of available internal resources and scheduling conflict. One CRE firm did not list a direct sustainability contact, and no response was received to the email requests sent to a general information email address. Two (2) other CRE firms were unable to participate due to lack of available internal resources. In spite of being unable to participate, both firms did demonstrate strong interest in participating in future CR\&S research targeted for the CRE industry. Only one (1) construction firm was unable to participate in the interview session due to schedule conflicts.

Table 4 Interview Session

\begin{tabular}{|c|c|c|c|}
\hline \multicolumn{5}{|c|}{ Interview Sessions } \\
\hline Stakeholder & Total Sample Set & $\begin{array}{r}\text { Conducted } \\
\text { Interviews }\end{array}$ & Percentage \\
\hline Tenant & 9 & 7 & $77 \%$ \\
\hline CRE & 7 & 4 & $57 \%$ \\
\hline Construction & 4 & 3 & $75 \%$ \\
\hline TOTAL & 20 & 14 & $70 \%$ \\
\hline
\end{tabular}

All fourteen (14) interview sessions were recorded and later transcribed. Even though all sixteen (16) questions were designed to be answered by all three (3) CRE stakeholders, one question was not applicable across the sample population and was therefore omitted from the interview. For example, question number 16 was applicable to neither tenants nor the construction sector, as neither track vacancy rates. Also, depending on the nature of the discussions and the level of comfort from each participant, certain interviews lead to more in-depth answers and engagement.

\section{Interviewing}

Each research interview was recorded so as to mitigate the potential of interviewer bias or omitting crucial details. Participants were provided with the option of participating in 
person or over the phone. As indicated by Kvale (1996), providing such level of flexibility ensures an in-depth and detailed understanding of the participants' experience

\section{Transcribing}

All of the interviews were fully transcribed. Kvale (1996) defines transcripts as decontextualized conversations, abstractions and topographical maps from the original landscape from which they were extracted. Unlike the quantitative nature of data analysis, transcripts offer the interviewer key words and phrases whose interpretations hold great value to the research objective.

\section{Analyzing}

Similar to the report and documentation content analysis, the research interview transcript was broken down into four categories and coded using the NVivo software. the four identified four categories have been identified as follows:

- General Background Information: assessing the overall market trends across all three stakeholders, their asset holdings, leading industry tenants and current office development statistics. The Canadian based data is also compared against available Global data, which will provide a holistic understanding of the Canadian CRE market and it stakeholders. This category is intended to assist in understanding the general market background across the selected sample population so as to address the leading research question in identifying possible CR\&S integration strategies

- Assessing CR\&S: identifying definitions of CR\&S, published mission statements and commitment levels, along with details on each stakeholder's reporting and general CR\&S programs, and their respective motivators for engaging in CR\&S. The aim of this data analysis is to uncover how CR\&S is understood, defined and supported by executive teams across all three identified CRE stakeholders. This category also aims to determine the driving motivators for committing to CR\&S goals.

- Leading CR\&S Goals: identifying and listing the CR\&S objectives and goals, the reasons they have been chosen, the metrics that are used to track the implementation measures and success rates, the current status of the goal, the associated financial cost and the associated barriers to implementing CR\&S goals. The intent under this category is to uncover which environmental aspects of sustainability are common across the board. 
- Tracking Methods and Processes: determining methods and processes for tracking CR\&S goals and commitments, along with their results and impacts on meeting CR\&S goals and commitments. This final category allows addressing the main research question, along with supporting sub-questions.

\section{Verifying}

In qualitative research, it is argued that an important method of verifying the transcribed data and establishing scientific knowledge is through implementing methods of reliability, validity, and generalizability (Kvale, 1996). Reliability involves the level of consistency maintained across the transcripts, while validity questions if the study's transcripts facilitate the research's intended investigation, to "the extent to which the (researcher's) observations indeed reflect the phenomena or variables of interest" (Kvale, 1996).

Reliability was established across the transcripts by consistently applying and following the REB's approved interview protocol across all 14 interview sessions. The research ensured that each of the participants were consistently asked and provided answeres to the predetermined questions, where and if applicable. In order to confirm that the research accurately captured and understood what participants disclosed during their interview session, each participant was provided with a copy of the transcript to review and approve before any analysis was conducted. The observations made throughout the transcripts apply across the Canadian CRE stakeholders, in addition to the selected sample population, as they are representative of the general relationships across the Canadian CRE sector (inclusive of CRE firms, tenants and construction firms). Validity was established through the use of multiple sources of evidence. It is recognized that the results will not necessarily directly apply to all companies in the industries studied. However, the use of companies identified through leading industry reports, such as REALpac, The Leaders, and Corporate Knights, provides an indication that the practices uncovered represent the leading edge within the industries studied.

\section{Reporting}

Inevitably, the researcher's influence weighs in significantly on levels of contextual interpretation and the conveyed message. Nonetheless, attempts were taken to minimize the levels of bias in reporting through implementing the above mentioned verification methods. As suggested by Kvale (1996) and Miles and Huberman (1994), the research established the validity of the consenting participants' interview disclosures and minimized bias in reporting by verifying the research process with continual checks of credibility, plausibility and trustworthiness of the investigation and its findings. 


\subsubsection{APPLYING NVIVO 10 as a Qualitative Research TOOL}

Nvivo 10 was employed as a qualitative research tool in order to manage and analyze the data collected from CR\&S reports (made available either through online publications or web pages) and interviews (NVivo, 2013). The NVivo 10 data gathering and analyzing process is described as an iterative process, through which exploration, coding, reflection, memo gathering, and querying are performed (NVivo, 2013). Figure 9 illustrates the iterative process employed as a research methodology to assess and identify observations set to address the research's objective. As per NVivo 10 (2013), reports, documents, web pages and transcribed documents are first imported into the program. Once imported, all documents are then coded in order to create nodes to address the main question and sub-questions. A code is described as "a fundamental task in most qualitative projects - it involves gathering all the material about a particular theme or case into a note for future exploration", while a node is defined as "a collection of reference about a specific theme, place, person or other area of interest" (NVivoe, 2013).

For the purpose of this research, the codes are divided in three sections: CRE firms, anchor tenants, and construction firms. This organization allows each node to be allocated to each appropriate CRE stakeholder and to be set up based on both the main central research question and semi-structured interview questions. The detailed code and nodes selection process and development are illustrated in Appendix D. Once the codes and nodes have been developed, the transcribed interviews and CR\&S reports and associated documents (online publication and web pages where applicable) were assessed and nodes where applied to address each question (as illustrated in Appendix D).

Word frequency queries were then established in order to generate and analyze the most frequently occurring words contained within each developed node. Tests conducted to verify the effects of displayed words in word frequency query concluded that changing the display word query from ten (10), twenty-five (25), fifty (50) or one hundred (100) most frequent words did not alter the results. In order to capture a relevant portion of the word frequency generated, the research established 25 as the selected "display word frequency". Once the queries were set, Excel tables were extracted for reporting purposes, providing length, count and weighted percentage per word. Length is defined as "the number of letters or character in the word", count refers to "the number of times that the word occurs within the project items searched" and the 
weighed percentage is the "frequency of the word relative to the total words counted." The "length" column generated from the word frequency query onto the excel spread sheet bears no relevance to the research and was therefore omitted.

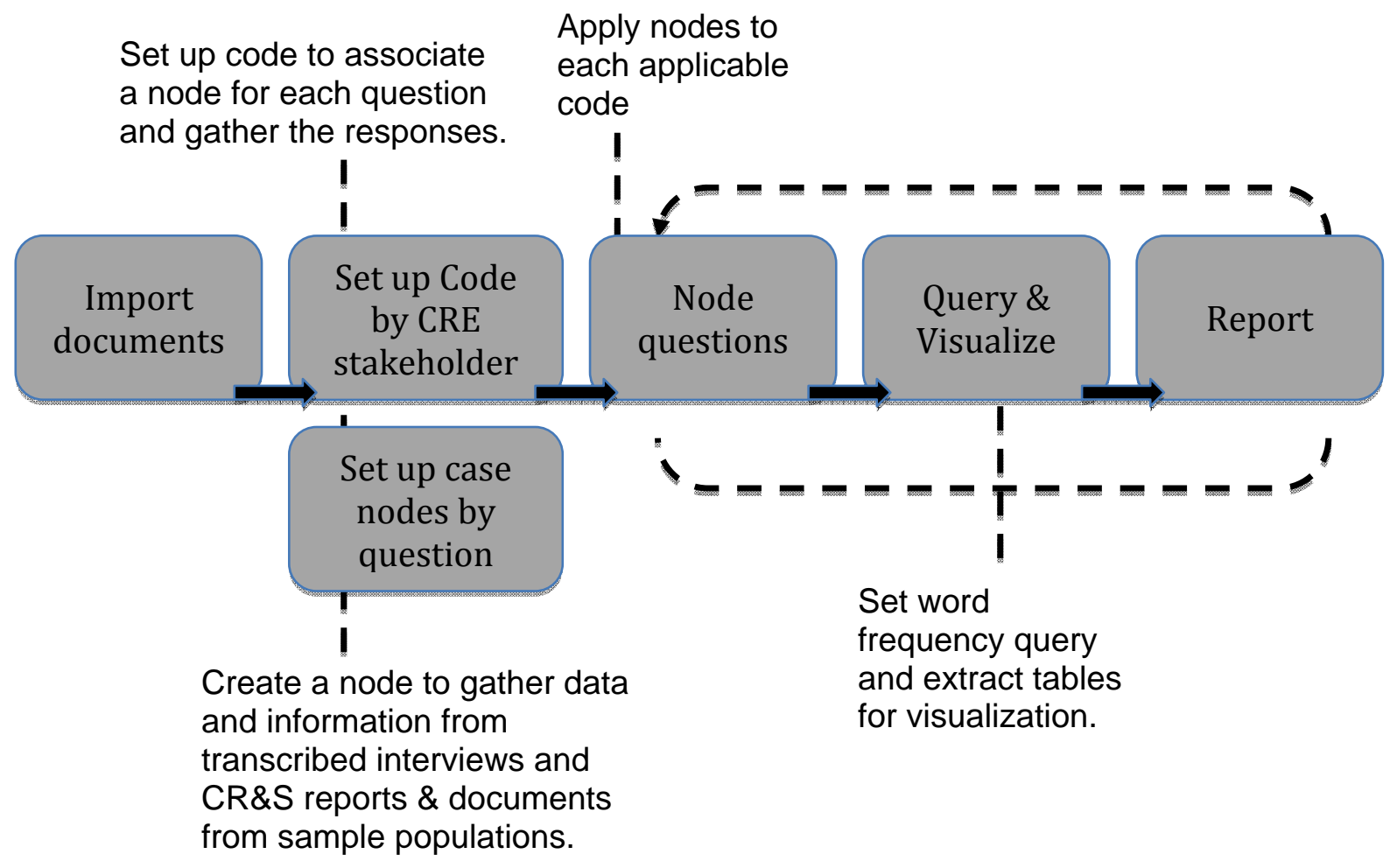

Figure 9 NVivo as a Qualitative Research Tool - An Iterative Process (Nvivo, 2013)

Further information on NVivo's qualitative research methodology and screen shot examples are listed in Appendix D. 


\section{CHAPTER 4: RESULTS}

The following section presents the key results of the research. The results are presented in three sections: CRE firms, tenants, and construction firms. First, each section provides a general background on the selected sample population, detailing their current market conditions and portfolio. Second, in order to address the requirements of the four research sub-questions, each section will sequentially assess general CR\&S across the selected sample population, inclusive of their CR\&S reporting and definitions, followed by CR\&S goals and commitments, motivators, implementation and strategies, and finally assessing barriers to integrating CR\&S strategies. Finally, this section will summarize the overall results derived from the sub-questions and will aim to address the principle question on how to integrate CR\&S across the Canadian CRE stakeholders. Figure 1 below illustrates the organizational outline for Chapter 4 .

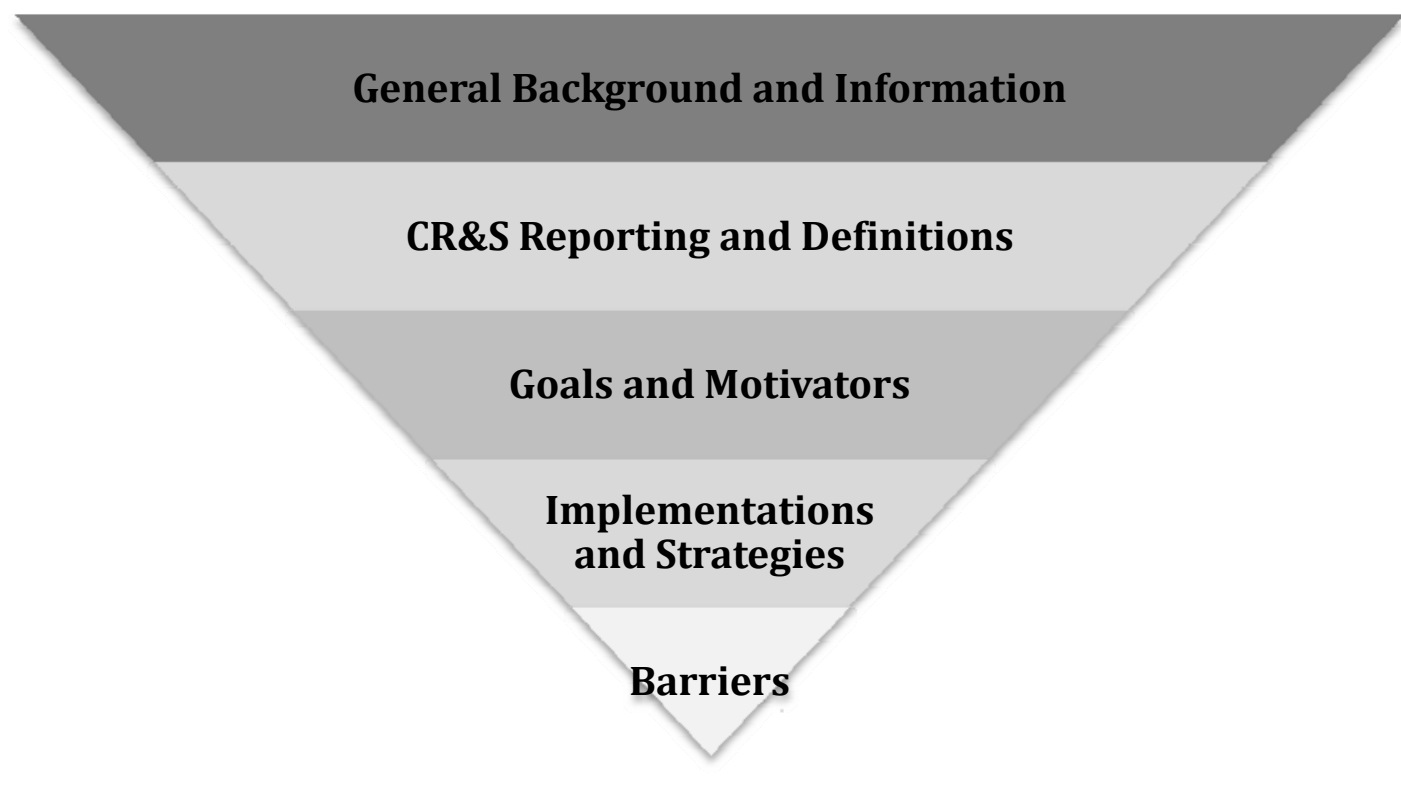

Figure 10 Organizational Outline 


\subsection{CRE FIRMS SAMPLE POPULATION}

\subsubsection{GENERAL BACKGROUND INFORMATION - CRE FIRMS}

Representing approximately twenty-three percent (23\%) of Canada's total commercial office space under either management or ownership, the selected CRE firms cover an estimated aggregate of 119 million $\mathrm{ft}^{2}$ of office space across Canada (as illustrated by Table 5). Due to inconsistencies in asset holding reporting across the selected CRE firms, it was not possible to derive the number of buildings represented in the estimated aggregate of a hundred and nineteen (119) million $\mathrm{ft}^{2}$ office space. Although publically traded REITs and real estate operating companies publically disclose their asset holdings, privately held firms managing clients' real estate portfolios (in most cases institutional investors') are not required to do so (REALpac and Jantzi-Sustainalytics, 2012).

Table 5 Office Building Space (Canadian Property Management Vol. 26)

\begin{tabular}{|c|c|c|c|c|}
\hline \multicolumn{5}{|c|}{ OFFICE BUILDING SPACE } \\
\hline CRE COMPANIES & $\begin{array}{l}\text { Total Office } \mathrm{ft}^{2} \\
\text { (Millions) }\end{array}$ & $\begin{array}{c}\text { Manages } \mathrm{ft}^{2} \\
\text { (Millions) }\end{array}$ & $\begin{array}{l}\text { Owns } \mathrm{ft}^{2} \\
\text { (Millions) }\end{array}$ & $\begin{array}{c}\text { Owns \& } \\
{\text { Manages } \mathrm{ft}^{2}} \\
\text { (Millions) }\end{array}$ \\
\hline Company 1 & 29.266 & 29.266 & - & - \\
\hline Company 2 & 18.528 & 5.330 & 4.555 & 8.643 \\
\hline Company 3 & 21.800 & 7.200 & & 14.600 \\
\hline Company 4 & 9.393 & 0.319 & 3.595 & 5.479 \\
\hline Company 5 & 14.211 & - & 0.569 & 13.642 \\
\hline Company 6 & 18.545 & 9.454 & - & 9.091 \\
\hline Company 7 & 8.078 & 0.090 & 0.528 & 7.460 \\
\hline TOTAL SQ.FT & \multicolumn{4}{|c|}{119.821} \\
\hline INDUSTRY TOTAL SQ.FT & \multicolumn{4}{|c|}{517.243} \\
\hline REPRESENTATIVE RATE & \multicolumn{4}{|c|}{$23 \%$} \\
\hline
\end{tabular}


Table 7 provides a list of the roles identified during interview sessions. Although the research did not attempt to investigate the roles and responsibilities as they relate to each interviewed subject matter expert, the concluding remarks of the research will urge further comparative investigation on the impact various roles and responsibilities within the CRE sector pose on integrating CR\&S strategies.

\section{Table 6 CR\&S Based Roles for Selected CRE Firm Samples}

\begin{tabular}{|l|l|}
\hline \multicolumn{2}{|c|}{ CR\&S Titles - CRE Firms } \\
\hline CRE Firms & \multicolumn{1}{|c|}{ Titles } \\
\hline Company 1 & Director of Sustainability \\
\hline Company 2 & Director of Strategic Initiatives and Planning \\
\hline Company 3 & Director of Operations and Sustainability \\
\hline Company 4 & Director of Sustainability \\
\hline Company 5 & No Interview Conducted \\
\hline Company 6 & No Interview Conducted \\
\hline Company 7 & No Interview Conducted \\
\hline
\end{tabular}

\subsubsection{ASSESSING CR\&S ACROSS CRE FIRMS}

\subsubsection{CR\&S REPORTING - CRE FIRMS}

The first CR\&S report among CRE firms to be made publically available was in 2008 (as illustrated by Figure 11). Since then, five (5) out of seven (7) ( representing seventy-one percent (71\%)) selected CRE firms developed a CR\&S report by 2012 . Although all firms have made general public commitments to sustainability, only those five companies developed a direct "CR\&S report" detailing their corporate and operational commitments. The two firms (representing $28 \%$ of the CRE firms sampled) have neither developed nor publically released a CR\&S based report as of the first quarter of 2013. These two firms have instead disclosed their general commitments either through their corporate websites or have included a paragraph addressing general commitments made toward CR\&S in their annual financial reports to investors. 


\section{CR\&S Reporting for CRE Firms \\ $2008-2012$}

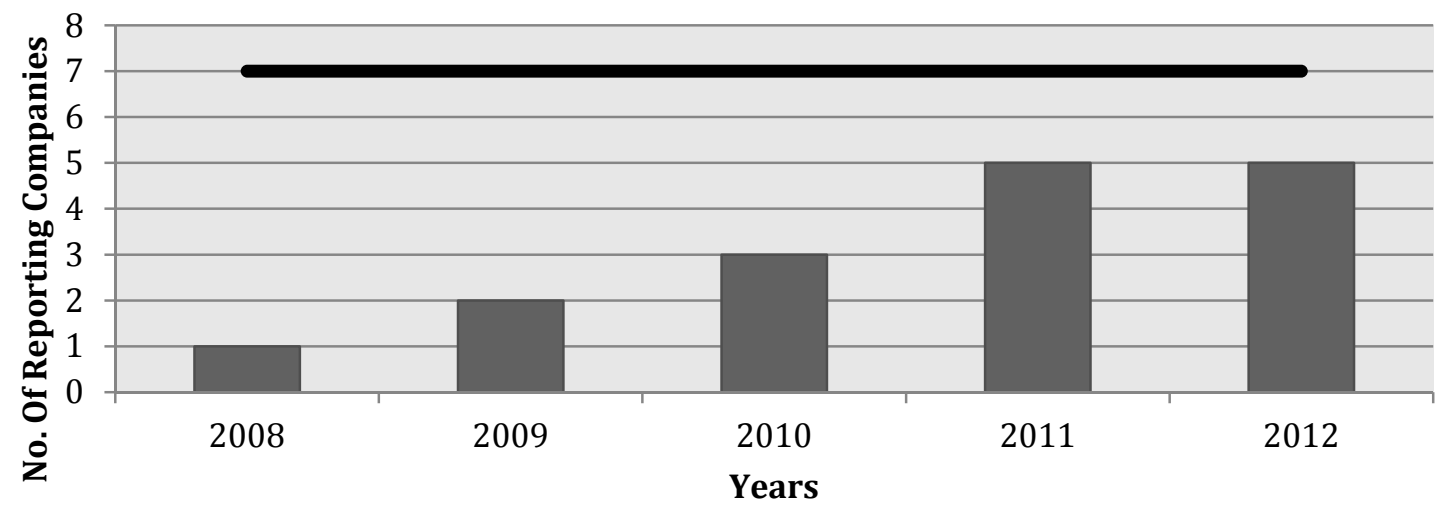

Figure 11 Number of Companies in the CRE Sample Reporting on CR\&S

Generally, CR\&S reports across the studied CRE firms include an overview of their ESG commitments, operational strategies and targets to date, along with a disclosure on their building performance as it relates to specific environmental commitments and goals. All CR\&S reports for the sampled CRE firms also include social and community commitments, in addition to their environmental commitments. Reporting practices also include comprehensive annual reports that directly disclose operational performance goals and set targets per asset portfolio, along with implementing strategic actions in response to the environmental set goals and targets. A detailed breakdown by asset type of building certifications that are either achieved or in the process of being achieved were also included by some of the sampled CRE firms. Online portals directly addressing commitments toward implementing CR\&S building performance practices were also included.

\subsubsection{CR\&S DEFINITION - CRE FIRMS}

Prior to investigating the possible integration of CR\&S across the CRE stakeholders, a common understanding and definition of CR\&S needs to be established. Ensuring that all three stakeholders have a common definition and understanding of CR\&S as it applies to the CRE sector will facilitate cross-integration. As such, all CR\&S reports were assessed to uncover the corporate definition of CR\&S, along with directly asking interview participants the question: "How does your organization define CR\&S?".

Using NVivo 10, the top 25 word frequencies related to definitions were extracted from the reports and interview data respectively. In Appendix F, Tables 20 and 21 
display the top 25-word frequency results generated from the nodes set to extract the definition of CR\&S from CR\&S reports and conducted interviews among the selected CRE firms sampled population. CR\&S definitions were found in the "commitment" section at the beginning of the CR\&S reports, while interviewed participants were asked to respond to a direct question on the definition of CR\&S. Following "environmental" (which was counted 8 times and accounts for $3.67 \%$ of the weighted percentage ${ }^{8}$ ), "commitment" and "corporation" account for 5 counts respectively and bears a 2.22\% weighted percentage. Other words below the 5-word count include "business", "clients" and "efficiency", with "employees" returning the lowest frequency word count to define CR\&S in reports.

Assessing published CR\&S reports, CR\&S is broadly viewed within the CRE sector as a commitment to help reduce the impact of their business operations on the environment in which they operate. The operating environment comprises of surrounding communities in which assets are held, managed and operated. The CR\&S reports also detail their firms' accountability toward shareholders' (inclusive of institutional investors) and their commitments to create healthy environments for their tenants and employees. As explained by one CRE firm's CR\&S report: "Sustainability encompasses the risks and organizational responsibilities surrounding our environmental, social and governance (ESG) impacts. Sustainability is of particular concern to the real estate sector - given the scale and extent of its ESG impacts - as well as to key stakeholders such as our shareholders, clients, tenants and employees." This statement underlines that elements of CR\&S, particularly with respect to ESG, hold great implications and interest to the CRE sector.

During the interview segments, participants used CSR and CR\&S interchangeably. In addition to "sustainability", other words used more frequently to define CR\&S include "assets", "environment", and "corporate branding" generating 3 counts each. One participant's answer summed up their corporate CR\&S definition as "Our sustainability program is our way of managing our performance, meeting our customer's expectations, and building and creating additional value for our (NAME CENSOR) brand and to further developing the (NAME CENSOR) brand." The interviewee's given CR\&S definition resonates across all four interviewed participants. Rising obligations toward responsible property investment (RPI) and references to global comparative benchmarks, such as GRESB, were reported by only 2 out the 4

\footnotetext{
${ }^{8}$ refer to Section 3.2 .3 for a definition of "counted" and "weighted percentage".
} 
interviewed subject matter experts. Although RPI was not commonly included or mentioned as a supporting CR\&S definition across CR\&S reports and interviews, one participant did indicate that "...how we apply the principles (of CR\&S), it's through responsible property investment...", while another participant stated that they "...think the three prong is that many of our clients who are pension funds understand a longterms risk associated with various sustainability indicators, and therefore want to make sure that their manager, i.e (NAME) being one of those, is mitigating those long term sustainability risks because they think it's going to obviously impact the assets they have, the management for the assets they hold and the value of those assets." Based on the CR\&S definitions provided by the sampled CRE firms and their CR\&S reports, it is evident that Canadian CRE firms, led by key industry players, are progressing toward linking elements of $C R \& S$ as an integrated strategic action plan to mitigate investment risk.

What is more, when asked to define CR\&S, one participant provided an explanation differentiating between social and environmental sustainability, stating that: "sustainability is social as well as environmental. Social would be charitable organizations... so for this call I think we view sustainability from an environmental perspective. So from an environmental perspective some of the things we look at are green building certification, energy and waste reduction and alternative transportation." Overall, aspects of environmental resource management returned the highest frequency in defining CR\&S, both within CR\&S reports and during conducted interviews. Given the aforementioned CR\&S definitions expressed both through CR\&S reports and interview segments, CRE firms associate the environmental element of ESG as holding more applicability in defining and integrating CR\&S across the CRE sector.

\subsubsection{LEADING CR\&S GOALS FOR CRE FIRMS}

The content analysis indicated that the sampled CRE firms reported on their community involvement (the social component of ESG), workplace and tenant engagement initiatives, along with environmental commitments. Reflective of the certification prerequisites and public reporting requirements identified in the literature review; along with direct statements made during interview segments by subject matter experts, energy, water, GHG, and waste were identified as leading CR\&S goals bearing significant importance to operations and risk management across the sampled CRE firms (as identified in Tables 7 and 8). The fact that all of these are primarily environmental goals underlines the importance of environment issues within CRE firms. 
Table 7 Top Environmental Resource Management Based CR\&S goals for CRE Sector - Identified by CR\&S reports

\begin{tabular}{|c|c|c|c|c|}
\hline \multirow{2}{*}{ Company } & \multicolumn{5}{|c|}{ CRE Sector } \\
\cline { 2 - 5 } & Energy & Water & GHG & Waste \\
\hline 1 & - & - & - & - \\
\hline 2 & $\mathrm{x}$ & $\mathrm{x}$ & $\mathrm{x}$ & $\mathrm{x}$ \\
\hline 3 & $\mathrm{x}$ & $\mathrm{x}$ & $\mathrm{x}$ & $\mathrm{x}$ \\
\hline 4 & $\mathrm{x}$ & $\mathrm{x}$ & $\mathrm{x}$ & $\mathrm{x}$ \\
\hline 5 & $\mathrm{x}$ & $\mathrm{x}$ & $\mathrm{x}$ & $\mathrm{x}$ \\
\hline 6 & $\mathrm{x}$ & - & - & $\mathrm{x}$ \\
\hline 7 & $\mathrm{x}$ & $\mathrm{x}$ & $\mathrm{x}$ & $\mathrm{x}$ \\
\hline TOTAL & $86 \%$ & $71 \%$ & $71 \%$ & $86 \%$ \\
\hline
\end{tabular}

Table 8 Top Environmental Resource Management Based CR\&S goals for CRE Sector - Identified Through Interview Segments

\begin{tabular}{|c|c|c|c|c|}
\hline \multirow{2}{*}{ Company } & \multicolumn{5}{|c|}{ CRE Sector } \\
\cline { 2 - 5 } & Energy & Water & GHG & Waste \\
\hline 1 & $\mathrm{x}$ & $\mathrm{x}$ & $\mathrm{x}$ & $\mathrm{x}$ \\
\hline 2 & $\mathrm{x}$ & $\mathrm{x}$ & $\mathrm{x}$ & $\mathrm{x}$ \\
\hline 3 & - & & & \\
\hline 4 & $75 \%$ & - & - & - \\
\hline TOTAL & $\mathrm{x}$ & $50 \%$ & $50 \%$ & $50 \%$ \\
\hline
\end{tabular}

Three participants (roughly $42 \%$ of the CRE sample) declined interviews. However, information relating to their CR\&S commitments were available in their reports and on their corporate websites. Two of the three companies that declined interviews had not committed to direct goals and targets and had not released a public CR\&S report as of the first quarter of 2013. Nonetheless, commitments to certify office portfolios to BOMA BESt levels (without disclosing a committed time frame or certification level objective), disclosing general community involvement (one firm mentioned their corporate support toward the arts community), and broadly identifying the three pillars of CR\&S (inclusive of the environment, community relations and employee engagements) without disclosing specific reduction goals or targets were published on their websites. All four companies represented in the interviews also 
published publicly available material relevant to their CR\&S programs. Table 10 outlines the top 25-word frequency query generated from CR\&S reports to identify published CR\&S goals. Based on the defined limits set for the node to identify CR\&S goals across the selected CRE firms' CR\&S reporting, "energy", "water", "waste", and "emissions" count among the top 25-word frequency counts. As noted in one CR\&S report, "Our Sustainability Policy guides our rolling three-year Sustainability Strategy. This strategy addresses objectives in six areas: 1. Energy, water and greenhouse gases 2. Waste management 3. Indoor and outdoor environment 4. Leadership 5. Branding and marketing 6. Social Responsibility." The same CR\&S report also differentiated between short-term versus mid- and long-term priorities, where the reduction of energy, water, GHG emissions, and waste, as well as engaging tenants to alter their occupant behaviour, were accounted as short-term priorities. Mitigating the risk of water scarcity and rising energy costs, were examples of the identified mid- to long-term goals.

Additional reported sustainability principles by another CRE firm include: "1. Eliminating (...) contribution to the progressive build-up of substances extracted from the Earth's crust (e.g. fossil fuels and heavy metals use); 2. Eliminate (...) contribution to the progressive build-up of chemicals and compounds produced by society (e.g. use of dioxins, PCBs, and asbestos); 3. Eliminate (...) contribution to the progressive physical degradation and destruction of natural systems (e.g. paper derived from over-harvested forests, greenfield development, and reduction of wildlife habitat); and 4 Eliminate (...) contribution to condition that undermine people's capacity to meet their basic human needs (e.g. eliminating unsafe working conditions)." Aiming to reduce their operational impact on the environment; while carrying social conscientiousness, sampled CRE firms reported on specific environmental resource management goals, which were further asserted during the interview sessions.

Environmental resource management goals, such as those associated with energy, water, GHG emissions, and waste, were frequently discussed in terms of costs savings. Although these four key environmental resource management elements did not generate top 25-word frequency counts under NVivo (as illustrated under Appendix F, Table 22 and 23), subject matter experts collectively referenced them as key CR\&S goals. As explained by one interviewed subject matter expert, given the nature of the CRE business, the first and foremost CR\&S focus is environmental in scope. The participant further explained the rising congruent expectations between tenants and investors with regards to real estate management and investment as: "It is sort of that environmental side of resource consumption, and then for energy...there is certainly 
from the client side (institutional investors) and from the tenant side, there is a keen interest in greenhouse gas emissions...what we are going be staying focused on it's going to continue to be energy. Water is increasing, in terms of the level of attention it's getting. I think that will change and waste as well - waste while not a big cost piece, important from a globalistic perspective and very important from tenant perspective". Another participant identified the need for better data collection, stating, “...we can't manage what we can't measure properly". Consequently, managing the consumption of energy, water, GHG emissions, and waste are central requirements in strengthening the management of environmental resources (illustrated in Table 7 and 8). As such, details relating to data disclosure in CR\&S reports of these four environmental resource management goals are listed as follows:

\section{Energy Management}

Energy management practice reports are inconsistent across the CRE firms sampled. Although the majority (71\%) of CRE firms publically identified energy management and consumption reductions as key commitments, only 3 out of the 7 (42\%) disclosed their energy consumption reduction for the 2011/2012 reporting period. Only 28\% disclosed energy reduction targets. These reductions were $10 \%$ and $15 \%$, respectively, against a given base line (2010 and 2008, respectively) for the target reduction year of 2015 and 2014, respectively. Discrepancies were also found for the reporting of energy consumption and intensities per asset types. Most CRE firms disclosed their energy consumption and reduction targets per asset type (office, industrial and retail) separately, while others aggregated data for their entire asset portfolio. Although the study attempts to assess data exclusively for the Canadian office space, industrial and retail energy consumption and energy use intensity (EUI) rates are also included.

Energy performance across the sampled firms is generally based on the collection and assessment of their electricity and natural gas utility bills, and normalized for occupancy rate, weather and changes in their portfolio size. Due to varying baseline reports and data inconsistencies (reports where portfolio assets were not segregated accordingly), the annual energy consumption reduction for the 2010 - 2011 reporting period was assessed and uncovered an aggregated energy reduction average of $4 \%$ for that period. For example, the energy consumption reduction of $1.63 \%$ for Company 2 was determined by calculating the change in energy consumption from $28.07 \mathrm{ekWh} / \mathrm{ft}^{2}$ in ekWh/ft ${ }^{2}$ in 2010 to $27.61 \mathrm{ekWh} / \mathrm{ft}^{2}$ in 2011. Company 4 achieved a 12\% energy reduction in the 2010 - 2011 reporting period and maintained a consistent consumption 
reduction since their reporting baseline of 2008. However, it is important to note that the reported energy reduction for Company 4 also includes total consumption for both retail and office space. Based on the public reporting disclosure of 5 out of the 7 CRE firms (representing 42\%), their average EUI amounted to $29.5 \mathrm{ekWh} / \mathrm{ft}^{2} / \mathrm{yr}$, which ranks among the "lower middle" $25 \%$ to $50 \%$ of building energy performance indices under BOMA Canada (2011). Only one CRE firm disclosed an energy intensity of $21 \mathrm{ekWh} / \mathrm{ft}^{2} / \mathrm{yr}$, earning BOMA BESt's top building performance ranking. According to BOMA BESt, the national average energy intensity for office building is $36.65 \mathrm{ekWh} / \mathrm{ft}^{2} / \mathrm{yr}^{9}$, which ranks under the lowest performing $25 \%$ of buildings. Figure 12 discloses the energy consumption benchmark for all selected CRE firms, and demonstrates that Company 5 and Company 7 have not reported on their energy consumption reduction.

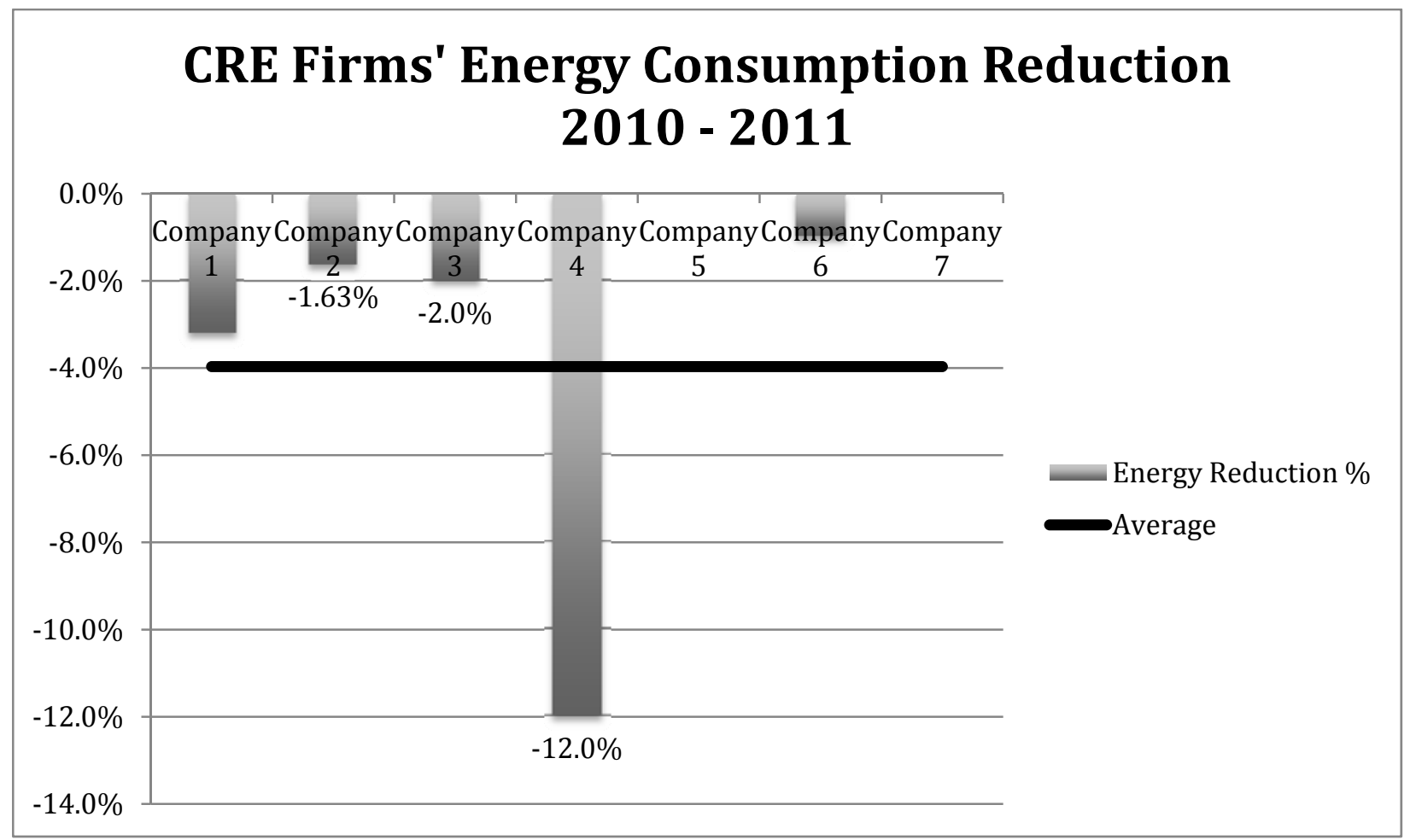

Figure 12 Energy Consumption Reduction for CRE Firms

${ }^{9}$ BOMA Canada (2011). 
Water Management

Water management was identified as a leading environmental commitment by $71 \%$ of the sampled CRE companies. Figure 13 lists the average water consumption reduction at four percent $(4 \%)$ by the companies that disclosed their consumption reduction rates for the 2010 - 2011 reporting period. Two firms disclosed direct water reduction targets of $10 \%$ and $15 \%$ with targeted goal dates of 2015 and 2014, respectively. One CRE firm (Company 3) reported on their commitment to incrementally decrease their water consumption by $3 \%$ each successive year in order to achieve the corporate water consumption reduction target of $15 \%$ by the targeted year of 2014 . Water intensities were also reported by $71 \%$ of the companies, however, there were unit inconsistencies across the board, adding to the complexity of conducting a comparative benchmark. Two companies (approximately 29\%) did not disclose their commitment toward water management.

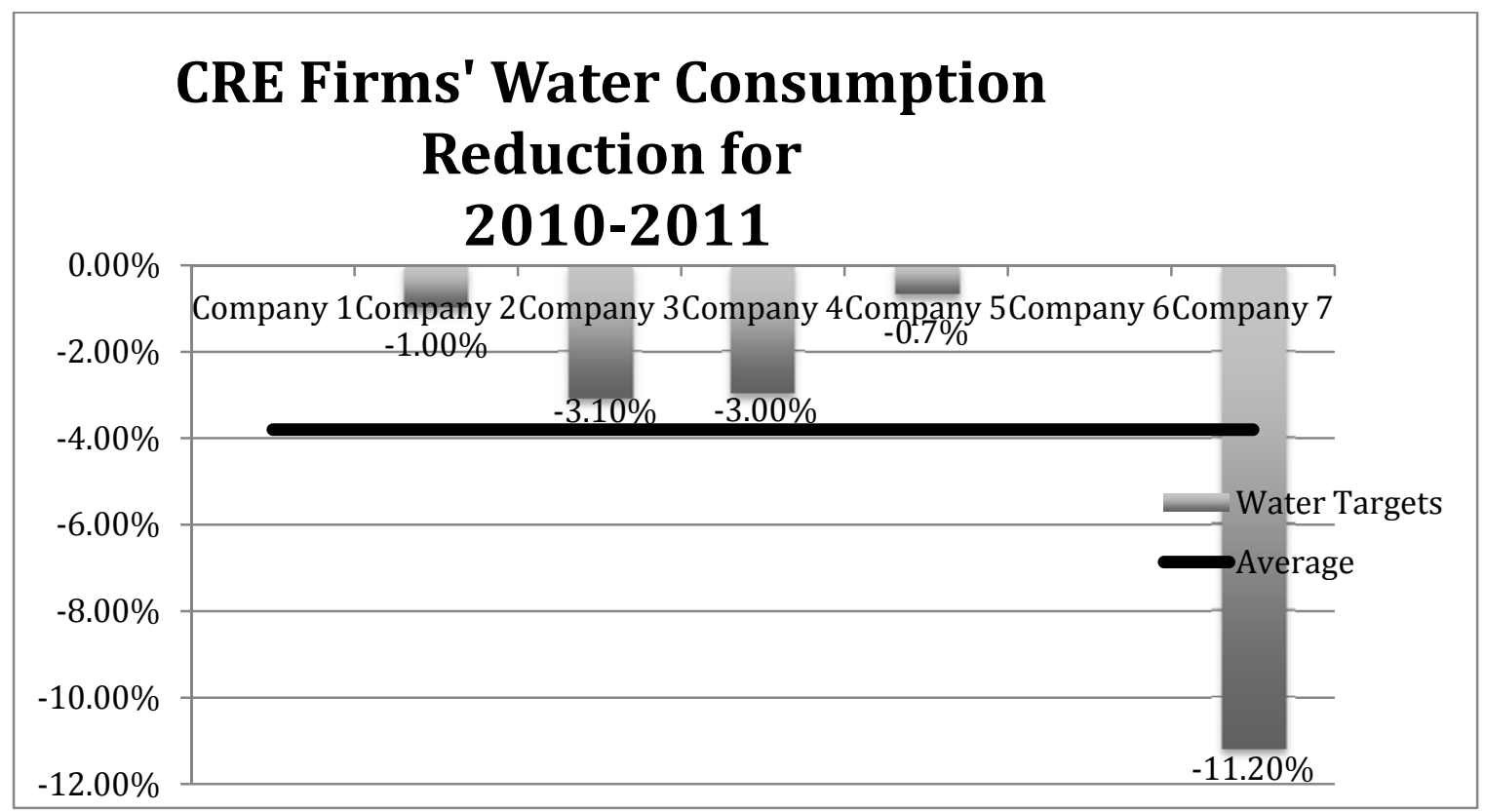

Figure 13 Water Consumption Reduction for CRE Firms

\section{GHG Reduction}

Most of the CRE firms ( $71 \%$ of the sample) reported commitments to GHG reduction.

Two firms did not list GHG targets as part of their general CR\&S commitment. Similar to energy reduction disclosure, GHG reduction data were inconsistently reported. Often the GHG reduction data reflected the companies' aggregate managed portfolio, inclusive of industrial, retail, and data centres. Only one firm (Company 7) disclosed GHG reductions specifically for their office portfolio. Only one company (Company 2 ) went as 
far as including Scope $3^{10}$ emissions, while the majority of CRE firms (Companies 3, 4, 5 and 7) listed Scope 1 and Scope 2. The most aggressive GHG reduction achieved for the $2010-2011$ period was a reduction of $9.7 \%$, which is more than double the sample industry average of $4 \%$. Baselines and targeted years were also inconsistently reported. Figure 14 below illustrates the CRE's GHG reduction for 2010-2011.

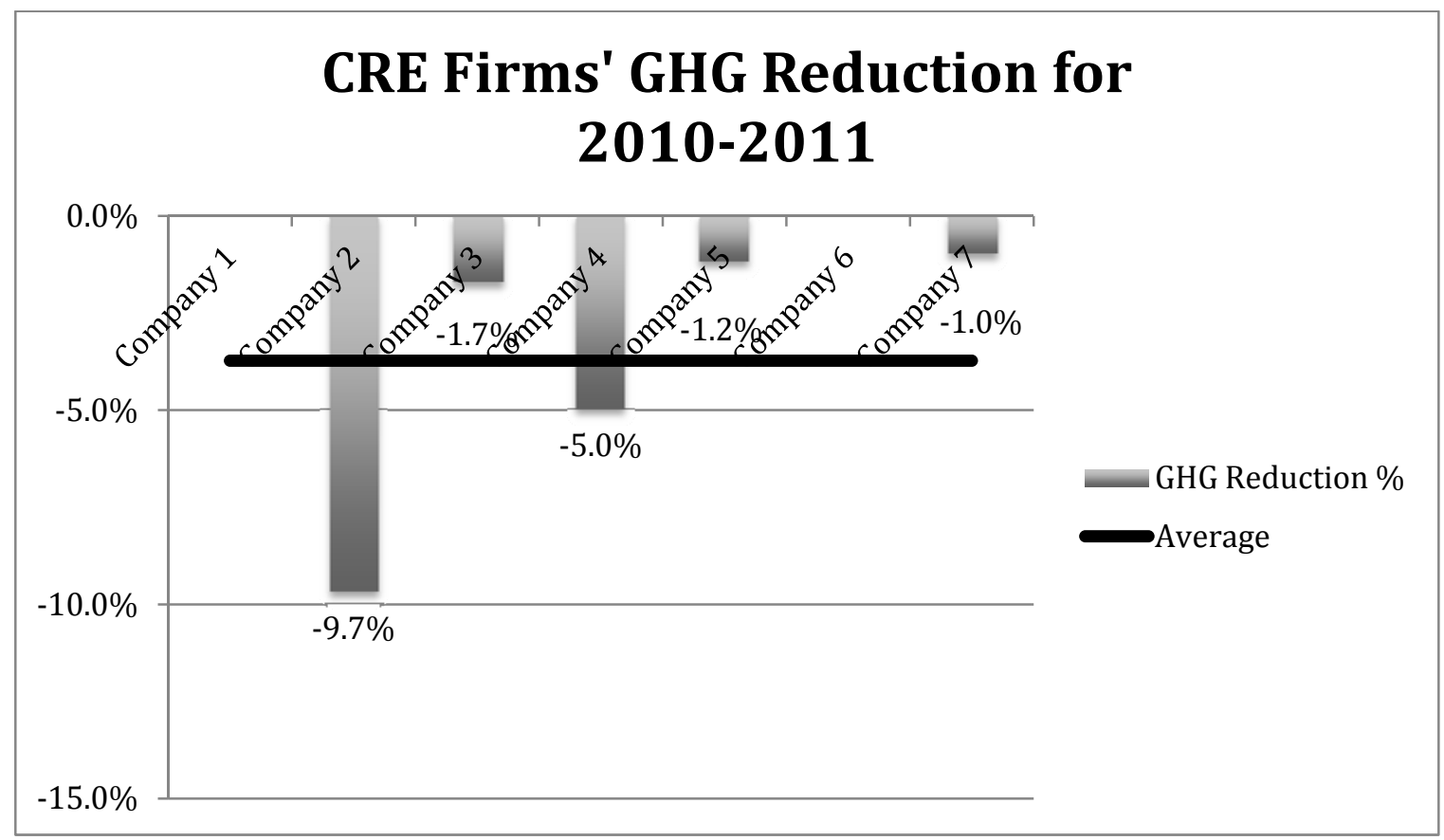

Figure 14 GHG Reduction for CRE firms

Waste Management

The management of hazardous and non-hazardous waste was also reported by $71 \%$ of the CRE firms sampled as a targeted CR\&S goal. As indicated in Appendix G, waste reporting baselines ranged from 2006 to 2010, with most CRE firms (Companies 2, 3, 4, and 5) reporting rates of waste diversion increase between 1.0\% to 5.9\% for the 2011 reporting period, while Company 7 reported a diversion rate decrease of 3\%. Table 15 discloses the waste diversion improvement rates from 2010 - 2011, averaging to an

\footnotetext{
${ }^{10}$ The Environmental Protection Agency (EPA) classifies GHG emissions generated directly or indirectly by an entity as "scopes". Scope 1 emissions are direct GHG emissions from sources that are owned or controlled by an entity (this includes emissions from fossil fuels burned onsite, emissions from entity-owned or entity-leased facilities or direct sources). Scope 2 emissions are indirect GHG emissions resulting from the generation of electricity, heating and cooling, or steam generated off site but purchased for the entity (this includes chilled water, team and high temperature hot water). Scope 3 emissions include indirect GHG emissions from sources not owned or directly controlled by the entity, but related to the entity's activities (this includes business travel, employee commuting, contracted solid waste disposal and contracted wastewater treatment).
} 
aggregate of two percent (2\%) improvement. It should be noted that the reporting of waste diversion data and units was generally consistent.

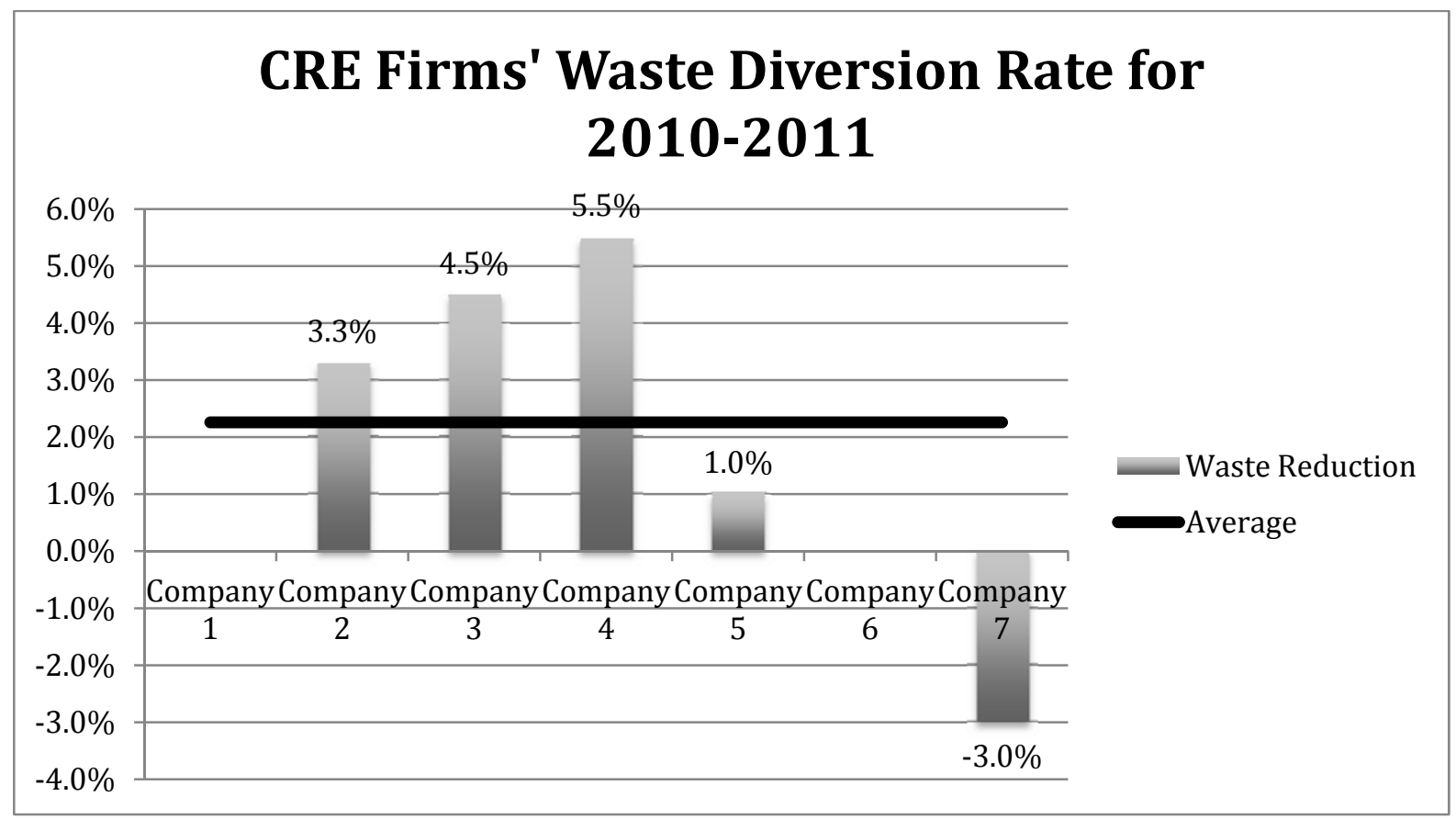

Figure 15 Waste Reduction for CRE Firms

As previously explained, all of the above environmental resource management data were extracted from CR\&S reports. No data were provided from interview segments conducted with subject matter experts. Given that environmental resource management is identified as a key element in establishing and evaluating CRE companies' CR\&S goals by both subject matter experts and published CR\&S reports, the aforementioned goals hold great value in cross-integration between all three CRE stakeholders. CR\&S reports and interview participants have both identified the growing necessity of collecting data as they relate to energy, water, GHG emissions, and waste consumption in order to effectively and responsibly manage their portfolios and meet the growing requirements of investor clients and tenants. Thus, the following section will further investigate the leading CR\&S motivators among the selected CRE companies. 


\subsubsection{Leading CR\&S Motivators for CRE firms}

The motivators were identified based on an analysis of the CR\&S report and interview data using NVivo 10. As illustrated in Appendix F Tables 24 and 25, the top 25 frequency words were identified as leading CR\&S motivators across the sampled CRE firms. Assessing the entirety of each CRE company's CR\&S reports, the top 4 (excluding the count for "2011" as a word) of the 25 most frequently used words were "energy", "building", "sustainability", and "environmental" (counting 296, 242, 224 and 197 times, respectfully). Given the high frequency count these words generated throughout all assessed CRE firms' CR\&S reports, they were considered as potential CR\&S motivators for the CRE firms.

Further details on the motivations were obtained from the interviews conducted, as illustrated in Appendix F - VI. Excluding the first two words ("think" and "piece" due to lack of relevance), "sustainability", "clients", "employees", and "tenants" were the top 4 of the 25 most frequently used words (count 6, 5, 5, and 5, respectively). Setting nodes under NVivo for all responses relating to $C R \& S$ motivators during the interview segments generated these data. The interviews highlighted that three participants (Companies 1, 2 and 3) viewed the pursuit and commitment of ESG based goals, particularly as it relates to environmental management, as strategic market differentiators set to attract investors who are seeking to reduce potential risks to their long-term investment objectives. A respondent noted that commitments to CR\&S will "benefit our clients to whom we have a fiduciary duty." Participants generally felt that their clients have a general understanding of the significance of integrating sustainable practices (particularly as it applies to energy, water, and GHG reductions) into their long-term investment strategies and are starting to seek management teams capable of mitigating and managing associated environmental risks through sustainable risk planning that can increase and safeguard the value of their assets. One CRE company's (Company 2) $C R \& S$ report made a direct link to the fact that "rising energy costs and potentially higher emissions regulations drive us to redouble our efforts to reduce energy consumption and GHG emissions". Therefore, the collection of data (inclusive of energy, water, waste and GHG emissions) becomes essential in managing and mitigating potential risks associated to managing high performance office buildings. Ultimately, CRE participants have indicated the potential for alleviating the negative environmental implications their organizations must be weighed against the potential risk of becoming uncompetitive or 
industry or policy non-compliant. Ultimately, potential rising investment risks resulting from environmental impacts cannot be effectively managed if measurement data are not available. Building on a widely known axiom, the CRE sector cannot manage what it cannot measure.

\subsubsection{Leading CR\&S Implementation and Tracking Methods for CRE Firms}

Through content analysis of the CR\&S reports and transcribed interviews, it was determined that the sampled CRE companies used a number of key strategies and processes to implement and manage CR\&S targets. Conducting top word frequency queries through Nvivo for both CR\&S reports and transcribed interviews (as per Appendix F, Table 26 and 27, respectively) did not generate relevant data that is indicative of which CR\&S tracking methods where employed. However, directly assessing both CR\&S reports and transcribed data for the employed tracking measures and processes generated the results illustrated in Table 9. The resulting tracking measures and processes include developing sustainable procurement policies (conducted by $29 \%$ of the sample population, Company 2 and 4 ), ongoing investor and tenant communication plans (100\% of sampled population, Companies 1-7), data collection and management (71\% of sampled population, Companies 2, 3, 4, 5 and 7), voluntary building certifications and industry reporting (71\% of sampled population, Companies 2, 3, 4, 5 and 7 ), tenant engagement ( $57 \%$ of sampled population, Companies 2, 3, 4, 5 and 7), community engagement (100\% of sampled population) and green leases (14\% of sampled population, only Company 7 reported). Two companies, Company 2 and 4 (29\%) reported on their procurement strategies directly in their CR\&S report, disclosing their intent to engage and partner with suppliers and contractors in order to incorporate their respective sustainable management strategies. Additionally, communication strategies, including CR\&S reporting, financial statements and website portals, were employed by all CRE firms as a means to track and communicate their CR\&S goals. Details pertaining to each strategy and process are provided below. 
Table 9 CR\&S Implementation Processes - CRE Firms

\begin{tabular}{|c|c|c|c|c|c|c|c|}
\hline \multicolumn{8}{|c|}{ CRE Firms } \\
\hline \multirow[b]{2}{*}{ Participant } & \multicolumn{7}{|c|}{ Strategies and Processes } \\
\hline & Procurement & Communication & Data Management & $\begin{array}{c}\text { Voluntary } \\
\text { Certification and } \\
\text { Industry Reporting }\end{array}$ & Tenant Engagement & Community & Green Leases \\
\hline 1 & - & $\mathrm{x}$ & - & & - & $x$ & \\
\hline 2 & $\mathrm{x}$ & $x$ & $x$ & $x$ & $x$ & $x$ & \\
\hline 3 & - & $x$ & $x$ & $x$ & $x$ & $x$ & \\
\hline 4 & $x$ & $x$ & $x$ & $x$ & $x$ & $x$ & \\
\hline 5 & - & $\mathrm{x}$ & $x$ & $\mathrm{x}$ & $\mathrm{x}$ & $x$ & \\
\hline 6 & - & $x$ & - & & - & $x$ & \\
\hline 7 & - & $x$ & $x$ & $x$ & $x$ & $x$ & $x$ \\
\hline TOTAL & $29 \%$ & $100 \%$ & $71 \%$ & $71 \%$ & $57 \%$ & $100 \%$ & $14 \%$ \\
\hline
\end{tabular}

Data Management

Results relating to the collection and management of data were primarily determined though the interview sessions. 4 out of the 7 interview participants (representing $71 \%$ of the sample) discussed issues relevant to this point. One other firm disclosed their data management strategy in their CR\&S reporting. During the interview process, participants identified "Eco-tracker", data made available by utility providers (such as Direct Energy and Toronto Hydro), along with managing their database through the use of Excel spreadsheets as "fairly robust management systems" set to track and implement their CR\&S goals. The application of these tracking systems accounts for the collection and management of energy, water, and waste data. In spite of the management systems that some of the CRE participants have in place, most are unable to set reduction targets, mainly due to the complexity of their corporate governance structure. One participant (Company 1 ) explained that they would likely not be able to set nor publish targets "... because we have so many different clients and it's their portfolio that we manage under their behalf, as opposed to us having the ability to really go out and set a big target." Therefore, investor clients may potentially inhibit CRE firms who manage investment assets for multiple investor clients to develop and further their commitment to CR\&S. Alternatively, CRE firms with a single investor client focus have the added ability to set more aggressive CR\&S strategies and targets. The details of such barriers will be discussed in further detail in Section 4.1.6.

\section{Voluntary Certification and Public Reporting}

Certification processes; such as LEED EB:OM, BOMA BESt, and voluntary compliance with industry benchmarks, including REALPAC and GRESB were identified throughout the literature review as influencing the commitment and management of CR\&S goals and targets. However, the study uncovered that building certification for the CRE sample set is poorly reported. Although $57 \%$ of the sampled companies reported on their LEED 
rating and certification levels, few differentiated between their Canadian and American asset holdings and asset types. Instead, the reporting of building certification and their associated levels was generally consolidated. As such, it was not possible to conclusively draw certification comparisons. However, based on the $57 \%$ of firms who reported on their portfolio's LEED ratings, it was determined that LEED certifications for the selected CRE firms' aggregated asset holdings ranged between $4 \%$ and $40 \%$. Nonetheless, one firm (Company 3) indicated their corporate commitment of achieving LEED NC on future building development, while another (Company 4) is targeting LEED certification for 11 properties across their portfolio.

Eighty five percent (85\%) of the CRE sample set has reported achieving some level of BOMA BESt certification across their portfolios. One participant did not report on their portfolio's BOMA BESt certifications, focusing instead on LEED certifications. Out of the $85 \%$ of CRE firms who are aiming to certify their assets to BOMA BESt certification levels, $28 \%$ (2 out of 7 ) of the CRE sample set have reported 100\% BOMA BESt certification for their office assets, while the remainder ranged between $4 \%$ to $77 \%$ of their office portfolio. No breakdown was made available between the various BOMA BESt level certifications (ranging between Level 1 to Level 4). Overall, tracking and managing CR\&S based goals for the selected CRE sample set closely follow the CR\&S targets outlined under Table 2, with a particular focus on building performance indicators (energy, water, waste, and GHG emissions) as they bear the highest scoring weight across BOMA BESt, LEED and GRESB. With regards to GRESB reporting, only 3 CRE firms out of 9 (Company 2, 3 and 5) made reference to the international benchmark in their CR\&S reports. Nonetheless, voluntary certifications and industry reporting present the Canadian CRE sector with opportunities for cross-integrating CR\&S goals due to their established performance indicators.

\section{Community and Tenant Engagement}

Recognizing the interdependence between tenants and the CRE industry, several firms are seeking ways to engage their tenants, particularly as it relates to energy management. One interviewee (Company 2) stated that a key strategy their team would like to focus on is tenant engagement: “... office class tenants, account for $50 \%$ of energy use, so really figuring out to work with tenants to reduce their energy use, because they're [a] major part of the factor." In addition to energy management, other tenant and community engagement strategies performed at the building level include tenant and community surveys, which earn potential credit points for LEED certified 
properties. Offering parking and transportation options to tenants, such as bike racks, preferred parking options for carpooling, or electric charging stations are tenant engagement strategies and potential credits under LEED and BOMA BESt certifications. In terms of community engagement, $43 \%$ of the CRE firms sampled have publically disclosed their support toward the arts community by displaying local artists' work or hosting events and galleries in their lobbies as a way to engage the local community. Details pertaining to these key engagement strategies were unmentioned during the CRE interviews. However, brief references were made in the corporate public reports and websites.

\subsubsection{Leading CR\&S BARRIERS FOR CRE FIRMS}

Based on the interviews conducted, two classifications of predominant barriers for the CRE sector were identified: internal and external. Internal barriers result mainly from the lack of available resources set to collect, measure, and manage environmental data. Executive buy-in at the corporate level was another internal barrier identified during the interview sessions. Alternatively, external barriers are caused by stakeholders' (tenants and investor clients) lack of either general understanding or commitment in CR\&S strategy. Table 10 lists the internal and external barriers. Details pertaining to each barrier are as follows:

Table 10 Barriers in the CRE Sector

\begin{tabular}{|l|l|}
\hline \multicolumn{1}{|c|}{ Internal } & \multicolumn{1}{c|}{ External } \\
\hline Corporate Management - Data Collection & Stakeholder - Tenants \\
\hline Corporate Management - Executive Buy-in & Stakeholder - Clients \\
\hline
\end{tabular}

Internal Barriers - CRE Sector

A key challenge and barrier expressed by all of the CRE interview participants was the lack of sufficient and available data. Given the operational structure of CRE firms, the collection and management of data presents a real barrier for most, which prevents sustainability teams from building strong business cases supporting CR\&S programs and initiatives. This in turn makes it difficult to measure the correlation and causation of sustainability projects. As further explained by a CRE firm:

...getting data from other sources, there's an element or a challenge in just managing all of the data that we do have. We have a lot of data and it's spread across a few different systems. So if you want to draw a correlation, for example on a financial metric like a vacancy rate, that's something that's held in the accounting system world. If we want to compare that to which buildings are certified or not certified, that 
information is held elsewhere, and those two systems don't necessarily talk.

Financial costs relating to capital improvements need to be supported by a solid business case. Given the lack of investment and resources allocated to measuring and managing data, a perception often emerges that investing in capital plans supportive of sustainable initiatives is very costly. As explained by one interviewee (Company 3), “ ... executive buy-in is still a challenge, the board of directors are still a challenge in understanding sustainability."

\section{External Barriers - CRE Sector}

The associated costs of managing a building with high performance features (commonly referred to as "green" features) also pose challenges to implementing CR\&S goals, especially when the associated costs are passed on to the tenants through the form of increased rents. One participant (Company 2) states “...they (tenants) are not willing to pay for upgrades or any way involve their financials in the greening of our buildings". This challenge highlights the discrepancy in the lack of integrated accountability and responsibility between the CRE firms and their tenants in implementing cohesive CR\&S strategies. One CRE interviewee further explains the challenge found through the varying sophistication levels of tenants:

...they (tenants) definitely have a role to play in understanding that they really want to be able to reduce their costs, but I would also say that it's difficult because if you're working with smaller tenants, their organization has a lot of B-class suburban buildings, and there's a lot of smaller less sophisticated tenants whose last worry is really about energy use or water use. So working with them makes it quite a bit more challenging. They're a small company just trying to survive, so they really don't have that level of sophistication, so it really depends what kind of tenant you're working with.

Single-occupant tenants with established CR\&S mandates have a stronger potential opportunity to integrate their sustainability strategies with their landlords, than multi-tenant occupants who may lack the sophistication to understand the benefits of integrating elements of CR\&S into their real estate space. Similar internal barriers were expressed by most of the subject interviewees. Most of the CRE interviewees (representing $75 \%$ of the sampled population, Companies 1, 2 and 3) identified tenant engagement as a second challenge to capital cost.

Similar to the challenges presented by multi-tenants, managing investment strategies of multi-investor clients also presents barriers and challenges within the CRE 
industry. These challenges are particularly prevalent when a given CRE firm attempts to develop corporate environmental reduction targets. Participants managing several institutional investors are unable to develop corporate wide reduction targets due to their multi-client governance structure. Varying fiduciary accountabilities will limit the level of CR\&S opportunities a CRE firm that manages multiple clients' real estate portfolio can commit to and implement. A CRE participant explains the multi-client challenges as follows:

I would say clients that own the majority of the portfolio or a significant portion, are very keen on sustainability and therefore they can afford us the opportunity to push the boundaries and to do that in partnership with them. There are some clients who are less interested, and so sometimes that just creates a certain challenge for us.

Alternatively, setting reduction targets and integrating CR\&S strategies for CRE firms that manage single investors do not face similar challenges. Two CRE firms wholly owned by a single institutional investor were assessed in this research and they are the only two CRE firms in the sample to set reduction targets for energy, water, waste, and GHG emissions. Similar to multi-tenant challenges, multi-investors create external barriers for CRE firms seeking to integrate elements of CR\&S in the management of their portfolios.

Setting an NVivo 10 word frequency query for barriers within the transcribed interviews for the sample CRE sector generated the above list (Appendix F - IX). Tenant, engagement, clients, and data ranked as top 25 highest word frequencies in the query, supporting the study's assessment of categorizing internal and external as two main barriers for the CRE sector.

\subsection{Corporate Tenant Sample Population}

\subsubsection{GENERAL BACKGROUND INFORMATION - CORPORATE TENANTS}

Key tenants from the financial, insurance, professional, and legal service sectors were identified. As previously indicated in Chapter 3, these tenants hold a significant gross leasing area (GLA). Table 11 illustrates that only 55\% of tenants reported on the footprint of their leased office real estate space. It should be noted that the available public data did not always account exclusively for Canadian offices. The data provided in Table 11 therefore also includes some international offices. Since the research aims to investigate CR\&S behaviour for tenants leasing office space, owner occupied office buildings by tenants, such as data centres, are excluded from the aggregated GLA. 
Nonetheless, the listed GLA of the study's selected tenant samples bears significant influence as they represent occupants across the Canadian CRE sector.

Table 11 Tenant Sample Set's GLA

\begin{tabular}{|c|c|c|}
\hline \multicolumn{2}{|c|}{ OFFICE } \\
\hline TENANT COMPANIES & TOTAL $\mathbf{f t}^{2}$ (MILLIONS) & Industry \\
\hline Company 1 & 1.800 & Professional Services \\
\hline Company 2 & 2.700 & Insurance \\
\hline Company 3 & 2.152 & Financial \\
\hline Company 4 & 1.863 & Financial \\
\hline Company 5 & 1.062 & Natural Resources and Gas \\
\hline Company 6 & - & Professional Services \\
\hline Company 7 & - & Professional Services \\
\hline Company 8 & - & Financial \\
\hline Company 9 & - & \\
\hline TOTAL & 9.576 & \\
\hline
\end{tabular}

Table 12 provides a list of the titles identified during interview sessions with the tenant participants. As will be recommended in the concluding remarks, it is recommended that further comparative investigation on the roles and responsibilities between the CRE sector is conducted so as to aim to identify further possible integration measures.

Table 12 - CR\&S Based Roles for Selected Tenant Sample Population

\begin{tabular}{|c|c|}
\hline \multicolumn{2}{|r|}{ CR\&S Titles - Tenants } \\
\hline TENANT COMPANIES & Titles \\
\hline Company 1 & Director of Environmental Sustainability and Compliance \\
\hline Company 2 & $\begin{array}{ll}\text { - } & \text { Director of Corporate Real Estate } \\
\text { - } & \text { National Leader for Real Estate }\end{array}$ \\
\hline Company 3 & $\begin{array}{ll}\text { - } & \text { Executive Director of Procurement and Real Estate } \\
\text { - } & \text { Manager of Community Leadership }\end{array}$ \\
\hline Company 4 & Environment and Energy Manager \\
\hline Company 5 & Senior Sustainability Issues Management Specialist \\
\hline Company 6 & $\begin{array}{ll}\text { - } & \text { Senior Vice President of Enterprise Real Estate } \\
\text { - } & \text { Communications Officer at Enterprise Real Estate }\end{array}$ \\
\hline Company 7 & No Interview Conducted \\
\hline Company 8 & No Interview Conducted \\
\hline Company 9 & No Interview Conducted \\
\hline
\end{tabular}

\subsubsection{ASSESSING CR\&S ACROSS CORPORATE TENANTS}

\subsubsection{CR\&S REPORTING - CORPORATE TENANTS}

As previously noted, nine (9) anchor tenants' were included in the study. A review of the CR\&S reports published by each selected tenant revealed that the first reports were 
released in 2002 (by two companies in the finical industry). Although CR\&S reporting increased annually for the sampled firms, the study found that by $2009,100 \%$ of identified anchor tenants have developed public CR\&S reporting (Figure 16). The general layout of tenants' CR\&S reports include a message from their CEOs and affirmations of corporate commitments and governance toward their triple bottom line.

\subsubsection{CR\&S DEFINITION - CORPORATE TENANTS}

Content analysis of tenants' CR\&S reports generally defines CR\&S as a commitment to protecting both the physical and human environments in which they operate, while striving toward continuous operational improvement. Some examples of CR\&S definitions (illustrated under Appendix $F-X$ ) extracted from NVivo, include "...how we manage the environmental, social and governance impacts of our business while creating value for our customers, investors, the economy and society" and "responsible business; people, diversity, and inclusions; community engagement; and environmental stewardship." Overall, CR\&S reports provide a general definition of CR\&S, encompassing of all three elements of ESG.

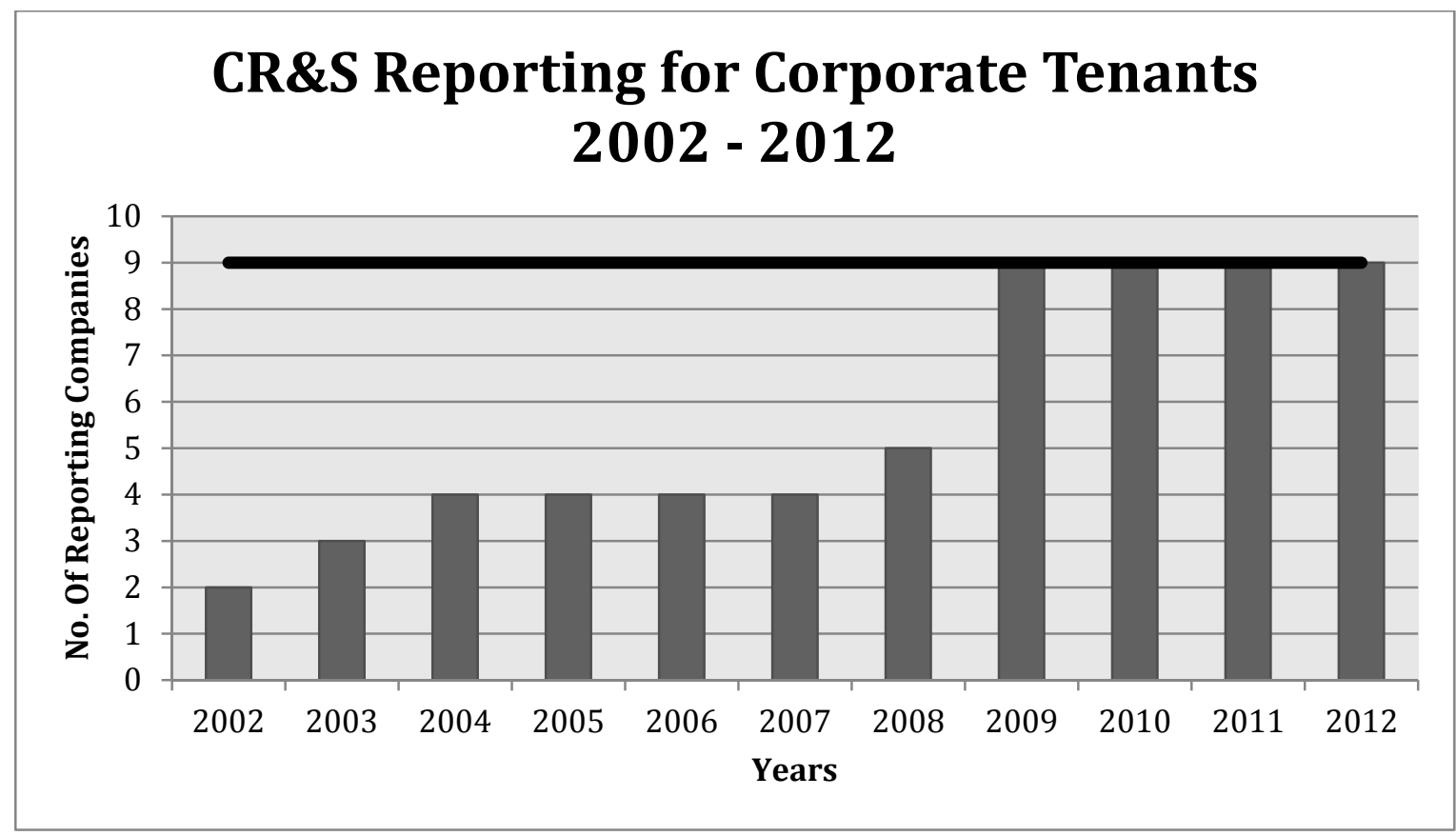

Figure 16 Anchor Tenants Historical CR\&S Reporting

During the interview segments, tenants identified environmental and energy management as an integral focus of their overall CR\&S approach as it directly relates to their real estate operations. One interviewee (Company 4) stated that regarding the "environment side, which is the area I guess I'm most familiar with because that's what I do (...), it's looking at how do we reduce our footprint on the environment". Another 
interviewee (Company 2) explained, “...for the corporate real estate, energy and environment is sustainability because in corporate real estate we don't do charitable giving or anything like that. Sponsorships, the larger organization does that." Therefore, tenants' focus as it relates to their occupant behaviour is on managing their environmental and energy footprint.

The same participant (Company 2) also explained that their organization's overarching CR\&S definition “...used to be people, planet, profits. Probably the view we subscribe to more reflects that the economy exists within society, which exists within the environment and the quality of the environment. So this schematic (. . .), with three circles all within each other. This is the view that we would subscribe to." The latter affirms the earlier argument made under section 2, of using Schumann's (2010) Russian doll framework of sustainability to define CR\&S across the CRE market.

Overall, terms such as "corporate social responsibility", "corporate responsibility", and "sustainability" are used interchangeably in both public reports and interviews to define corporate level of commitments toward sustainability. This is further exemplified by one tenant's (Company 6) explanation that "I think all of the terms are used interchangeably. (...) [It] really focuses on sustainability, which is really triple bottom line thinking. Looking at the ideal solution or the optimal solution for the environment, the communities that we work in and society at large, as well as the economy." The top 25 counted words resulting from NVivo's query on anchor tenants' CR\&S definition as contained in publically available CR\&S reports, documents, and interviews are available in Appendix F (Tables 29 and 30).

\subsubsection{LEADING CR\&S GOALS FOR CORPORATE TENANTS}

Similar to the CRE group, tenants also found that following and committing to the principles of CR\&S makes good business sense. One respondent (Company 2) indicated that "... without a healthy environment, we cannot have healthy communities or healthy societies, and we cannot have a healthy economy." Tenants operating in the financial and professional services industry have a fiduciary responsibility in maintaining transparency toward their shareholders and their clients. As such, tenants have disclosed across their public CR\&S published reports that "Balancing our commitments means managing the environmental, social and governance impacts of our business while creating value for our customers, investors, the economy and society" (Company 2). Following the triple bottom line, anchor tenants' CR\&S goals commonly center on community engagements (often in the form of philanthropic engagements); workplace 
diversity and employee engagement; and the impact of their business operations on the environment. Tables 31 and 32 in Appendix F - XII list the top 25 frequently used words related to environmental commitments extracted from both the CR\&S reports and transcribed interviews using NVivo 10.

By establishing these query limits, the study identified water, energy, carbon emissions, and waste reduction as four key environmental resource management goals generated from CR\&S reports. Although waste reduction did not generate the same word frequency as in the CR\&S reports, the transcribed interviews also generated paper reduction as a leading CR\&S goal with environmental resource management. Although paper and waste did not generate high counts in comparison to the other identified goals, tenants nonetheless reported them as environmental goals.

Table 13 Corporate Tenants' Top CR\&S Goals - CR\&S Reports

\begin{tabular}{|c|c|c|c|c|c|}
\hline \multirow{2}{*}{ Company } & \multicolumn{7}{|c|}{ Goals } \\
\cline { 2 - 7 } & Energy & Water & GHG & Waste & Paper \\
\hline 1 & $\mathrm{x}$ & $\mathrm{x}$ & $\mathrm{x}$ & $\mathrm{x}$ & $\mathrm{x}$ \\
\hline 2 & $\mathrm{x}$ & $\mathrm{x}$ & $\mathrm{x}$ & $\mathrm{x}$ & $\mathrm{x}$ \\
\hline 3 & $\mathrm{x}$ & $\mathrm{x}$ & $\mathrm{x}$ & $\mathrm{x}$ & $\mathrm{x}$ \\
\hline 4 & $\mathrm{x}$ & $\mathrm{x}$ & $\mathrm{x}$ & $\mathrm{x}$ & $\mathrm{x}$ \\
\hline 5 & $\mathrm{x}$ & $\mathrm{x}$ & $\mathrm{x}$ & $\mathrm{x}$ & $\mathrm{x}$ \\
\hline 6 & $\mathrm{x}$ & $\mathrm{x}$ & $\mathrm{x}$ & - & - \\
\hline 7 & $\mathrm{x}$ & $\mathrm{x}$ & $\mathrm{x}$ & $\mathrm{x}$ & $\mathrm{x}$ \\
\hline 8 & $\mathrm{x}$ & $\mathrm{x}$ & $\mathrm{x}$ & $\mathrm{x}$ & - \\
\hline 9 & $\mathrm{x}$ & $\mathrm{x}$ & $\mathrm{x}$ & $\mathrm{x}$ & $\mathrm{x}$ \\
\hline TOTAL & $100 \%$ & $100 \%$ & $100 \%$ & $89 \%$ & $78 \%$ \\
\hline
\end{tabular}

Top environmental goals, as identified through both the content analysis and interview sessions, are listed in Table 13 above. Similar to the word counts in Tables 31 and 32 under Appendix F, energy, water, GHG, waste, and paper reduction were identified as the top 5 environmental management goals for most anchor tenants. While energy, water, and GHG management are prominent goals for $100 \%$ of selected anchor tenants, 89\% (Companies 1, 2, 3, 4, 5, 8, and 9) view waste management as a key CR\&S goal, while 78\% (Companies 1, 2, 3, 4, 5, 7 and 9) focus on their office paper reduction. Details pertaining to anchor tenants' goals are as follows:

\section{Energy Management}

Management and conservation efforts relating to energy consumption were reported as a prime environmental management strategy for $100 \%$ of the anchor tenants. The majority of financial anchor tenants detailed their energy consumption data in 
"environmental performance" based reports separate from their annual CR\&S reporting, while occupants in the professional service field, insurance and natural resources and gas industry disclosed their offices' energy consumption directly into their CR\&S report.

Inconsistencies in reporting on energy use and consumption were evident across all tenants sampled. Although $100 \%$ of tenants identified energy management as a core environmental goal, only $77 \%$ (7 out of 9 tenant sample population, Companies 1, 2, 3, 4, 5, 6, 8 and 9) disclosed the breakdown of their energy consumption. There was also a disparity in differentiating energy consumption between global, North American, and Canadian-specific office operations, along with their energy consumption between owned versus leased office assets. Notably, 2 out of the 9 (Companies 3 and 9 ) tenants separated their energy consumption by geographical location in their CR\&S reports. The first sample tenant is a financial anchor tenant who mainly operates in Canada (holding limited market share in the United States), and the second is a global professional services tenant whose disclosure on energy consumption is solely based on their Canadian business operations. Inconsistencies in the units of measurement were noted. Gigajoules (GJ) was the principal unit of measure for energy consumption across most tenants. However, additional metrics included terajoules, megawatt hours (MWh) and kilowatt hours $(\mathrm{kWh})$. There were also inconsistencies in the detailed breakdown of energy consumption between direct and indirect energy. As defined by one financial anchor tenant (Company 3), "direct energy use refers to our use of fossil fuels (natural gas, heating oil and propane)" while "indirect energy use refers to our use of purchased energy".

Accounting for the aforementioned reporting variables on energy management, the study benchmarks tenants' energy consumption reduction for the 2011 - 2012 reporting period (Figure 17). The average reduction for tenants' energy consumption was slightly above 3\%. Five out of the seven (7) (71\%) anchor tenants (Companies 1, 2, 5,8 and 9) who reported their energy consumption were below that average. One tenant from the professional services industry (Company 9) uniquely disclosed an annual energy reduction target of $2 \%$ based on their global 2011 baseline year. However, due to new office expansion, the tenant's energy consumption increased by $28 \%$ between the 2011 - 2012 reporting period and as a result was unable to reach its $2 \%$ energy reduction target. No further tenant energy reduction targets were noted. 


\section{Tenants' Energy Consumption Reduction \\ 2011-2012}

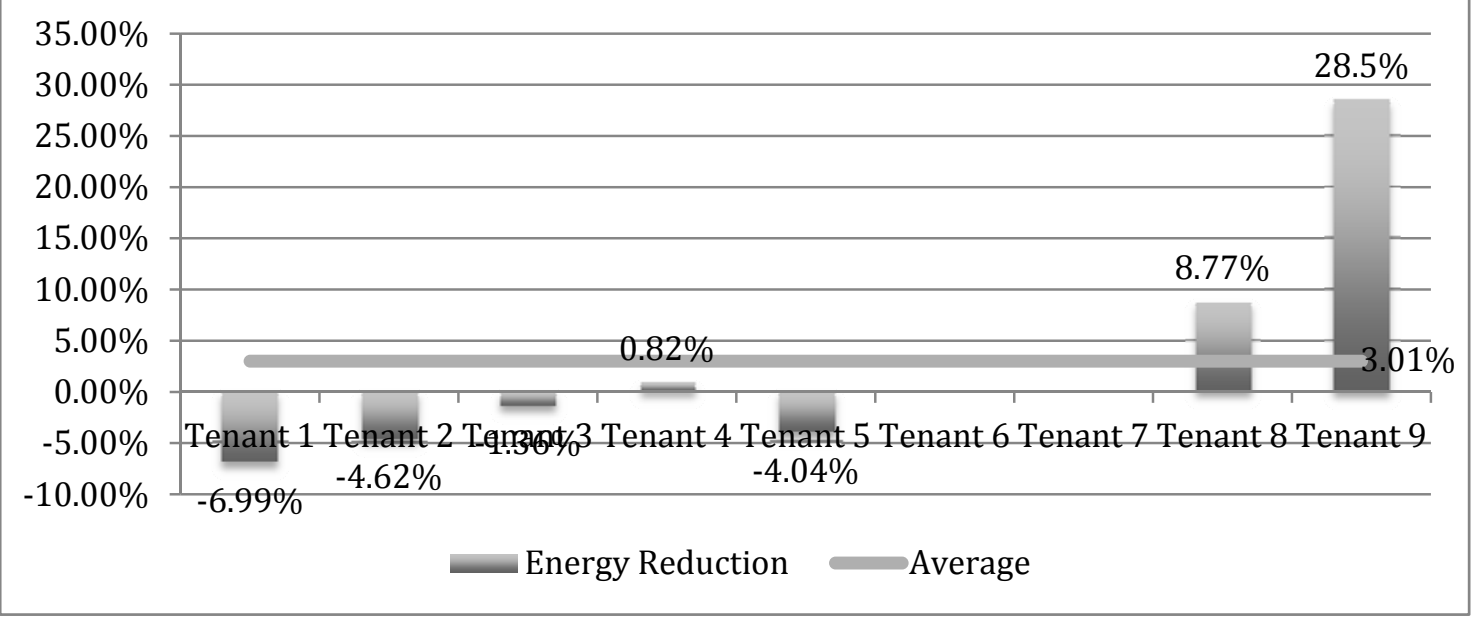

Figure 17 Tenants' Energy Consumption Reduction Benchmark

Generally, the increase in energy consumption for tenants was mainly attributed to their office square foot increase through either the acquisition of new office space or expansions. Barriers pertaining to energy reduction goals for tenants are identified and discussed in Section 4.2.3. Overall, corporate energy consumption reduction goals were driven, at least in part, by green building certifications and CR\&S reporting mandates, such as the GRI. Section 4.2.5 discusses the certifications and reporting mandates that drive tenants' sustainability goals.

Water Management

In an effort to reduce their environmental footprint, the majority of tenants reported water consumption reduction and management as another area of CR\&S focus. Even though water conservation and management was a leading CR\&S goal across all tenants, one tenant (Company 3) indicated during their interview that it is "to a lesser extent a third goal" that their organization has recently started to monitor and track. The tenant also indicated that their organization has identified water management as the next big environmental issue, and one that they will proactively drive efforts to manage and reduce, in order to match their current advancements in carbon and paper neutrality. "Water shortages and lack of access to clean and fresh water" were identified by one tenant's CR\&S report as "the two greatest threats to human health and economic development around the world". In the same CR\&S report, the tenant also states that industry sectors that depend on water for their operations are anticipating tighter 
regulations, fewer supplies and higher costs resulting from risk of possible water shortages.

Three tenants (representing $33 \%$ of the sample, Companies 2,3 , and 6 ) listed either specific reduction targets or disclosed their water consumption in cubic metres $\left(\mathrm{m}^{3}\right.$, the pricipal unit of measure). One tenant (Company 2) committed to water reduction strategies set to reduce their water consumption by $27 \%$ compared to the current plumbing code. Another tenant (Company 3 ) disclosed their water consumption at $366,971 \mathrm{~m}^{3}$, with plans to coordinate efforts with their landlords to obtain additional data and manage their consumption. The third tenant (Company 6) has a water reduction target of $12 \%$ by 2015 , though this is only applicable to their refinery process and not office space. Although water was also identified as a leading CR\&S goal, tenants who were unable to measure their water consumption have stated in their CR\&S reports that they will "continue to focus on establishing a reliable baseline before committing to reduction targets".

\section{GHG Management}

Commitments to reduce GHG emissions were disclosed by $100 \%$ of tenants. Only one tenant did not report their GHG emissions and reduction target as it applies to their office footprint. Instead, that one tenant (Company 4) disclosed their refinery's GHG emissions. Contributions to GHG emissions in tenants' offices have been primarily identified through the use of fossil fuels in heating, ventilation and air condition (HVAC) systems, along with the purchasing of electricity, the production and distribution of paper documents, production and hauling of waste, the fleet of vehicles owned by tenants, and employee travel. One tenant (Company 1 ) reported in their CR\&S annual report that the largest contributing factor to the carbon footprint is the real estate space that they occupy. All tenants also affirmed during the interviews that GHG reduction is a primary environmental goal for their organizations.

As illustrated in Appendix G, over 77\% percent of the assessed tenant organizations (Companies 1, 2, 3, 5, 7, 8 and 9) have directly measured and monitored their carbon footprint or emission intensities for their office building operations. The GHG emissions calculations have been conducted as follows. Where applicable (Companies 1,2,3,5,7,8 and 9), 2012 was selected as the chosen reporting period with 2011 as the baseline year (with the exception of Company 6 whose reporting year was 2011 and baseline was set at 2010). The rate of change was calculated by dividing the total GHG emissions $\left(\mathrm{tCO}_{2} \mathrm{E}\right)$ from the reporting year against the baseline year, which 
resulted in either positive or negative rate. Scope 1 and Scope 2 emissions were reported across the entire tenant sample population, while limited reporting was conducted on Scope 3 emissions (Company 5 and 7 only). Forty four percent (Companies 3, 5, 5 and 8) of sampled tenants developed GHG emission reduction targets, ranging from $2 \%$ to $15 \%$, or targeting to reduce one tonne per full time employee ( $\mathrm{tCO}_{2} \mathrm{e} / \mathrm{FTE}$ ) by either setting annual targeted reduction targets (as per Company 8 ) or targeted years such as 2015 and 2016 (as exemplified by Companies 3, 5 and 6). Tenants consistently used tonnes of carbon dioxide equivalent $\left(\mathrm{tCO}_{2} \mathrm{e}\right)$ as the principal unit of measure for GHG emissions. GHG emission and reduction data faced barriers similar to the energy consumption data and will be discussed in Section 4.2.4.

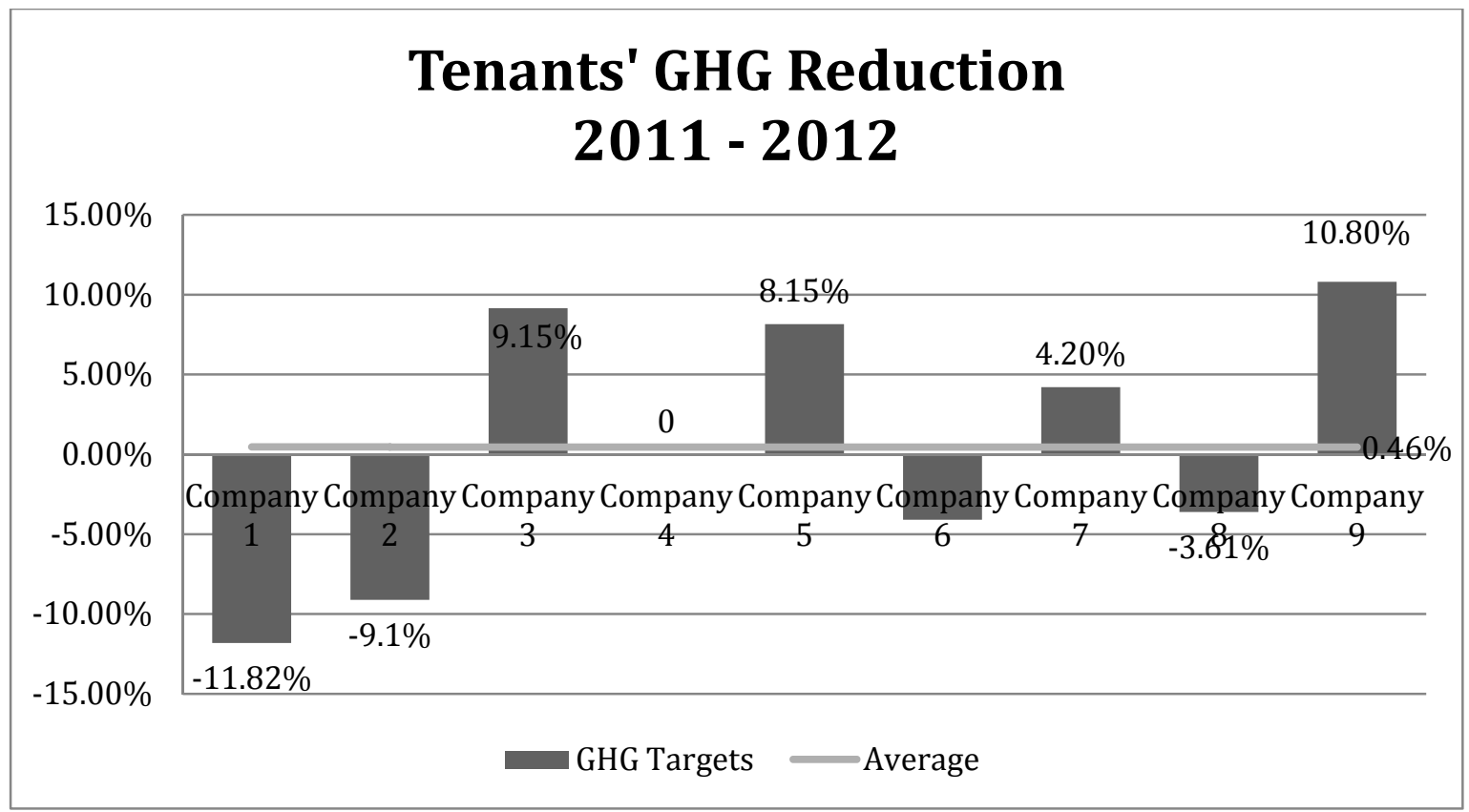

Figure 18 Tenants' GHG Reduction 2011 - 2012

Waste Management and Paper Reduction

The management of waste was identified by $89 \%$ (8 companies, namely 1, 2, 3, 4, 5, 7, $8,9)$ of tenants as an integral aspect of their CR\&S objectives. Tenants' waste management goals were designed to reduce and divert waste from landfills that result directly from their administrative operations. Although tenants identified and reported paper reduction strategies separately from general waste reduction, both are combined in this section. Unlike the previously stated CR\&S goals, no tenant was able to report on reliable data for their waste diversion or reduction rates. Instead, tenants listed leading programs implemented across their offices. Establishing a baseline for waste is a challenge most tenants face, mainly due to lack of reliable data. Section 4.3.4 will 
discuss such barriers further. Overall, little evidence of tenant commitment toward a waste reduction target was found.

Generally, the tenants' CR\&S goals and reporting measures followed the reporting principles of the GRI. That is, their environmental policies and practices reflected the categories under the GRI's economic, environmental, and social sections. Assessing the environmental section of the GRI, tenants reported on their GHG emission reductions, along with their commitments toward energy, water, biodiversity, and waste management. Similar motivators are identified below.

\subsubsection{LEADING CR\&S MOTIVATORS FOR CORPORATE TENANTS}

Tenants' motivators were identified based on an analysis of their respective CR\&S reports and the responses from the interviews. Using NVivo 10 as illustrated in Appendix F Tables 33 and 34, the top 25 frequency words were identified to assist the identification of CR\&S motivators in the sampled firms.

Assessing the entirety of each tenant's CR\&S report, the top 4 (excluding the count for "2012", "Canada", and "report" as a words) most frequently used words included "environment", "business", "company", and "employees" (counting 722, 717, 675 and 666 times respectfully). Given the high frequency count these words generated throughout all assessed tenants' CR\&S reports, they were considered as potential CR\&S motivators for tenants. Further details on the motivations were obtained from the interviews conducted, as illustrated by Table 32. "Environment", "business", "firm", and "footprint" were the most frequently used words (count 7, 6, 6 and 6 respectively) to describe $C R \& S$ motivators during interview sessions. Operating in healthy communities, responding to consumer demands and attracting top talent are some of the motivators that were described as "good business" strategies for all tenants. As such, the study identified the following two main tenant motivator categories.

First, protecting the communities in which they operate, along with their employees, are identified as prime motivators across all tenants. Communities, customers, and employees resulted in equal weighted percentages of $0.90 \%$ in NVivo 10 's word frequency count during interview segments. Meeting health and safety measures was one perspective taken by a tenant who also identified healthy communities and engaged employees as a prime motivator for committing to specific CR\&S policies and goals. Rising client demands and opinions toward minimizing corporations' environmental and social impacts are also identified as key CR\&S motivators. The inability to directly quantify the impacts of their clients' sustainability 
choices on profits was cited as a barrier by one company (refer to Section 4.2.4 for a detailed explanation on these barriers).

Second, all tenants identified operating in healthy communities as a responsible business strategy. Two tenants in particular stated that publicizing their CR\&S commitments was a great market differentiator within their respective industries. In turn, their corporate slogans reflect their CR\&S commitments to the protection of their communities and the environment. Leasing office space in LEED and BOMA BESt certified buildings have also been identified as key market differentiators for some tenants. Displaying their corporate logos on LEED and BOMA BESt certified buildings across leading Canadian markets is another way for tenants to align their CR\&S commitments and goals. One interviewed tenant stated: "taking a long term perspective saying let's act like 'owners not renters' let's be responsible in how we do all of the things we do".

Overall, tenants' motivators in engaging CR\&S commitments are based on corporate strategies set to differentiate their service offerings from industry peers and mitigate any potential risks that may rise from their operational behaviour, which could impact their profits.

\subsubsection{Leading CR\&S Implementation and Tracking Methods for Corporate TENANTS}

Tenants identified both through their CR\&S reports and interview sessions concrete methods set to track and meet identified CR\&S goals. NVivo 10's word frequency query for methods of tracking and measuring the implementation and success of tenant goals are listed in Tables 35 and 36 under Appendix F. Table 14 breaks down the identified strategies into seven (7) categories: audits; voluntary certifications and industry reporting; communication (CR\&S reporting); corporate culture; data management; green leasing and corporate policies. 
Table 14 Implementation Strategies found through Tenants' CR\&S reports

\begin{tabular}{|c|c|c|c|c|c|c|c|}
\hline \multicolumn{8}{|c|}{ Tenants } \\
\hline \multirow{2}{*}{ Company } & \multicolumn{7}{|c|}{ Strategies and Processes } \\
\hline & Audits & Certifications & Communications & Corporate Culture & Data Management & Green Leases & Policies \\
\hline 1 & & $x$ & $\mathrm{x}$ & & $x$ & & \\
\hline 2 & & - & $\mathrm{x}$ & & & & $\mathrm{x}$ \\
\hline 3 & $\mathrm{x}$ & $\mathrm{x}$ & $\mathrm{x}$ & & & $\mathrm{x}$ & $\mathrm{x}$ \\
\hline 4 & $x$ & $\mathrm{x}$ & $x$ & & $x$ & & $\mathrm{x}$ \\
\hline 5 & & $x$ & $x$ & $\mathrm{x}$ & & $\mathrm{x}$ & $\mathrm{x}$ \\
\hline 6 & $\mathrm{x}$ & $x$ & $x$ & $x$ & $x$ & & $\mathrm{x}$ \\
\hline 7 & & - & $x$ & $x$ & $x$ & & $x$ \\
\hline 8 & $\mathrm{x}$ & $\mathrm{x}$ & $\mathrm{x}$ & $\mathrm{x}$ & & & $\mathrm{x}$ \\
\hline 9 & - & $\mathrm{x}$ & $\mathrm{x}$ & & $x$ & & $\mathrm{x}$ \\
\hline
\end{tabular}

Audits

Forty-four percent of tenants (Companies 3, 4, 6, and 8) reported that they conduct energy, water, and waste audits. One tenant indicated during the interviews that implementing audit strategies improve their overall operational efficiencies, which in turns allows them to reduce their consumption, improve employee and costumer comfort, while also reducing their GHG footprint. Another tenant directly reported in their online CR\&S reporting about their energy-efficient building program and their attempt to align energy optimization strategies with their property management team.

\section{Certifications and Industry Benchmarks}

Standards of certification, which include BOMA BESt and LEED EB:OM for the Canadian office market, have been identified as leading measures for tenants to track and report on the impacts of their operational footprint. Tenant subject matter experts (Companies 2, 3, 4, 7 and 8) indicated during their interviews that high value is placed in leasing office space whose high building performance is ensured through building certifications. The study assessed that 55\%.of the CR\&S reports (Companies 2, 4, 6, 8 and 9) disclosed either BOMA BESt or LEED certification as a part of their reporting. No clear distinction between the certification levels was available in the reports. Tenants who reported their building certifications were from the financial sector and gave their percentage allocation between BOMA BESt and LEED. One (11\%) participant in building certification programs (Company 9 ) belongs to the insurance sector.

One tenant (Company 4) reported their Canadian office space holdings at $306,000 \mathrm{ft}^{2}$ of green real estate, which represents forty-one percent (41\%) of their total Canadian commercial real estate portfolio. The same tenant also provided further distinction between BOMA BESt, LEED and BREEAM (a UK based building certification); and included a "LEEDING the way in Green Real Estate" web portal to disclose details on their leased office space as it relates to LEED certifications. Another 
tenant (Company 8) provided LEED specific certification levels, including 8 buildings in total spread between 6 certified, and 1 platinum and 1 silver respectfully.

\section{Communications}

Annual reports and publications demonstrated transparency with respect to corporate commitments. Section 4.2 identifies that all tenants developed a CR\&S report. Although each tenant follows a relatively similar reporting framework, the inclusion of data management, audits, building certifications and rankings, along with other strategies are not consistently reported. Generally, tenants reported on social, environmental and economic elements in their CR\&S reporting. With respect to environmental strategies, all companies disclosed various plans relating to environmental leadership in their CR\&S reports. Some examples extracted from financial tenants' CR\&S reports include mentions such as "maintain carbon neutrality as (NAME) continues to grow", and "the reduction in energy use achieve in a one year pilot test to remotely control cooling, heading, lighting and signage..." as well as an example from a professional service tenant stating that they have experienced "...more than $50 \%$ increase in the number of member firms reporting on environmental sustainability and social impacts". As such, environmental stewardship and leadership is accounted as a key element tracked through tenants' CR\&S reports.

\section{Corporate Culture}

The buy-in and support from executive management to implement and push for CR\&S initiatives were evident in all of the tenant reports studied. Each CR\&S report included a message from their organization's CEO detailing their CR\&S commitments and achievements. One tenant (Company 3) remarked during the interview segment that their CEO supported their firm'S CR\&S strategies from the on-set and approved their move toward carbon neutrality. Although two tenants (Company 2 and 4) remarked during the interviews that corporate CR\&S support is generated from the top-down, some tenants (Company 7 and 8) were also increasingly experiencing a bottom-up approach with the intention of reaching a middle ground in integrating varying corporate levels and commitments across their organization.

Relating sustainability across their real estate footprint, some tenants (Companies 1 and 2) recently started to engage their corporate real estate consulting department through offers of CR\&S services. This is a new business strategy for tenants who are seeing operational cost saving opportunities and meeting their CR\&S commitments. 


\section{Data Management}

All tenants identified in the interviews that effective management to set targets and goals cannot be achieved without comprehensive data collection and measurement. The industry wide accepted axiom, "you cannot manage what you cannot measure", reaffirms the need for tenants to collect data for their energy use, water consumption, waste generation, and GHG emissions so as to gain insights on how to further develop their CR\&S management practices. Certifications and benchmarking measures are also interconnected motivators with the collection and management of data that provides tenants with comparative measures. Implementing systems that track energy and water consumption along with waste, are among those efforts employed by the tenants interviewed for the study. However, as one tenant (Company 7) pointed out during the interview session, the data were not always shared with tenants and as such is often conducted in silos.

\section{Green Leases}

Given the long-term nature of leases, which average between 10 to 25 years, altering contractual obligations to include "Green Leasing" in existing leases is often unavailable. Nonetheless, tenants have indicated (Companies 2, 3, 4, 6, 7 and 8) during the interviews that principles and provisions of green leases are typically incorporated in their future lease negotiations, instead of annulling their existing lease agreement and committing to a new Green Lease framework. Tenants' real estate teams confirmed during the interviews that they often include requirements set to satisfy their building performance specifications for the space that they seek to occupy. One tenant (Company 7) views those as less than negotiating tactics and more mutual agreements between the landlord and the tenant. Company 3 indicated in their interview that they "have all sort of requirements in our lease that are environmentally focused. So right down to targets of equivalent kilowatts per square foot, the type of cleaning that done within our facilities, if a landlord's doing any construction for us that they're following the proper LEED guidelines...Where appropriate, that the building is LEED certified. We want to support that and that's build into our lease." Alternatively, when asked if their corporate CR\&S goals are incorporated in a Green Lease, one (Company 7) tenant specifically indicated that such a lease is not yet offered in Canada. Two tenants (Company 2 and 8) also point out that they are able to leverage their GLA during negotiation stages to implement principles of CR\&S into the management of the building they will occupy. Further research is needed, however, to assess the level of influence 
tenants occupying medium and small square footage of office space hold on influencing CR\&S across the management of buildings.

\section{Corporate Policies}

Establishing sustainable-based procurement policies for goods and services is one method widely referenced by tenants (Companies 2 through 9 ) to manage and meet their CR\&S commitments. Incorporated into their lease agreements, tenants engage both landlords and their goods and service providers to abide by the requirements stipulated across purchasing policies. Driven from certification mandates, such as LEED and BOMA BESt, the sustainable procurement of materials and resources are "meant to reduce the environmental impacts of materials acquired for use in the operations, maintenance and upgrade of buildings" 11 .

\subsubsection{LEADING CR\&S BARRIERS FOR CORPORATE TENANTS}

Table 37 in Appendix $\mathrm{F}$ lists the 25 top word frequency query generated for barriers identified during the tenants' interviews. Based from the word query, internal and external causes were identified as two distinct yet interconnected barriers tenants experienced when aiming to integrate CR\&S goals across their organizations. Table 15 breaks down the two factors as follows.

Table 15 Internal versus External Barriers - Based on Tenants' Interiew Segments

\begin{tabular}{|l|l|}
\hline \multicolumn{1}{|c|}{ Internal } & \multicolumn{1}{c|}{ External } \\
\hline Organic Growth & Landlord Driven - Available Data \\
\hline On-going Innovation & Landlord Driven - Common Spaces \\
\hline Internal Communication & Geography \\
\hline Human behaviour & Aging Stock \\
\cline { 1 - 1 } Technology & \multicolumn{1}{|}{} \\
\cline { 1 - 2 } Resources &
\end{tabular}

Internal Barriers

Corporate organic growth, including lateral growth through acquisitions, has been identified as one of the primary challenges tenants face in terms of achieving their CR\&S reduction targets. As the square footage of their real estate footprint increases, reducing their environmental impact becomes a moving target that is hard to achieve. During interview sessions, several tenants (Companies 2, 3, 4, 6, 7, and 8) identified their organization's portfolio size as a continuous challenge in their efforts to drive emissions and consumption reductions down, while increasing their market share and keeping healthy profitability levels. Managing global and local targets was also factored as an

11 CaGBC - LEED EB:OM 2009 (2013) 
internal hurdle faced by tenants. Financial companies (Companies 2, 4, 6, and 8) disclosed and separately reported their overall consumption and reduction data for their Canadian operations from their international operations. With the exception of one company (Company 7), consulting firms reported their energy data across their global operations and were unable to provide Canadian specific data. During the interviews, 2 consulting firms (Companies 7 and 8) indicated that they are in the process of collecting and assessing the energy data for their Canadian operations. The tenants unanimously indicated during the interviews that data is often difficult to acquire from landlords, as they do not own their office space, and as such, have limited control over consumption. Company illustrates this barrier by stating that:

We do not own the buildings, although we work closely with the landlords in how they're managed and we're always looking to improve our energy conservation and improve the environmental performance of these big buildings that have our logo on it. We don't have that level of control that some people might think we have. And now we've been talking about our priority issues, talking about biodiversity, talking a little bit about water, but where we really play a large role is on climate change and energy, and energy is our bag so to speak.

Additionally, as internal complexity continues to grow for tenants due to their organic and lateral growths, innovation becomes harder achieve. As described by several tenants (Companies 2, 3, 4 and 7), reaching for the lower hanging fruit allowed them to set the base for their CR\&S targets. However, as organizations continue to grow, tenants (Company 3 and 7) have indicated that more engineering and investment will be required in order to reach and achieve the longer expected paybacks. As such, building a business case in support of furthering their CR\&S targets also becomes a hurdle for many tenants. Focusing on short-term gains, usually identified by tenants as between three to five year ROls poses a significant barriers for tenants in terms of setting long-term CR\&S strategies.

Company 3 also identified the impacts organizational growth plays on maintaining updated levels of internal communication. As a result of their organizational growth, three tenants (Company 3,4, and 7) identified several factors that impacts their communication as it relates to awareness of CR\&S objectives and targets. First, as their organization grows nationally and globally, maintaining CR\&S communication and integration proves more challenging. What's more, tenants recognized turn-over rates as adding to the instability and inadequacy of maintaining communication across their organizational levels. 
Human behaviour patterns are another internal barrier tenants (Company 3, 7, and 8) identified during the interviews. Changing their operational processes to better reflect and manage CR\&S targets and goals are ongoing challenges, particularly when aiming to modify their existing corporate human culture and behaviour. Managing energy reduction is one such identified human behaviour barrier identified by all interviewed tenants. As employees are shifting toward flexible working hours, and in some industries translating into either working-from-home policies or extended working office hours, there is increased electricity consumption demand both at home and in the office. Although there are systems in the place that can help control energy consumption, such as lighting censors, tenants (Companies 2, 3, 4, 6, 7 and 8) explained that often a behaviour change from their corporate culture is required in order to meet some of the set CR\&S targets.

\section{External Barriers}

The leading external barrier for all interviewed tenants (Companies 2, 3, 4, 6, 7 and 8) was the collection, measurement, and management of data. The participants all occupied multi-tenant office space, and as such can only hold responsibility for the square footage that they occupy. Although tenants can control energy consumption and GHG emissions data internally, waste and water reduction data typically fall under the control of landlords. Collecting and sharing data for common spaces with landlords is not often possible, particularly (as identified by Company 7 ) for relatively unsophisticated tenants who are not pursing CR\&S strategies across their portfolio.

Due to common elements within office buildings, such as washrooms and lobbies, the consumption of water and energy across the building space environment becomes hard to manage for tenants who not control those spaces. One tenant (Company 7) also mentioned that integrating certification measures could also pose challenges for tenants, in terms of investing in the building's certification and sharing the resulting benefits. The tenant (Company 7) mentioned that BOMA 1980 was more favourable to tenants.

Similar to internal barriers, several interview participants (Companies 2, 3, 4, 6, 7

and 8) identified geographical constraints as prevalent external barriers. The geographical spread of their office locations within Canada makes it often costly to travel (both financially and adding to their Scope 3 emissions) and for CR\&S teams to be physically present and responsive to address operational challenges across any given 
office location. Ultimately, this geographical barrier offers opportunities for the CRE sector to facilitate the management of their tenants' CR\&S goals and strategies.

Variants in building stocks were also identified as barriers for tenants. One tenant (Company 3) finds the existing design of older stock buildings to hold robust building envelopes that render them effective insulators during the winter times, while others (Company 2 and 8 ) find that newer stock buildings to have intuitive green designs with higher efficiency track record. Although the Canadian building code has recently incorporated principles of LEED, new buildings are expected to generally outperform existing stock. However, similar performance principles and measures need to be applied for the management of existing buildings.

\subsection{CONSTRUCtion SAMPLe Population}

\subsubsection{GENERAL BACKGROUND INFORMATION - CONSTRUCTION FIRMS}

Collectively, the 4 construction firms selected for inclusion in the research had \$12.1 billion of self-reported gross revenues in 2011 from their Canadian operations (including revenues from all branch operations) (Leaders 2012, National Construction Ranking). Although limited corporate reporting was available on current development projects, an increase was identified in the construction pipeline across the country, with a particular emphasis on Clagary, Vancouver, and Toronto (AltusInSite 2013; Jones Lang Lasalle, 2013). Nationally, nearly 1.8 million square meters of office space was under construction as 2012 drew to a close (Jones Lang Lasalle, 2013). This new building stock should be deigned to align with current CRE management and occupant behaviour trends.

Table 16 provides a list of the roles identified during interview sessions. As explained in previous sections, the roles and responsibilities as they relate to each interviewed subject matter expert are not analyzed. However, further comparative investigation on the impact various roles and responsibilities within the CRE sector pose on integrating CR\&S strategies is recommended. 
Table 16 CR\&S Based roles for the selected construction firms

\begin{tabular}{|l|l|}
\hline \multicolumn{2}{|c|}{ CR\&S Titles - Construction Firms } \\
\hline CRE Firms & Titles \\
\hline Company 1 & Sustainability Manager \\
\hline Company 2 & $\begin{array}{c}\text { Managing Director for Sustainable Building } \\
\text { Services Department }\end{array}$ \\
\hline Company 3 & Manager of Sustainability Construction \\
\hline Company 4 & No Interview Conducted \\
\hline
\end{tabular}

\subsubsection{ASSESSING CR\&S ACROSS CONSTRUCTION FIRMS}

\subsubsection{CR\&S REPORTING - CONSTRUCTION FIRMS}

Two CR\&S reports were available (Company 1 and 4) for the four selected construction firms. Although only half of the sample population disclosed annual CR\&S reports, online documentation was still available for all four companies. Figure 19 illustrates the CR\&S reporting trend for the selected Canadian construction firms between 1999 to 2012.

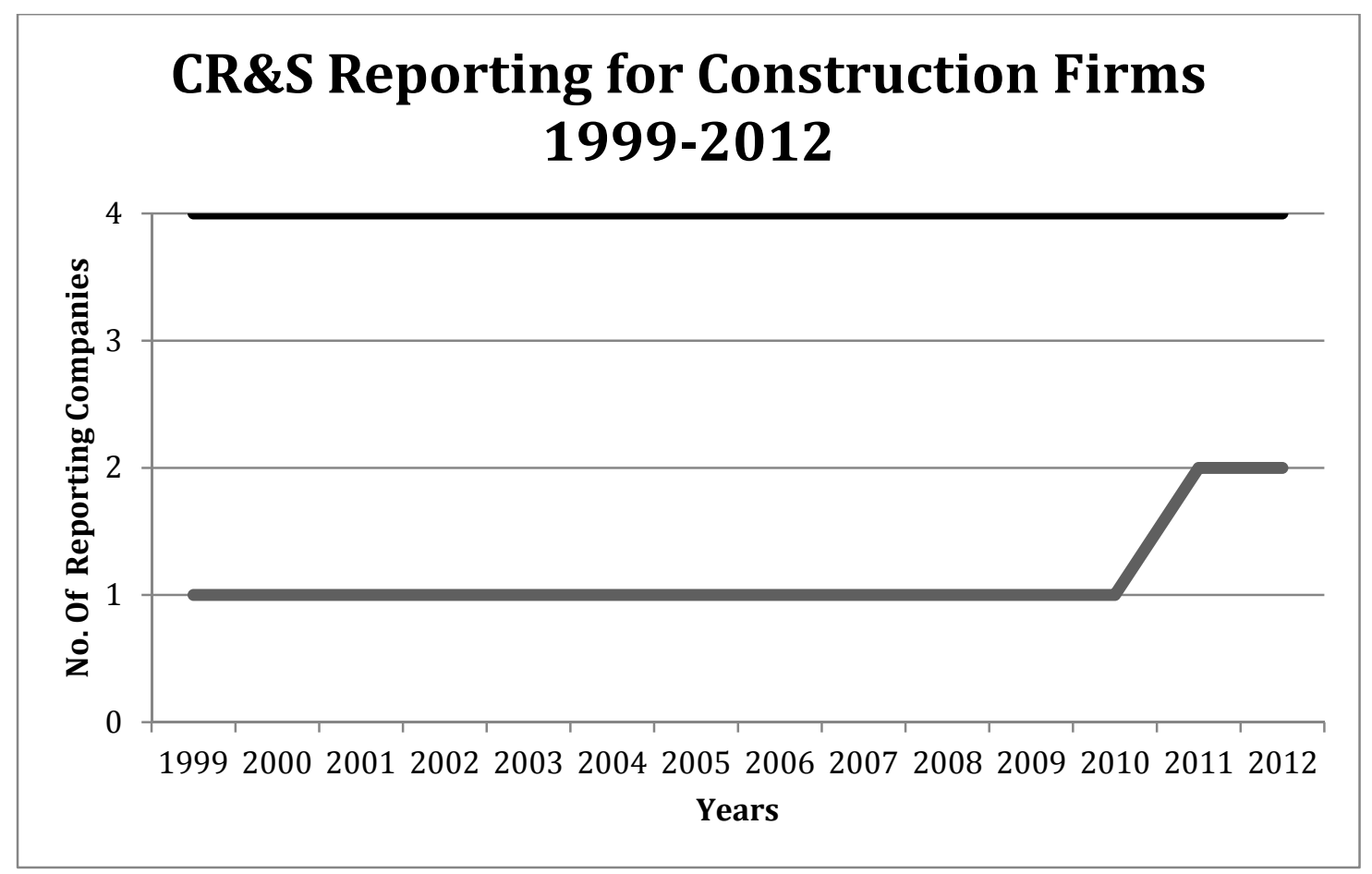

Figure 19 Construction historical CR\&S Reporting 


\subsubsection{CR\&S DEFINITION - CONSTRUCTION FIRMS}

Based on an assessment of the available documentation on CR\&S and transcribed interviews with construction subject matter experts, Tables 38 and 39 under Appendix F list the common words extracted from NVivo's top 25 frequent word query on the definition of CR\&S. CR\&S is generally defined as a business strategy set to minimize risks by providing efficient, healthy and enduring projects that maximizes as much as possible its applicability for all stakeholders. One construction firm's (Company 2) online documents define sustainable construction as "developing and implementing costeffective, sustainable solutions with clients, adding real business value and higher return-on-investment for clients, utilizing construction methods and materials that minimize harmful effects to people and the environment and reducing operating and maintenance costs". During the interviews, one respondent (Company 1 ) indicated that their firm has clear corporate wide policies, procedures and goals as part of their business strategy, which guides their CR\&S reporting. Company 2 defined principles of CR\&S as risk management by stating that "sustainability being more of an encompassing concept that involves as well, risk management and also green services. In terms of risk management, sustainability means that things are becoming an expectation, practically a deliverable in many of the building we are working at." One interviewee (Company 3) disclosed that although social responsibility and green buildings are their guiding principles during projects, they are currently in the process of defining their CR\&S approach and action plan moving forward.

\subsubsection{LEADING CR\&S GOALS FOR CONSTRUCTION FIRMS}

The construction firms sampled identified both in their online documentation and interviews their social, economic, and environmental goals and commitments. Tables 40 and 41 in Appendix $\mathrm{F}-\mathrm{XXI}$ and $\mathrm{F}-\mathrm{XXI}$ list the top 25 most frequently used words that were generated on CR\&S goals from the CR\&S reports and interviews. Although the Canadian construction firms studied did identify social and economic elements of ESG within their CR\&S goals, this study focuses on the environmental component.

Commitments and action plans for environmental goals centered mainly on efforts to reduce GHG emissions. Both construction companies that reported their annual CR\&S commitments listed GHG reduction as an encompassing environmental goal and disclosed metrics and targets. One firm (Company 1) disclosed their short-term fuel purchase and office space energy consumption reduction targets at thirteen percent (13\%) and fifteen percent (15\%), respectively, for the 2012 period. Their long-term 
targets for 2015 were set at fifty percent (50\%) and twenty percent (20\%) for fuel purchase and office energy consumption reduction. The second construction firm (Company 4) that reported on their CR\&S developed a company-wide GHG inventory process and established their reporting baseline year based on two years of collected data. Company 3 answered during the interview session that “...I won't say we've come up with specific initiatives and goals. It's a guiding principle, we are out there with the sole purpose to be responsible corporate citizens, so I don't think we need to measure that with a goal here, it's a culture that exists within our company." As previously mentioned, GRI and LEED NC have been identified as guiding principles by Companies 1 through 4.

\subsubsection{LEADING CR\&S MOTIVATORS FOR CONSTRUCTION FIRMS}

All three participants in the interviews of construction firms noted industry leadership recognition and sustainable building design compliance as two main motivators. Similar to the CRE sector and anchor tenants, construction firms recognize that CR\&S leads to good business, and as such engaging in sustainable projects mitigates potential risks that could arise from compliance and competition. Company 2 clearly indicates that their clients are driving sustainability compliance by stating that

They (Clients) are asking more specific questions and in some cases they are making sustainability requirements, so for us to participate, we need to let them know what it is that we're doing, the programs we have in place and not only show them that we are committed to these but that we have the framework and infrastructure to deliver more sustainable buildings so compliance is very important.

Increased governmental regulations are also part of the compliance motivation one company (Company 4) referenced in their CR\&S reporting, particularly for GHG emissions. Additionally, construction firms also mentioned that sustainability is seen as a prerequisite for doing business with many clients who are demonstrating higher levels of transparency, responsibility and leadership in areas relating to CR\&S. Although Tables 42 and 43 in Appendix F - XXIII and F - XXVI did not generate direct words containing leadership, recognition or compliance, they do allude to their importance through terms such as "clients", "employees", "governments", "accountability, "responsibility", and "regulations" (Table 42 under Appendix F - XXIII) and "competitive" and "management" (Table 43 in Appendix F - XXIV). 


\subsubsection{LeAding CR\&S ImPLEMENTATION AND TRACKING MethOdS FOR CONSTRUCTION FIRMS}

Given that only half (Company 1 and 4) of the identified Canadian construction companies report on CR\&S, tracking methods, as explained by one interviewee (Company 3), are very subjective. All construction companies document social and economic metrics, including those who have not publically disclosed or reported on their CR\&S commitments. Currently, GRI and LEED are two leading reporting and certification frameworks guiding the Canadian construction industry toward their efforts in implementing and tracking their CR\&S performance. Appendix F's Tables 44 and 45 provide the top 25 most frequently used words as referenced across CR\&S reports and transcribed interviews. However, the study found no significant bearing on the results.

\subsubsection{LEADING CR\&S BARRIERS FOR CONSTRUCTION FIRMS}

Several categories representing major barriers toward the CR\&S efforts of the construction firms in the study were identified. The following categories were identified through the interviews conducted with subject matter experts:

\section{Awareness}

All interviewed construction participants (Companies 1 through 3) identified a general lack of awareness and understanding toward CR\&S, particularly the notion of sustainability, as a major barrier in gaining corporate buy-in. Aligning corporate targets and employee engagement were considered particularly challenging given the lack of consensus on terminology and definition surrounding CR\&S. During the interview, one participating construction firm (Company 1), noted that the company still finds it challenging to align corporate vision across organizational departments and regions: "...one of the barriers is trying to get people to understand what the word sustainability means and being comfortable that it means something slightly different in one place to another". This is despite the fact that the company had been reporting since 1999 . General lack of awareness and understanding toward CR\&S often leads to associating sustainable projects with high cost, a barrier that all participants (100\%) often face and attempt to overcome by educating both staff and clients. Building a business case around CR\&S, particularly targeting high performance building projects proves to be challenging when long-term vision and commitment do not align or are not well defined. 


\section{Commitment}

Varying levels of commitment were also deemed as key barriers to integrating CR\&S across the Canadian construction sector. One participant (Company 2) stated that in order to build a valuable business base in favour of CR\&S, organizations need to align their corporate values and goals toward future proofing their organization and addressing the short-sightedness associated with short term plans, and to focus instead on long-term investment solutions. Two participants (Company 1 and 2) also indicated that lack of adequate regulations and frameworks at the government level also disincentivizes the private sector from engaging or pursuing sustainable development projects. This is particularly due to the cyclical nature and lack of long-term commitments from government agendas and policies. One participant (Company 2) urged the Canadian government to participate more proactively and setting precedence in the area of sustainable development by leveraging its tenancy across its real estate portfolio. As explained by the same participant, the lack of governmental commitment forces organizations to internalize the change. All three interviewees stated that corporate and governmental long-term commitments need to reflect the relevance of CR\&S and keep up with the sense of innovation.

Table 46 under Appendix F lists the top 25 word frequency generated from NVivo 10 for barriers identified by the construction industry during their interviews. Although awareness and commitment were mentioned as two leading barrier categories, only awareness generated the most frequently used words.

\subsection{RESULTS SUMMARY}

Following the organizational structure outlined in Figure 10, the aforementioned subquestions, in support of the general background and CR\&S assessment per CRE stakeholder, help to address the principle research question. As such, the results illustrated in Figure 22 are summarized as follows: 


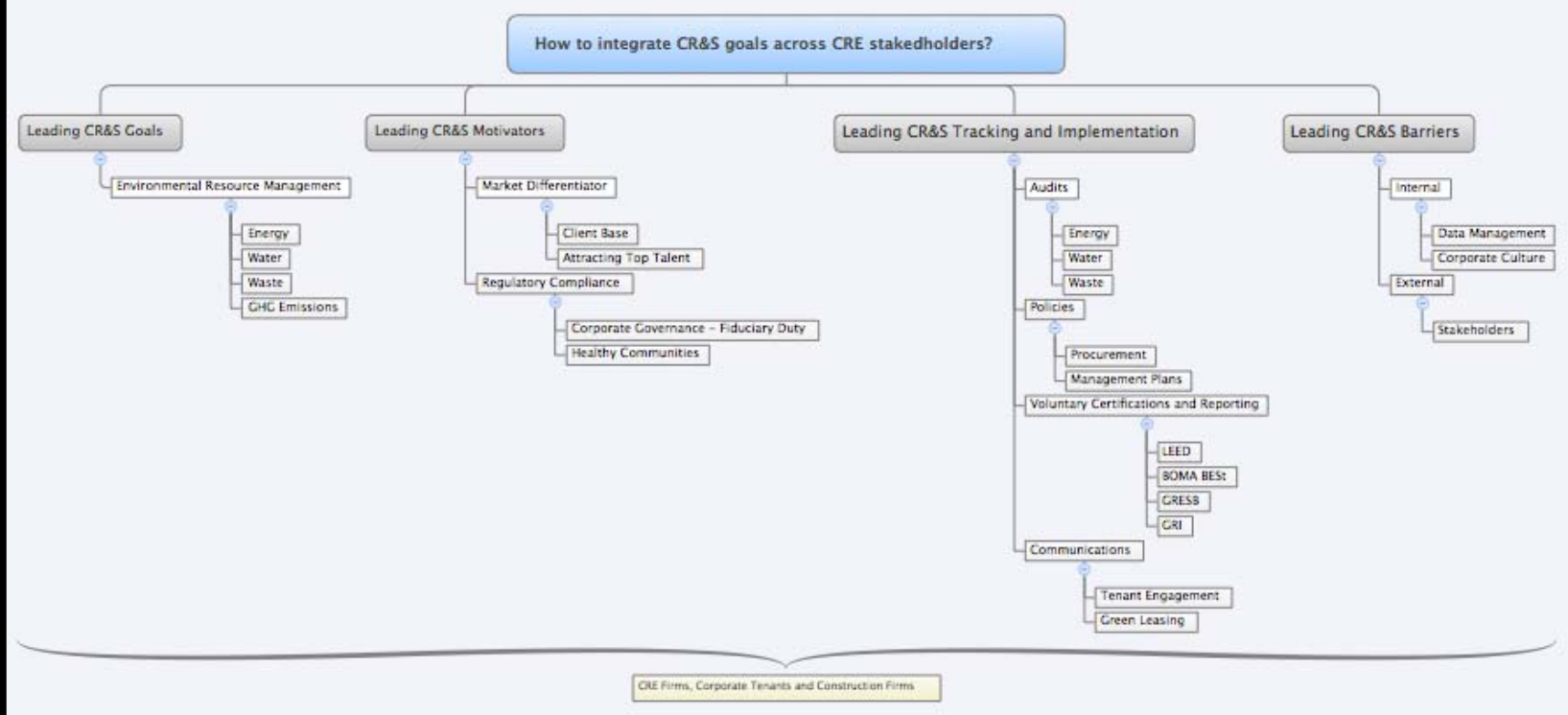

Figure 20 Integrating CR\&S Goals across Canadian CRE Stakeholders - Summary Analysis

\subsubsection{GENERAL BACKGROUND INFORMATION}

Overall the selected CRE stakeholders represent significant leverage for the Canadian CRE market, as they either own or manage approximately $23 \%$ of Canada's total square footage of office building assets, hold an estimated 2\% of Canada's gross office leasing area, and account for an estimated \$12.1 billion toward Canada's new building developments. Table 17 below provides an overall summary based on previously discussed general sector information, which confirms the sampled CRE stakeholders' industry influence.

Even though the research did not seek to investigate the roles and responsibilities as they relate to each interviewed subject matter expert, the representatives of all three CRE stakeholders held various levels of executive management titles, specializing across a range of related CR\&S roles as illustrated in Table 18. Further comparative investigation is recommended on the impact varying CR\&S based roles and responsibilities across the CRE sector pose on integrating CR\&S goals. 
Table 17 Overall Building Space and Construction Project Overview

\begin{tabular}{|c|c|c|l|c|}
\hline & \multicolumn{3}{|c|}{ STAKEHOLDER } \\
\cline { 2 - 5 } & CRE & Tenants & Construction \\
\hline $\begin{array}{c}\text { SAMPLED ft } \\
\text { (millions) }\end{array}$ & 119,821 & 9,576 & $\begin{array}{l}\text { SAMPLED } \\
\text { PROJECT }\end{array}$ & \multirow{2}{*}{$\begin{array}{l}\text { VALUE } \\
\text { (billions) } \\
\text { INDUSTRY }\end{array}$} \\
\hline $\begin{array}{c}\text { INDUSTRY ft } \\
\text { (millions) }\end{array}$ & \multicolumn{2}{|c|}{517,243} & \\
\hline
\end{tabular}

Table 18 Overall CR\&S based roles for sampled CRE stakeholders.

\begin{tabular}{|c|c|}
\hline \multicolumn{2}{|r|}{ CR\&S Titles - CRE Firms } \\
\hline CRE Firms & Titles \\
\hline Company 1 & Director of Sustainability \\
\hline Company 2 & Director of Strategic Initiatives and Planning \\
\hline Company 3 & Director of Operations and Sustainability \\
\hline Company 4 & Director of Sustainability \\
\hline Company 5 & No Interview Conducted \\
\hline Company 6 & No Interview Conducted \\
\hline Company 7 & No Interview Conducted \\
\hline Tenant Companies & Titles \\
\hline Company 1 & Director of Environmental Sustainability and Compliance \\
\hline Company 2 & $\begin{array}{ll}- & \text { Director of Corporate Real Estate } \\
- & \text { Executive Director of Procurement and Real Estate }\end{array}$ \\
\hline Company 3 & $\begin{array}{ll}- & \text { National Leader for Real Estate } \\
- & \text { Manager of Community Leadership }\end{array}$ \\
\hline Company 4 & Environment and Energy Manager \\
\hline Company 5 & Senior Sustainability Issues Management Specialist \\
\hline Company 6 & $\begin{array}{ll} & \text { Senior Vice President of Enterprise Real Estate } \\
\text { - } & \text { Communications Officer at Enterprise Real Estate }\end{array}$ \\
\hline Company 7 & No Interview Conducted \\
\hline Company 8 & No Interview Conducted \\
\hline Company 9 & No Interview Conducted \\
\hline CRE Firms & Titles \\
\hline Company 1 & Sustainability Manager \\
\hline Company 2 & Managing Director for Sustainable Building Services Department \\
\hline Company 3 & Manager of Sustainability Construction \\
\hline Company 4 & No Interview Conducted \\
\hline
\end{tabular}




\subsubsection{ASSESSMENT OF CR\&S ACROSS CRE FIRMS, CORPORATE TENANTS AND CONSTRUCTION FIRMS}

\subsubsection{CR\&S REPORTING}

Integration of CR\&S across the Canadian CRE stakeholders first requires an understanding of each sector's current reporting behaviour. Figure 21 illustrates the CR\&S reporting progression based on 16 publically available CR\&S reports across the 20 sampled CRE stakeholders. In addition to CR\&S based reports, the study also assessed 3 supplementary documents directly related to environmental performance management that were publically available (note that these documents were only provided by 3 corporate tenants from the financial industry). Appendix $\mathrm{C}$ provides a detailed list of the analyzed documentation. Figure 21 reveals that the construction sector was the first CRE stakeholder to commence reporting (in 1999). A second construction firm published their first CR\&S report in 2010, while the remaining 2 sampled construction firms have yet to issue a report. Corporate tenants began CR\&S reporting in 2002, with all 9 corporate tenants reaching CR\&S reporting by 2009; while one CRE firm began their first CR\&S reporting in 2008 with 5 out 7 CRE firms issuing a CR\&S report by 2011.

The $71 \%$ of CRE firms (5 out of 7 sampled CRE firms) who developed and published a CR\&S report indicates a growing industry trend and pressure for CRE firms to develop transparent CR\&S reporting behaviour that expands beyond websites. As previously indicated by interviewees from construction firms, half of the sampled construction sector is in the process of developing their CR\&S reporting structure in order to comply with GRI's CRESS reporting requirements. 


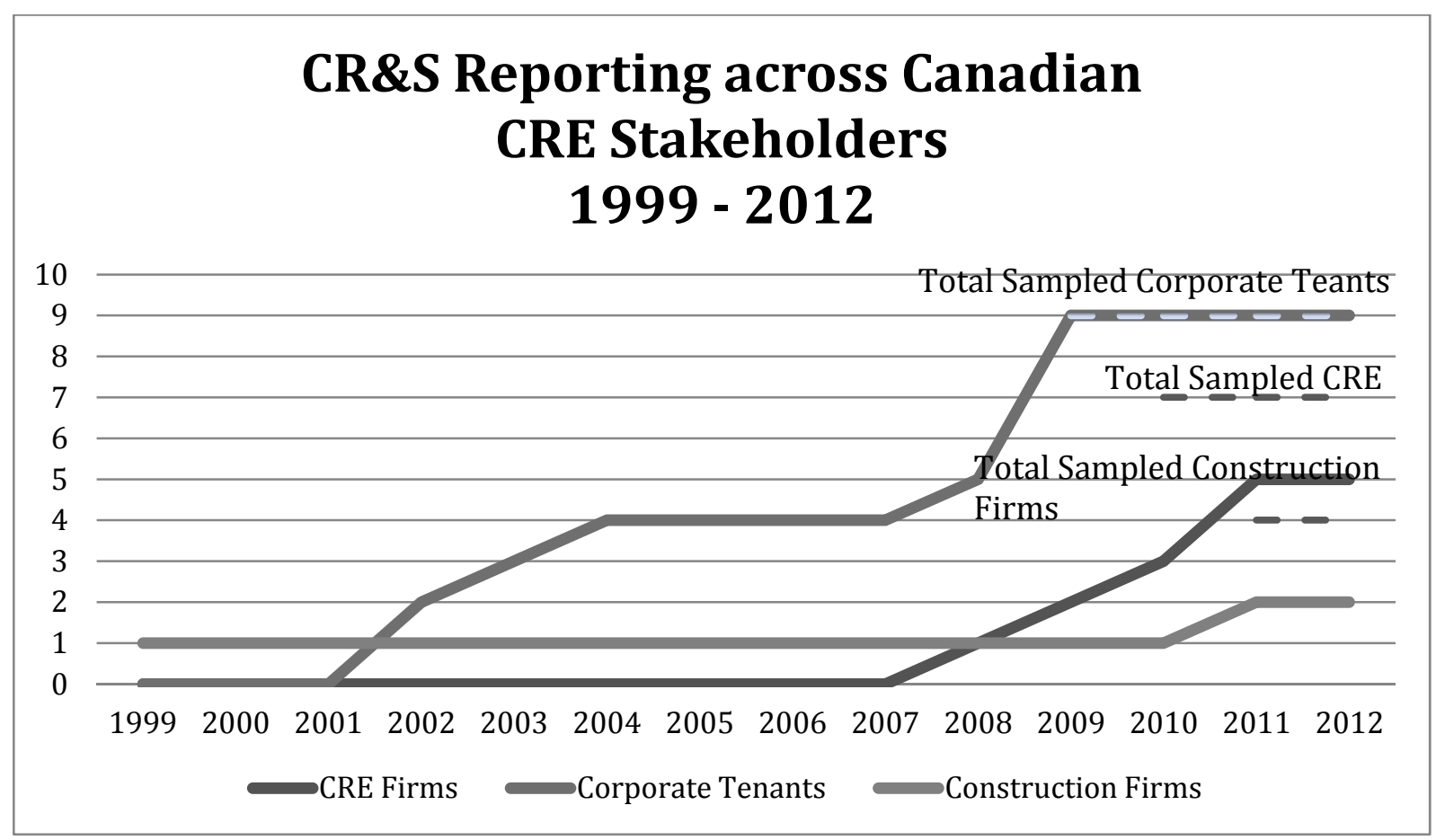

Figure 21 Overall CR\&S Reporting across CRE Stakeholders.

As identified by Prakash and Rappaport, information inductance explains the connection between reporting and actual performance. Voluntary certifications (such as LEED and BOMA BESt) along with industry reporting (GRI and GRESB) shape CRE'S overall reporting behaviour. However, this voluntary reporting and certification behaviour is not necessarily indicative of high building or occupant performance. Difficulty in finding comparable data and absolute data is one challenge attribute to poor performance behaviour.

\subsubsection{CR\&S DEFINITION}

Deriving a commonly accepted definition of CR\&S across the CRE industry would provide a strong basis for integrating CR\&S goals. The definitions of CR\&S used by all of the companies in the study were analyzed through both the publicly available documentation and the interviews. The analysis reveals that all three CRE stakeholders generally refer to "commitment", "reduction", "operations", "risk management" and "environment" as key words in their CR\&S definition. As previously stated, CR\&S is broadly viewed by CRE firms as a commitment to help reduce the impact of their business operations on the environment in which they operate. CRE firms' operating environment comprise of surrounding communities in which their assets are held, managed, and operated. CR\&S reports across CRE firms also detail their accountability toward shareholders (inclusive of institutional investors) and their commitments to create 
healthy environments for their tenants and employees. Generally, corporate tenants define CR\&S as a commitment to protecting both the physical and human environments in which they operate, while striving toward continuous operational improvement. Finally, construction firms largely defined CR\&S as a business strategy set to minimize operational and investment risks by providing efficient, healthy and enduring construction projects that maximize as much as possible their applicability for all stakeholders.

Overall, CRE stakeholders recognize the scale and extent their business operations impact elements of ESG, particularly with regards to environmental resource management. Ultimately, there are some common elements in terms of how all three CRE stakeholders define CR\&S, particularly with respect to the implementation of environmental resource management to safeguard business operations and mitigate potential investment risks. Given the established CR\&S definitions provided by each CRE stakeholder and their similarity in employing "commitment", "reduction", "operations", "risk management" and "environment", a common base for integrating CR\&S goals across the Canadian CRE sector is possible.

\subsubsection{Top CR\&S Goals}

Elements of ESG are included in the CR\&S goals across all three CRE stakeholders. However, as identified through the assessment of CR\&S reports and their supplementary documentation, along with the results derived from interviews, the environmental element of ESG is heavily emphasized due to its principal bearing on real estate operations. As explained during the interviews, the environmental element provides a quantitative framework that is directly related to the CRE sector's operating environment. Therefore, in an effort to integrate CR\&S goals across the CRE sector, emphasis was placed on exploring the following leading CR\&S goals whose main concern is on environmental resource management. Table 19 and Figure 21 illustrate the leading identified CR\&S goals for cross-integration within the Canadian CRE sector: 
Table 19 Top Leading CR\&S Goals Identified across CRE Sector through available CR\&S Reporting

\begin{tabular}{|c|c|c|c|}
\hline \multirow{2}{*}{ Goals } & \multicolumn{3}{|c|}{ CRE Stakeholders } \\
\cline { 2 - 4 } & CRE Firms & $\begin{array}{c}\text { Corporate } \\
\text { Tenants }\end{array}$ & Construction Firms \\
\hline Energy & $86 \%$ & $100 \%$ & $25 \%$ \\
\hline Water & $71 \%$ & $100 \%$ & $25 \%$ \\
\hline GHG & $71 \%$ & $100 \%$ & $50 \%$ \\
\hline Waste & $86 \%$ & $78 \%$ & $25 \%$ \\
\hline
\end{tabular}

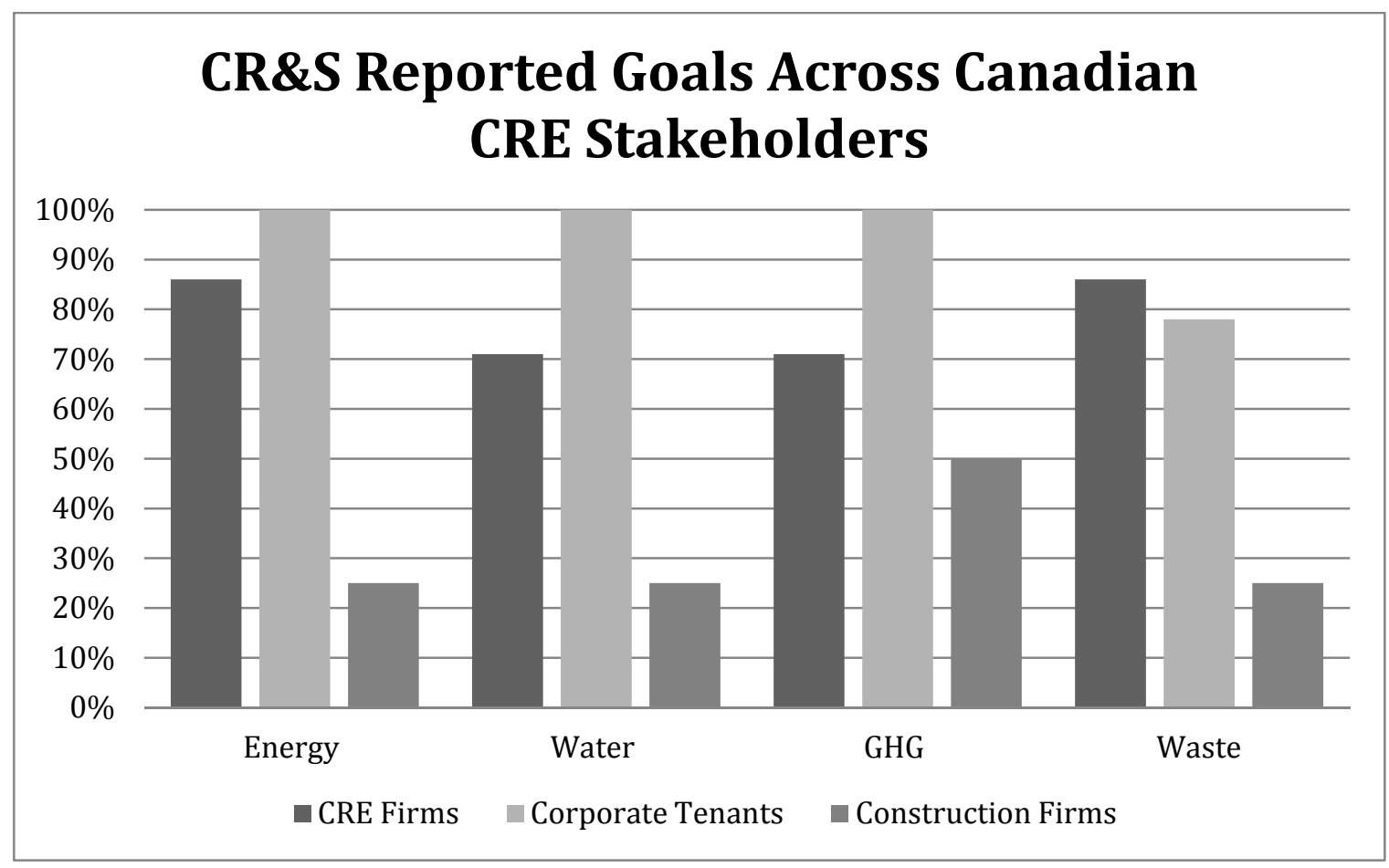

Figure 22 Leading CR\&S Goals Identified across CRE Sector through available CR\&S Reporting

\section{Energy Management}

A majority of the selected companies in the study reported on their overall corporate energy management. Eighty-six percent (6 out of 7) of the CRE firms, 100\% (9 out of 9) of corporate tenants, and $25 \%$ of construction firms reported to some degree on their 
corporate energy management. According to disclaimers listed under CR\&S reports, energy performance across the CR\&S reports were normalized by occupancy rate, weather and changes across individual asset holdings, as based per their collection and assessment of energy bills (for example, electricity, natural gas, or steam). Several overarching issues were prevalent across varying baseline reports for all CRE stakeholders reporting on energy management, such as inconsistent use of metric units, reporting baselines, and lack of set reduction targets (both consumption and yearly based targets).

Water Management

Public reports on water consumption data were reasonably consistent across CRE firms (reported by 5 out of 7 companies). In comparison, although $100 \%$ of public CR\&S reports published by corporate tenants identified water as a natural resource integral to their business operations, data related to their water consumption were scarce (only provided by 3 out of 9 sampled firms). Similarly, 25\% of construction firms identified the importance of water; however, no consumption data were made available on their building space operations nor on the possible savings resulting from the construction of their projects. As with energy management, inconsistencies in water consumption data reporting were evident across the CRE sector. Limited water consumption reduction targets were also noted. Due to tenants' lack of control over common areas (such as public washrooms and landscaping maintenance), sampled tenants underreported on their water consumption. However, tenants also reported and indicated during interview sessions plans to engage their landlords in obtaining data.

\section{GHG Management}

In publicly available CR\&S reports, one hundred percent (100\%) of corporate tenants commitments toward GHG reductions, followed by seventy-one percent (71\%) of CRE firms, and fifty percent (50\%) of construction firms. Scope 1 and Scope 2 emissions were reported by $57 \%$ of CRE firms, with no Scope 3 emissions reported. Two corporate tenants included Scope 3 emissions in their reporting. GHG reduction targets were only set and reported by $14 \%$ (represented by 1 out of 7) of the CRE firms. This compares to fourty-four percent (44\%) of tenants who set reduction targets, ranging from two percent (2\%) to fifteen percent (15\%) (as well as one corporate tenant committing to a 1 $\mathrm{tCO}_{2} \mathrm{e} / \mathrm{FTE}$ annual reduction). Both construction companies that reported their annual CR\&S commitments listed GHG reduction as an encompassing environmental goal and disclosed metrics and targets. Disclosures included short-term fuel purchase and office 
space energy consumption reduction targets, along with long-term targets for 2015 and the development of a company-wide GHG inventory process.

\section{Solid Waste Management}

Hazardous and non-hazardous waste diversion rates and commitments were widely reported. Eighty six percent of CRE firms, $78 \%$ of tenants, and $25 \%$ of construction firms identified solid waste management as another leading environmental resource management goal. Typical reporting in this area by CRE firms included annual waste diversion rates by materials, including waste to landfill, mixed paper and cardboard, recycled, comingled metals/sheet, organic compost and wood. Corporate tenants identified and reported on their paper reduction strategies separately from their waste management strategies. Collaboration with landlords to track, disclose and manage waste was reported by only one $(11 \%)$ of the anchor tenants. Generally, the construction sector only made general statements on their waste management commitments. Limited waste diversion targets where noted across the sampled CRE sector.

As indicated by the above results, the environmental element of ESG is identified as a key driver for developing CR\&S goals within the CRE sector, primarily intended to mitigate investment risks and reduce operational costs. This in turn presents the possibility of cross-integrating the identified leading CR\&S goals within the Canadian CRE sector. In order to ensure effective cross-integration of the identified leading CR\&S goals, it is evident that collecting and analyzing data as they relates to energy, water, waste, and GHG emissions is increasingly gaining importance. This is particularly important given the efforts of the companies studied to develop and establish reduction targets and further the environmental resource management element of their CR\&S strategy. Therefore, the above identified goals indicate the strong significance each environmental resource management element holds on the operational behaviour of those studied. As industry-based regulations and reporting requirements with respect to CR\&S continue to increase, these identified environmentally focused CR\&S goals will continue to hold significant bearing on the future development of CR\&S with the Canadian CRE sector. Given the respective operational interdependency between the stakeholders in the CRE sector, aiming to understand and integrate their respective CR\&S goals will assist in panoptic regulatory and reporting compliance. 


\subsubsection{Motivators}

The two main motivators that were consistently identified were market differentiators and regulatory compliance strategies. Through the market differentiator approach, the sampled companies aim to control their market share, both in terms of attracting and keeping new clients, corporate tenants or development projects. The findings indicate that CRE firms view their ESG based CR\&S initiatives as strategies set to align their asset management service offerings with investor clients seeking to reduce potential risks to their long-term real estate investment objectives. Similarly, tenants and construction firms sought alternative strategies to differentiate their corporate brands with respect to their competition, and as such, view CR\&S as an added approach to expand their market share and also attract and recruit top talent. Therefore, developing and implementing CR\&S commitments were generally identified as performance value driven and market differentiating strategies for the Canadian CRE sector.

Regulatory compliance is identified as a second main motivator for developing and implementing the identified CR\&S goals, which all three CRE stakeholders view as strategies for mitigating potential investment risks. Corporate governance, along with fiduciary accountability; and operating in healthy communities were classified as submotivators to regulatory compliance for all three CRE stakeholders. Complying with industry regulations as it relates to $C R \& S$, has been identified by all three CRE stakeholders as leading to "good business", both in terms of maintaining fiduciary responsibility and enhancing the communities in which all three stakeholders operate. Seeing as how "market differentiator" and "regulatory compliance" are the two leading CR\&S motivators identified by the sampled CRE stakeholders, integrating the four above mentioned CR\&S goals across the Canadian CRE sector becomes possible. As already stipulated, all three stakeholders share two leading motivators, which they can leverage in terms of furthering their respective CR\&S goals and commitments, building favorable business cases in support of CR\&S goals with elements of environmental resource management and ultimately leading to cross-industry integration.

\subsubsection{Tracking and Implementation}

Following the identification of leading CR\&S goals and subsequently their leading motivators, identifying how the aforementioned CR\&S goals are tracked and implemented across the Canadian CRE sector is central to integration. The sampled CRE firms, construction firms, and tenants identified a number of tracking and implementation methods for their CR\&S goals in the interviews. These included audits 
(energy, water and waste audits) and implementation of corporate CR\&S based policies, such as sustainable procurement and management plans (directed towards issues such as energy, water, and waste management). Voluntary certification and reporting frameworks, such as LEED, BOMA BESt, GRESB and GRI, are a few examples described by representatives from all three CRE stakeholders as providing CR\&S tracking and implementation directives. A rising necessity to understand building and operational performance was also identified unanimously across all three CRE stakeholders. The need to effectively align CR\&S objectives with the requirements listed under voluntary certifications and reporting frameworks was also acknowledged. Finally, communication strategies were also identified as CR\&S tracking and implementation strategies by CRE firms and corporate tenants. These typically centered on developing tenant engagement programs, along with establishing and negotiating elements of environmental resource management into leases (also referred as "green leases"). Although the latter presents an area requiring further investigation, elements of CR\&S (such as environmental resource management) are incorporated to certain levels within leasing agreements. Given the relatively new introduction of CR\&S among the construction sector, construction firms stated that implementation and tracking strategies are still under development.

Ultimately, given that general tracking and implementation strategies, such as audits; policies; voluntary certifications and reporting; along with communication strategies; are currently employed by 2 out of 3 sectors studied, they present possible integrative methodologies for CR\&S across Canada's overall CRE sector. These tracking and implementation strategies offer engagement opportunities between CRE firms and their corporate tenants to integrate respective CR\&S goals. Additionally, as construction firms continue to develop their CR\&S strategies, they play a responsive role to the demands generated by CRE firms and corporate tenants.

\subsubsection{Barriers}

Similar barriers regarding the integration of CR\&S goals across their respective organizations were identified by CRE firms, construction firms, and tenants. The identified barriers were categorized either as internal or external, where internal barriers often centered on data management and corporate culture, while external barrier addressed stakeholder behaviour. A key challenge and barrier expressed by $100 \%$ of interviewed participants was insufficient and unavailable data. CRE stakeholders have expressed that their main barrier to implementing sound and effective CR\&S goals and initiatives is due to insufficient data collection and tracking, which hinders their ability to 
manage building performance and occupant behaviour. Furthermore, the lack of available data to manage building performance and occupant behaviour supports the industry reports and academic research noted earlier on the topic of the "circle of blame" between contractors, developers, investors, and occupiers. This study identified that all three CRE stakeholders are willingly to blame others within the sector rather than taking accountability toward establishing methods for tracking and implementing CR\&S goals and minimizing associated barriers. Interviews indicate that CRE firms and corporate tenants circulate the blame for the lack of available data that inhibits their respective efforts toward effectively implementing environmental resource management. Construction firms have also attributed the inability to develop a value-based business case in favour of CR\&S to the lack of quantifiable and readily available data, stating that tenants and CRE firms do not yet request nor provide data. Keeping up with organic growth, on-going innovations, and engaging internal staff are also some of the additional barriers corporate tenants have attributed to corporate culture.

Stakeholder behaviour (identified by the participants as employees, clients, and tenants) was a key external barrier that highlighted the discrepancy in the lack of integrated accountability and responsibility across the CRE industry. The ability of CRE and construction firm's to implement their CR\&S commitments will vary depending on whether they are dealing with multi- to single-based occupancy or investors, as each will have their own CR\&S goals and commitment. CRE and construction firms identified multi-occupant buildings or the management of multi-investor portfolios as presenting additional challenges compared to buildings with single tenants. For example, CRE firms handling or construction firms developing projects for multi-tenants have a challenge in identifying and managing varying CR\&S goals and strategies, versus buildings occupied by a single tenant. On the other hand, corporate tenants identified varying regional mandates and regulations as key barriers and challenges to establishing and meeting their specific CR\&S goals. Understanding common CR\&S barriers allows for the CRE sector to develop strategies that will support CR\&S integration, while minimizing potential challenges that hinder the business case in favor of CR\&S strategies. Seeing as how lack of data collection is identified as a key barrier across all sampled firms, developing a common strategy set to collect, analyze, and management data will allow each CRE stakeholder to strengthen the management of their CR\&S goals and commitment. 


\section{CHAPTER 5: CONCLUSIONS}

\subsection{SUMMARY}

There is little research that addresses CR\&S across the CRE sector, particularly as it relates to the Canadian market. Principles of responsible investment (PRI), through risk management and the global green real estate movement are gaining momentum in Canada and provide a foundation for CR\&S cross-integration among CRE stakeholders. Employing a qualitative research methodology, this study addressed the central research question of how to integrate CR\&S goals across CRE firms, construction firms, and corporate tenants. Four research sub-questions supported the central question. Twenty companies formed the basis for the study. All publicly available documentation related to CR\&S from these companies was reviewed. Fourteen experts representing these organizations were also interviewed. The key results as they relate to the literature review are summarized and discussed below.

Based on the literature review addressing corporate governance, it was argued that the conventional hierarchical power relations between shareholders, managers, employees, and clients still remains the quintessential "black box" for businesses, including within the CRE sector. This implies that the development of CR\&S goals and their integration are driven and supported by the overall corporate governing structure. The identification of corporate governance and fiduciary responsibility as a main CR\&S motivator, sub-categorized under regulatory compliance, by all three CRE stakeholders exemplifies the influence corporate governance plays on determining CR\&S goals and their possible integration. As such, classifying corporate governance as a leading CR\&S motivator supports arguments on identifying environmental resource management as a key ESG element within CR\&S goals. The CR\&S definition provided across all three CRE stakeholders, through whom environmental resource management is defined as an integral element, supports the Russian Doll Framework developed by Schumann. According to Schumann (2010), sustainability is intrinsically embedded within the principles of wealth creation (economics) that drives the development engine, while being constrained by environmental and social considerations. Although the literature review on CR\&S reporting (Searcy and Buslovich, 2013; Adams, 2002) generally highlighted social and economic issues as key drivers of CR\&S reporting, this study underlined the direct role of the environmental elements of ESG in business operation and performance within real estate. 
The analysis in this research also confirmed that transparency and accountability are driving concepts of ESG. These arguments had previously been raised by Monks et al. (2004) and Dunlavy (2006) and illustrated through Figure 2. However, as previously explained in the result analysis, transparency and accountability toward CR\&S are still at the inception stage across CRE and construction firms. The $71 \%$ of CRE firms (5 out of 7 sampled CRE firms) who developed and published a CR\&S report shows a growing industry trend and pressure for CRE firms to develop transparent CR\&S reports that expands beyond websites(as demonstrated by 2 out of 7 CRE firms). Further evidence of this point is provided by the fact that half of the sampled construction sector is in the process of developing their CR\&S reporting structure in order to comply with GRI's CRESS reporting requirements. Moreover, the comparative study conducted by Wenhao and Kaufman (2011), who identified the financial sector as the industry most likely to report on their CR\&S performance, was supported by the analysis of the CR\&S reporting amid the sampled corporate tenants. Given the rising CR\&S reporting trend among all three CRE stakeholders, integration for CR\&S goals within the Canadian CRE sector is an important goal in supporting a more sustainable real estate movement.

In line with Jones Lang Lasalle's (2013) research, the study also supports that the Canadian office real estate space is incrementally embracing the sustainability agenda. However, given the novelty of the concept of sustainability across the Canadian CRE sector, opportunities for integrating CR\&S across all three stakeholders still remain. Similar to the research papers conducted by Warren (2009) and Ellison and Brown (2011), whose research was based on studies of the UK and Australia, the study found that Canadian CRE stakeholders, in general, have tendencies toward policy reporting; while demonstrating weaker practices on their implementation strategies. In addition, the study also concluded that a limited number of respondents in the Canadian CRE sector were able to provide data on their environmental resource management (inclusive of energy and water use, waste, and GHG emissions). This reflects similar CR\&S barriers as the ones identified by Ellison and Brown (2011) for the UK based research. This lack of consistency in reporting can make comparison difficult. As suggested by Warren (2009), research on a tool to rate companies on a like for like basis would be beneficial.

The rating tools identified by Canadian CRE stakeholders include voluntary certification, which Pivo (2008) and Hebb et al. (2010) list as part of the sustainable values that will improve investor's asset performance. Overall, the study affirms that addressing the environmental resource management element of ESG, by implementing 
conservation measures inclusive of energy, waste, waste, and GHG emissions, will allow the Canadian CRE sector to integrate CR\&S goals, which would in turn generate income growth and reduce operating costs by investing and occupying sustainable buildings holding superior value over those holding less desirable sustainable practices and strategies. As such, accounting for the general assessment on CR\&S reporting and definition, along with addressing the four sub-questions relating to leading CR\&S goals, motivators, implementation and tracking strategies, and identifying key barriers, provides a basis for developing strategies set to integrate CR\&S across the Canadian CRE sector. Possible integrative strategies include the development of environmental resource management tools, set to track resource consumption (as it relates to energy, water and waste) and GHG emissions, that CRE stakeholder can share and engage to minimize the collective investment risks and operational costs across the CRE sector. Integrating such a measurement strategy aligns with the identified CR\&S motivators, while addressing associated barriers identified across all three sampled CRE stakeholders.

\subsection{Academic Contributions}

Based on the limited available academic literature addressing CR\&S across the CRE sector, particularly as it applies to the Canadian market, this research provides an important academic contribution. First, the study confirmed that CR\&S reporting is relatively new amid the Canadian $\mathrm{CRE}$ and construction firms, while attesting that corporate tenants, particularly those within the financial sector, are more active CR\&S reporters. In order to ensure that the principles and elements governing CR\&S are common across the Canadian CRE market, the study also helped identify "commitment", "reduction", "operations", "risk management" and "environment", as common base for CR\&S definition as it applies to the CRE sector. As such, the study provides a base that will allow for further analysis and development on CR\&S reporting across the Canadian CRE industry, particularly with respect to global comparative analysis.

Second, the study identified environmental resource management as a key ESG element to integrating CR\&S within the Canadian CRE sector. Although social and governance elements remain identified as leading influences for CR\&S across numerous literature reviews, the study brought closer attention to the impact and significance environmental resource management plays on CR\&S. The study also took first note on the leading CR\&S motivators as they applies to the Canadian sector, an area that was previously conducted for the Australian and UK based markets. 
Third, the study was the first to identify the gaps in implementing and tracking CR\&S goals across the Canadian CRE sector. In particular, this research was the first to address audits, policies, and voluntary building certifications as potential methods to integrate CR\&S goals for the Canadian market. The study notes the need to further investigate the current $C R \& S$ tracking methods and their success rate in meeting $C R \& S$ goals for each respective CRE stakeholder.

Finally, the common elements identified across the internal and external barriers are indicative of the potential for CR\&S cross-integration for all three sampled Canadian CRE stakeholders. Identifying the lack of corporate data, variants in building stocks, and organic corporate growth (to name a few of the identified barriers), will encourage further research in the area of $C R \& S$ and $C R E$, as well as initiating dialogue for the Canadian CRE sector in addressing their common challenges. Notably, the study also identified leading CR\&S roles across the Canadian CRE sector. However, no attempt was made to further investigate their responsibilities and impacts as it relates to CR\&S integration. Therefore, further research on the roles and responsibilities across the CRE sector is recommended. Overall, it is anticipated that the identification of environmental resource management as a key integrative element of CR\&S across the CRE sector will lead to further academic research. The research should also provide a basis for developing further insight on the CR\&S integration measures available for the Canadian CRE sector.

\subsection{Industry Recommendations}

Several industry recommendations can be derived from the analysis presented in this thesis. First, by identifying goals and commitments, the study solidifies environmental resource management as an integral element of CR\&S in the CRE market. As such, it identifies the rising need to develop tools and mechanisms that will facilitate data management and reporting. The CR\&S reporting of the companies studied generally follows the framework and principles outlined in the GRI, which guides industry reporting on elements of ESG, including environmental resource management. Similarly, building certifications such as LEED and BOMA BESt, along with upcoming global benchmarks targeted directly at the CRE industry (i.e., GRESB), require reporting metrics that are inclusive of environmental resource management principles; focusing particularly on energy, water, waste and GHG management. Given the significant weight allocated to operational performance through rising reporting requirements and investment considerations, the collection, assessment, and management of consumption data holds 
incremental value for CRE firms, anchor tenants, and construction firms. Enhanced collaboration among all three CRE stakeholders is necessary in order to develop viable and sustainable environmental resource management plans that will be in alignment with regulatory, tenant, and, ultimately, investor-based pressures for the Canadian CRE market.

Second, the review of CR\&S reports and interviews with subject matter experts highlighted the limited transparency and reporting across the Canadian CRE and construction firms, mainly as it relates to commitments on environmental resource management. Although a number of barriers were identified that influence the inability to effectively report on CR\&S, such as a lack of executive buy-in and available data, the study provides evidence of the necessity to develop tools that will allow for the collection, assessment, and management of readily available data. The study also identifies that this not only plays a significant role for the integration and engagement of CR\&S goals between CRE firms and their tenants, but that it also holds increasing validity for construction firms whose project guidelines (as identified by all three interviewed consumption firms) are directed by both tenants and CRE developers.

\subsection{Limitations}

In the analysis of documents, it was necessary to rely on what was publicly available. It is recognized that there are limitations in terms of what companies choose to publicly disclose. As such, there may be relevant information that was not accessible. Specific limitation also lies across the varying forms of available public documentation and communication pieces that were analyzed through the research, such as material that was extracted through online websites versus PDF documents. Ultimately, the study applied the same analysis criteria used to assess CR\&S reports as it did for alternative communication pieces. However, the analysis takes into account the different time periods reported through these communication pieces, which pose limitations as it pertains to their CR\&S commitment. Additionally, it is possible that there may be a reporting bias in the CR\&S reports reviewed in that they may be emphasizing positive attributes of a company's CR\&S initiatives, rather than disclosing any potential negatives. Similarly, the interviews also contain risks of bias on the part of both the interviewer and the interviewees. Efforts were made to reduce this bias through the use of standardized interview questions and the promise of confidentiality. What is more, due to the study's identified criterion, which binds the analysis on CR\&S amid office buildings, self-selection of downtown class A buildings is identified as another possible 
limitation. Given CR\&S' novelty amid the Canadian CRE market, it possible that the selected sample population mainly occupies, manages or constructs class A office assets, and as such, the analysis may omit the behaviour of class B and C buildings.

\subsection{FUTURE RESEARCH}

As previously noted, limited research has been conducted to address CR\&S within the CRE sector, particularly for the Canadian market. Given CR\&S' infancy across the CRE market, a number of opportunities to further develop and explore possible integration of CR\&S elements within the Canadian CRE sector are evident. Although the study identified Canadian CRE firms, anchor tenants with Canadian operations, and Canadian construction companies as leading stakeholders, further research needs to be conducted to uncover the complex relationships and organizational structures as it relates to real estate investment, brokerage and development.

Developing research to assess CRE firms with similar organizational structure and fiduciary responsibility (for example, further differentiating between REITs, real estate advisory and management firms and brokers), may offer opportunities for in-depth exploration on the factors, incentives, and approaches taken towards implementing $\mathrm{CR} \& S$ across their respective portfolios. This also includes further research on evaluating current corporate lease agreements and their influence on integrating $C R \& S$ goals, mitigating investment risks and reducing operational costs. Firms managing multiple-investor clients, whose real estate investment and property management focus on specific portfolio assets (ranging from office, industrial and retail assets) are areas that hold immense opportunities for further comparative research. The demands driven from a single investor client (typically a leading institutional investor) versus multiple investors (inclusive of private and institutional investors) may generate different results and levels of engagement as it relates to RPI requirements and CR\&S. Additionally, the asset make up may pose a degree of influence in setting targets and achieving $C R \& S$ commitments, as industrial, retail, and office space may exhibit varying levels of operational and tenants behaviour.

The literature argues that institutional investors play a significant role in supporting CR\&S within the CRE sector. Unfortunately, due to the scope of the research, it was not possible to include institutional investors as part of the CRE stakeholders in this study. However, it is strongly recommended that further research be conducted to include Canadian institutional investors' commitment and interest in addressing RPI across their asset portfolios and uncover ways in which the Canadian 
CRE sector can further integrate and support elements of environmental resource management as a means to mitigate potential risks. Appendix B provides a list of UNPRI Canadian signatories that can form an exemplary sample study. An area meriting further research is the investigation of short-term versus long-terms ROIs and their impacts on RPI or CR\&S integration. Tenants pose an additional opportunity to further investigate elements of CR\&S across the CRE sector. Further research could be conducted to investigate tenant behaviour within their corporate offices versus their retail space as it relates to meeting their environmental performance and CR\&S commitments. Similarly, given the rise of CR\&S reporting (particularly with upcoming GRI requirements) across the Canadian construction sector, a comparative research study may also be encouraged in terms of assessing CR\&S across the varying types of projects construction firms undertake. Although corporations and industries focus on incrementally improving their operational and financial performance by implementing applicable elements of sustainability, further research work needs to be conducted to link direct connectivity of performance and reporting to the broader context of sustainability. Therefore, further assessment pertaining to the social and economic elements of sustainability; in addition to the environmental, aspect needs to be further assed. As indicated by the GRI 's G4 Sustainability Reporting Guidelines (2013), CR\&S reports are required to present the organization's performance in the wider context of sustainability, including the context of applicable limits and demands associated on environmental, social and economic resources toward their sector, local, regional or global level. Finally, further research can be aimed directly at assessing executive management teams' (particularly C-suite teams such as CEOs and CFOs) interaction with their boards as it relates to their responsiveness and accountability toward achieving CR\&S commitments. Conducting this type of research would further examine the corporate culture behaviour identified in this study, and also uncover if the discrepancy of achieving CR\&S lies at the operational or corporate governance level.

Regulatory and stakeholder pressures relating to CR\&S are evidently rising across the global CRE sector. Integrative CR\&S opportunities are presented to the Canadian CRE sector, in order to not only participate as a significant player at the global stage but to also mitigate inevitable investment risks associated with rising operational costs and climate change. As such, continuing to develop strategies in support of environmental resource management will allow the Canadian CRE sector to crossintegrate CR\&S and further the sustainable real estate revolution. 
Appendix A Canada's Commercial Real Estate Market-Geographical Spread

\begin{tabular}{|c|c|c|c|c|c|c|}
\hline $\begin{array}{l}\text { British Columbia } \\
\text { Vancouver } \\
\text { Downtown } \\
\text { Downtown Vancouver } \\
\text { Gastown } \\
\text { Yaletown } \\
\text { Vancouver Periphery } \\
\text { Broadway Corridor } \\
\text { Vancouver Outlying } \\
\text { Suburban } \\
\text { Burnaby } \\
\text { Langley } \\
\text { New Westminster } \\
\text { North Vancouver } \\
\text { Richmond } \\
\text { Surrey } \\
\text { Tri-Cities } \\
\text { West Vancouver }\end{array}$ & $\begin{array}{l}\text { Alberta } \\
\text { Edmonton } \\
\text { Downtown } \\
\text { Financial Core } \\
\text { Government District } \\
\text { Suburban } \\
118 \text { th Avenue } \\
124 \text { th Street } \\
149 \text { th Street } \\
\text { Eastgate } \\
\text { South Side } \\
\text { West End } \\
\text { Whyte Ave. } \\
\text { Calgary } \\
\text { Downtown } \\
\text { Central Core } \\
\text { East Core } \\
\text { West Core } \\
\text { Beltline } \\
\text { North Calgary } \\
\text { Northeast } \\
\text { Northwest } \\
\text { South Calgary }\end{array}$ & $\begin{array}{l}\text { Ontario } \\
\text { Toronto } \\
\text { Downtown } \\
\text { Downtown East } \\
\text { Downtown North } \\
\text { Downtown South } \\
\text { Downtown West } \\
\text { Financial Core } \\
\text { King and Dufferin } \\
\text { East } \\
\text { Consumers Rd. } \\
\text { Don Mills and Eglinton } \\
\text { Duncan Mill } \\
\text { Hwy } 404 \text { \& Hwy } 407 \\
\text { Highway } 404 \text { \& Steeles } \\
\text { Pickering } \\
\text { Scarborough } \\
\text { Midtown } \\
\text { Bloor } \\
\text { Eglinton } \\
\text { St. Clair } \\
\text { North } \\
\text { Downsview } \\
\text { Dufferin and Finch } \\
\text { North Yonge } \\
\text { Richmond Hill } \\
\text { Vaughan } \\
\text { Yorkdale } \\
\text { West } \\
\text { Airport Corporate Centre } \\
\text { Airport East } \\
\text { Airport North } \\
\text { Airport West } \\
\text { Bloor \& Ilsington } \\
\text { Brampton } \\
\text { Burlington } \\
\text { Cooksville } \\
\text { Dixie \& Eglinton } \\
\text { Etobicoke North } \\
\text { Etobicoke South } \\
\text { Heartland } \\
\text { Highway } 427 \text { Corridor } \\
\text { Meadowale } \\
\text { Mississauga City Centre } \\
\text { Oakville } \\
\text { Sheridan }\end{array}$ & $\begin{array}{l}\text { Ottawa } \\
\text { Downtown } \\
\text { Downtown } \\
\text { Byward Market } \\
\text { Centretown } \\
\text { Gatineau } \\
\text { Downtown } \\
\text { Suburban } \\
\text { Suburban East } \\
\text { Gloucester } \\
\text { Ottawa East } \\
\text { Suburban West } \\
\text { Kanata } \\
\text { Nepean } \\
\text { Ottawa West }\end{array}$ & $\begin{array}{l}\text { Quebec } \\
\text { Montreal } \\
\text { Downtown } \\
\text { Core } \\
\text { Downtown East } \\
\text { Downtown West } \\
\text { Downtown South } \\
\text { Old Montreal } \\
\text { Midtown } \\
\text { Midtown East } \\
\text { Midtown North } \\
\text { Midtown North West } \\
\text { Midtown Nuns Island } \\
\text { Midtown South West } \\
\text { East End } \\
\text { Laval } \\
\text { Laval Downtown and West } \\
\text { Laval Midtown and East } \\
\text { South Shore } \\
\text { Eastern Part } \\
\text { Western Part } \\
\text { West Islard } \\
\text { Dollard-des-Ormeaux } \\
\text { \& N. Dorval } \\
\text { Saint--Laurent } \\
\text { West End } \\
\text { Quebec City } \\
\text { Downtown } \\
\text { Downtown Fringe } \\
\text { Saint-Roch/OId Quebec } \\
\text { Upper Town/National } \\
\text { Assembly } \\
\text { North-West } \\
\text { Henri-IVHAMEL-Hamel } \\
\text { Leboulrgneuf } \\
\text { North End } \\
\text { Sainte-Foy } \\
\text { Sainte-Foy Laurier Blvd } \\
\text { Sainte-Foy Outskirt } \\
\text { South Shore }\end{array}$ & $\begin{array}{l}\text { Manitoba } \\
\text { Winnipeg } \\
\text { Downtown } \\
\text { Winnipeg Outlying Districts } \\
\text { East } \\
\text { North } \\
\text { South }\end{array}$ & $\begin{array}{l}\text { Atlantic Canada } \\
\text { Charlottetown } \\
\text { Downtown } \\
\text { Core } \\
\text { Outer Core } \\
\text { Waterfont District } \\
\text { Suburban } \\
\text { Fredericton } \\
\text { Downtown } \\
\text { Suburban } \\
\text { Moncton } \\
\text { Downtown } \\
\text { Suburban } \\
\text { St. John's } \\
\text { Downtown } \\
\text { City Core } \\
\text { Periphery Downtown } \\
\text { Suburban } \\
\text { Central } \\
\text { Mount Pearl } \\
\text { North East } \\
\text { West End } \\
\text { Halifax } \\
\text { Downtown } \\
\text { Halifax Outying } \\
\text { Bedford/Sackville } \\
\text { Dartmouth City }\end{array}$ \\
\hline
\end{tabular}

Source: AltusInSite, 2013 


\section{Appendix B UNPRI Canadian Signatories}

ASSET OWNER SIGNATORIES 16

British Columbia Municipal Pension Plan

Caisse de dépôt et placement du Québec

Canada Pension Plan Investment Board

Comité syndical national de retraite Bâtirente

Community Foundation of Ottawa

Fondaction CSN

Fonds de solidarité FTQ

Gestion FÉRIQUE

Healthcare of Ontario Pension Plan (HOOPP)

Native Benefits Plan

Ontario Teachers' Pension Plan

OPSEU Pension Trust

Régime de Retraite de l'Université de Montréal

Régime de retraite de l'Université du Québec

SSQ, Société d'assurance-vie Inc.c

University of Ottawa

\section{INVESTMENT MANAGER SIGNATORIES 26}

Addenda Capital Inc.

Alberta Investment Management Corporation

AlphaFixe Capital Inc.

Aquila Infrastructure Management Inc.

Birch Hill Equity Partners Management Inc.

British Columbia Investment Management Corporation

Caisse d’économie solidaire Desjardins

Cordiant

Fiera Sceptre Inc.

Fonds Desjardins

Global Alpha Capital Management

Hexavest

Montrusco Bolton Investments Inc. (MBII)

NEI Investments

OceanRock Investments Inc.

Optimum Asset Management Inc.

Presima

Qube Investment Management Inc.

Sarona Asset Management

TD Asset Management - TD Asset Management Inc. and TDAM USA Inc.

Tricon Capital GP Inc.

Vancity Investment Management

Waterton Global Resource Management, Inc.

XPV Capital Corporation

PROFESSIONAL SERVICE PROVIDER SIGNATORIES 7 
Corporate Knights

Ellio GP - Strategic Sustainability Consulting

Groupe Investissement Responsable

Mercer Investment Consulting

PBI Actuarial Consultants Ltd

RRSE

SHARE - Shareholder Association for Research \& Education 


\section{Appendix C Documentation checklist-sources used}

\begin{tabular}{|c|l|l|l|l|l|}
\hline \multicolumn{5}{|c|}{ Documentation Checklist } \\
\cline { 3 - 5 } $\begin{array}{c}\text { Company } \\
\text { No. }\end{array}$ & Stakeholder & \multicolumn{2}{|c|}{ Available Documentation } & \multirow{2}{*}{ Sources Used } \\
\cline { 3 - 5 } & & Report & $\begin{array}{l}\text { Supplementary } \\
\text { Documentation }\end{array}$ & Website & \\
\hline 1 & CRE Firm & No & No & Yes & Website \\
\hline 2 & CRE Firm & Yes & No & Yes & CR\&S and Website \\
\hline 3 & CRE Firm & Yes & No & Yes & CR\&S and Website \\
\hline 4 & CRE Firm & Yes & No & Yes & CR\&S and Website \\
\hline 5 & CRE Firm & No & No & Yes & Website \\
\hline 6 & CRE Firm & Yes & No & Yes & CR\&S and Website \\
\hline 7 & CRE Firm & Yes & No & Yes & CR\&S and Website \\
\hline 1 & Tenant & Yes & No & Yes & CR\&S and Website \\
\hline 2 & Tenant & Yes & Yes & Yes & All Three \\
\hline 3 & Tenant & Yes & Yes & Yes & All Three \\
\hline 4 & Tenant & Yes & Yes & Yes & All Three \\
\hline 5 & Tenant & Yes & No & Yes & CR\&S and Website \\
\hline 6 & Tenant & Yes & No & Yes & CR\&S and Website \\
\hline 7 & Tenant & Yes & No & Yes & CR\&S and Website \\
\hline 8 & Tenant & Yes & No & Yes & CR\&S and Website \\
\hline 9 & Tenant & Yes & No & Yes & CR\&S and Website \\
\hline 1 & Construction & No & No & Yes & Website \\
\hline 2 & Construction & No & No & Yes & Website \\
\hline 3 & Construction & Yes & No & Yes & CR\&S and Website \\
\hline 4 & Construction & Yes & No & Yes & CR\&S and Website \\
\hline
\end{tabular}




\section{Appendix D INTERVIEW PROTOCOL}

\section{Project Introduction}

The effective management of corporate real estate holds a critical influence for sustainable development due to the large shares of resource and energy consumption that are required to maintain building operations occupied by corporate organizations (referred to throughout the research as "tenants"). This research project aims to develop an approach for addressing social, environmental and economical (SEE) risks in the Canadian commercial real estate and design sector through integrating tenants' corporate responsibility \& sustainability goals and quantifying the resulting benefits.

\section{Details of the Interview}

This study will help address and integrate a more sustainable approach within the Canadian commercial real estate portfolio. As a starting point, the questions listed below will be asked.

1. Please state your title at the organization.

2. How does your organization define corporate responsibility \& sustainability?

3. What are your organization's motivations for engaging in corporate responsibility \& sustainability initiatives?

4. What are your organization's top CR\&S goals and why has your organization decided to focus on those particular goals?

5. How are these goals and their success rates tracked and ranked? What have been the results?

6. What process and systems has your organization implemented to address these CR\&S goals?

7. Identify any barriers impeding the achievement of your organization's CR\&S goals.

8. Are your organization's CR\&S goals incorporated in your lease (Green Lease)?

9. Discuss the general make-up of your real estate portfolio in Canada.

10. What factors does your organization consider when selecting a commercial real estate property? Who within the organization is involved in the process?

11. What percentage of your commercial real estate portfolio is "green building" certified and which type? Why?

12. Has your real estate portfolio and it's management been influential in meeting your organization's CR\&S goals?

13. Describe any benefits your organization encountered from greening building(s) or your commercial real estate portfolio?

14. What value does your organization see in integrating CR\&S goals into your commercial real estate portfolio?

15. How does your green portfolio fare against others? How do the operating costs of "regular" vs. "green" buildings vary?

16. What are your natural vacancy rates for conventional buildings versus green buildings? 
Appendix E - NVivo 10-Mapping and Screen Shots

\section{CODING AND NODES MAP}

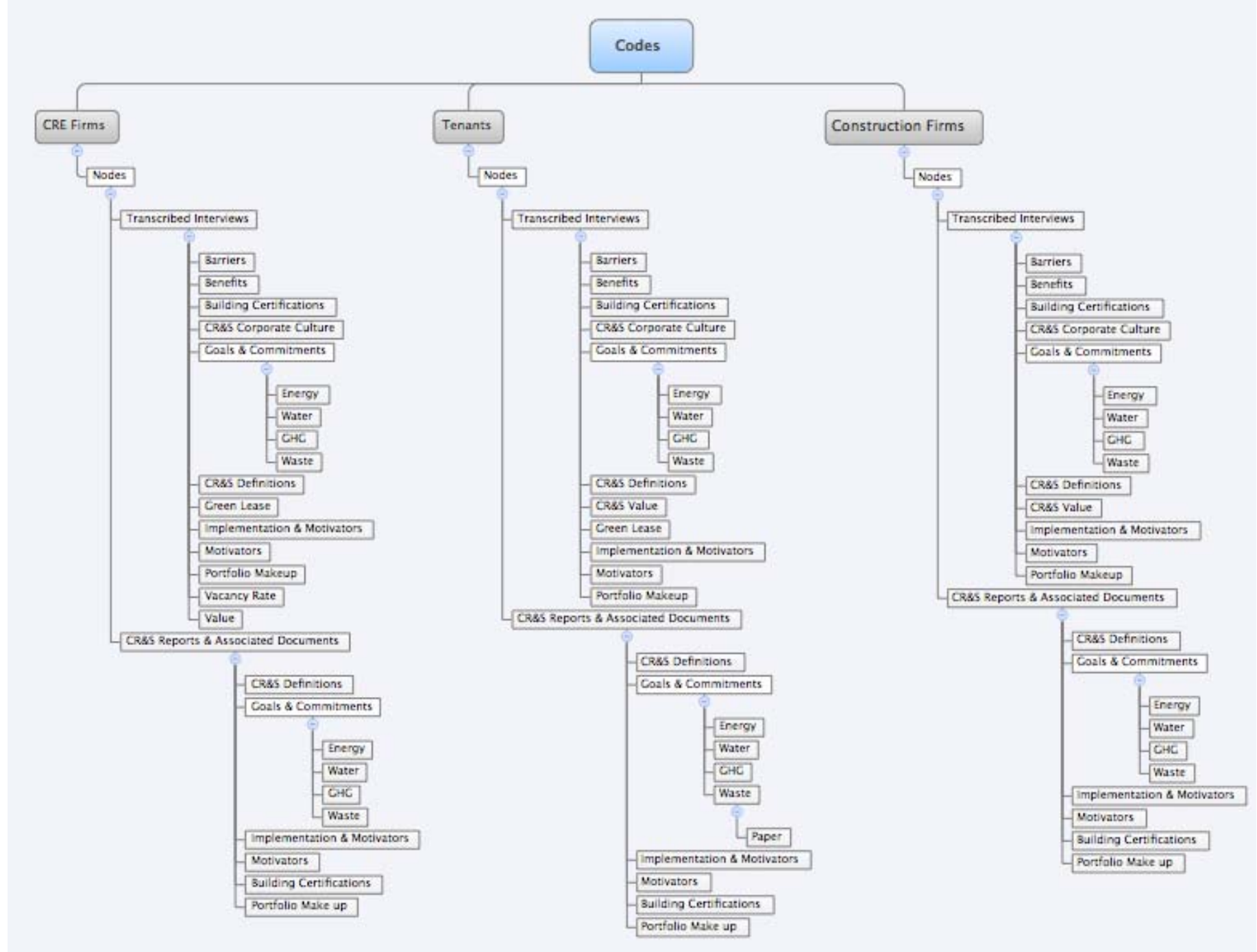


VIVO 10 - SCREEN SHOTS

WORD FREQUENCY QUERY

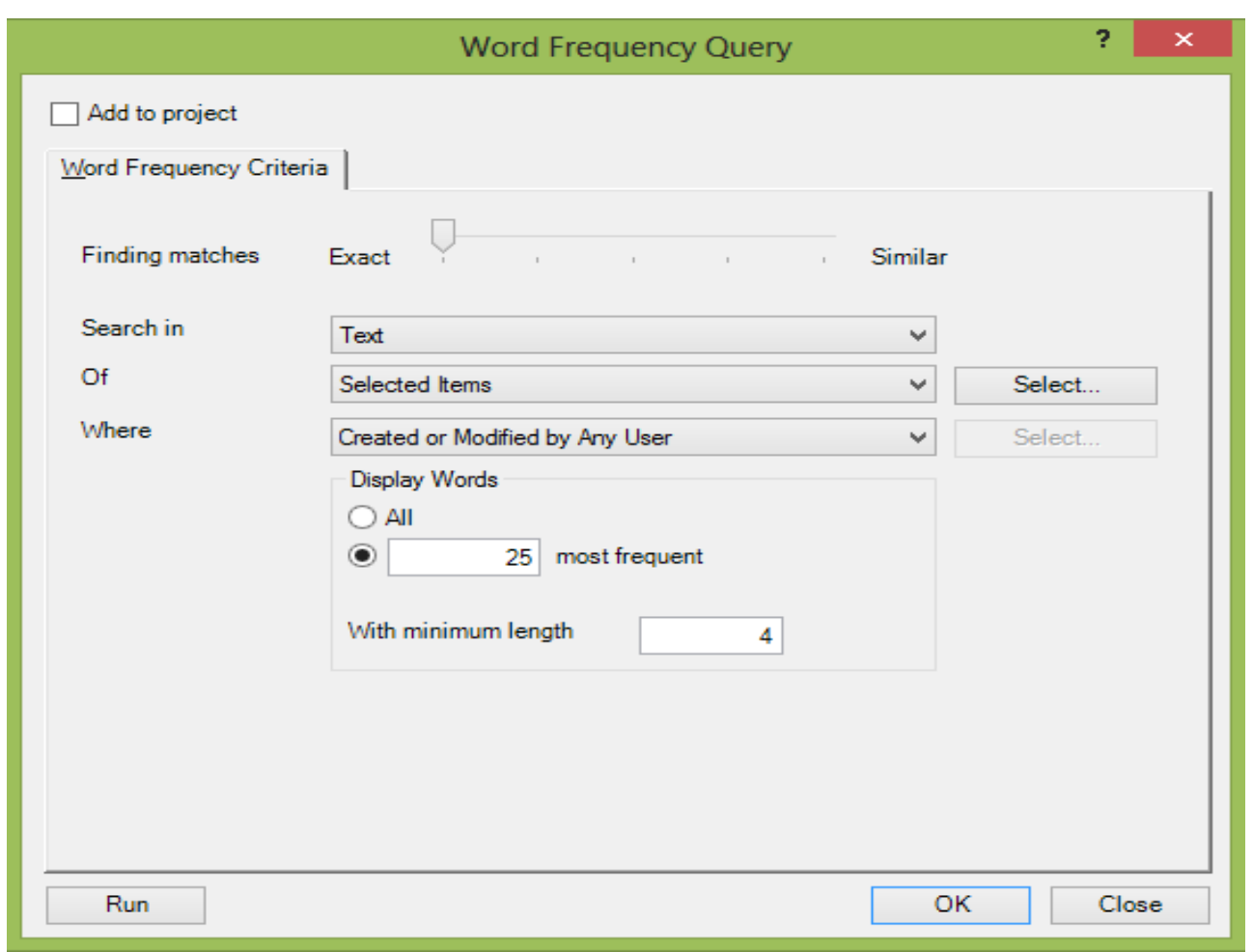




\section{NODES AND CODING}

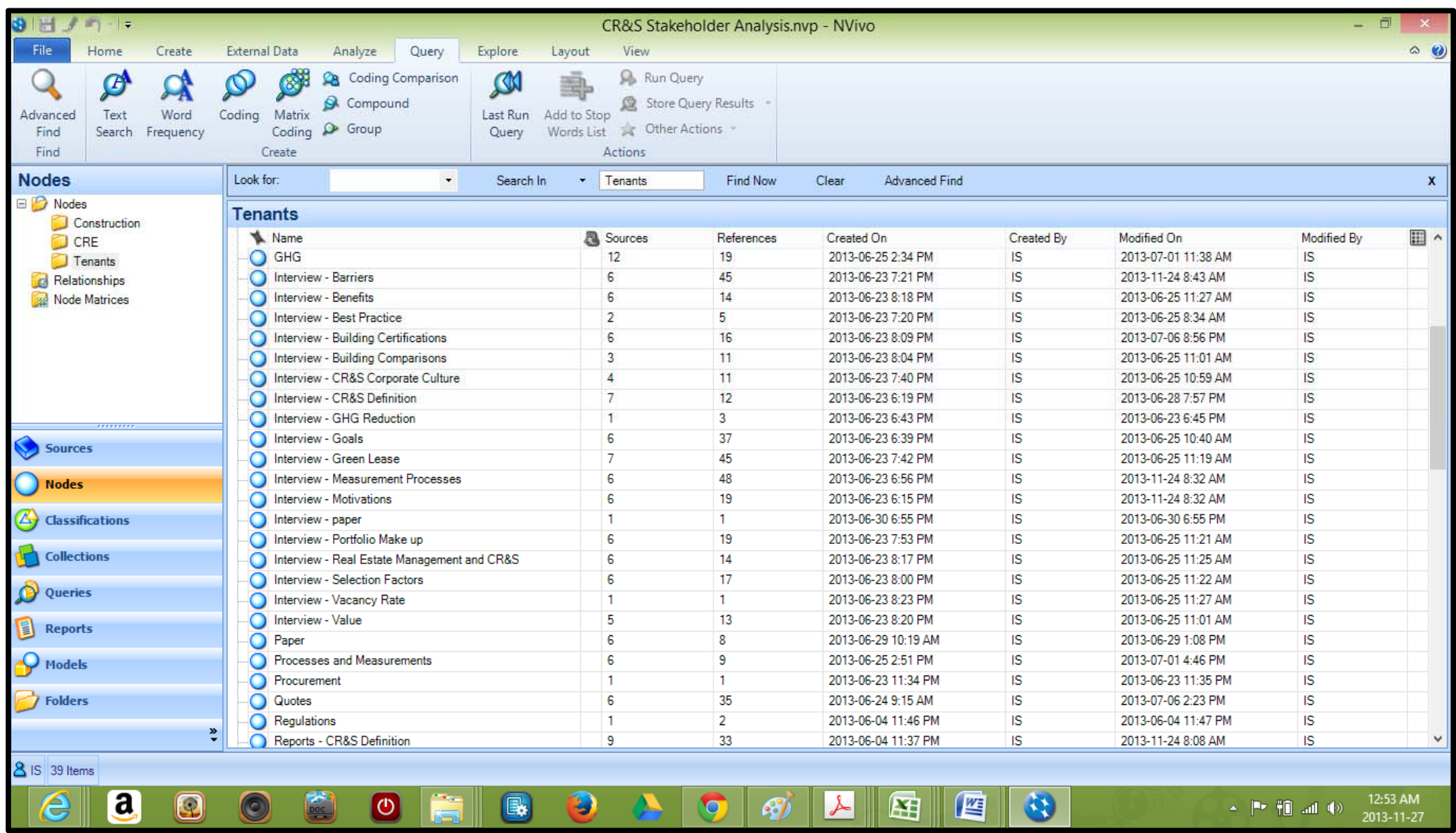


Appendix F - NVivo 10's Word Frequency Query Results - CRS Reports and Interviews

Table 20 Nvivo's Top 25 Word Frequency Query Results for CR\&S Definitions CRE Firms' CR\&S Reports

\begin{tabular}{|l|r|r|}
\hline Word & Count & Weighted Percentage (\%) \\
\hline environmental & 8 & 3.56 \\
\hline commitment & 5 & 2.22 \\
\hline corporate & 5 & 2.22 \\
\hline business & 4 & 1.78 \\
\hline clients & 4 & 1.78 \\
\hline efficiency & 4 & 1.78 \\
\hline enhance & 4 & 1.78 \\
\hline environment & 4 & 1.78 \\
\hline governance & 4 & 1.78 \\
\hline responsibility & 4 & 1.78 \\
\hline social & 4 & 1.78 \\
\hline sustainability & 4 & 1.78 \\
\hline committed & 3 & 1.33 \\
\hline communities & 3 & 1.33 \\
\hline encompasses & 3 & 1.33 \\
\hline energy & 3 & 1.33 \\
\hline live & 3 & 1.33 \\
\hline practices & 3 & 1.33 \\
\hline superior & 3 & 1.33 \\
\hline tenants & 3 & 1.33 \\
\hline work & 3 & 1.33 \\
\hline better & 2 & 0.89 \\
\hline canadian & 2 & 0.89 \\
\hline create & 2 & 0.89 \\
\hline employees & 2 & 0.89 \\
\hline
\end{tabular}


Table 21 Nvivo's Top 25 Word Frequency Query Results for CR\&S Definition CRE Firms' Interview Segments

\begin{tabular}{|l|c|c|}
\hline \multicolumn{1}{|c|}{ Word } & Count & Weighted Percentage (\%) \\
\hline sustainability & 6 & 4.29 \\
\hline think & 4 & 2.86 \\
\hline assets & 3 & 2.14 \\
\hline environmental & 3 & 2.14 \\
\hline social & 3 & 2.14 \\
\hline things & 3 & 2.14 \\
\hline brand & 2 & 1.43 \\
\hline building & 2 & 1.43 \\
\hline just & 2 & 1.43 \\
\hline long & 2 & 1.43 \\
\hline management & 2 & 1.43 \\
\hline obviously & 2 & 1.43 \\
\hline [NAME] & 2 & 1.43 \\
\hline perspective & 2 & 1.43 \\
\hline principles & 2 & 1.43 \\
\hline property & 2 & 1.43 \\
\hline put & 2 & 1.43 \\
\hline responsible & 2 & 1.43 \\
\hline term & 2 & 1.43 \\
\hline terms & 2 & 1.43 \\
\hline value & 2 & 1.43 \\
\hline additional & 1 & 0.71 \\
\hline also & 1 & 0.71 \\
\hline alternative & 1 & 0.71 \\
\hline approach & 1 & 0.71 \\
\hline & & \\
\hline
\end{tabular}


Table 22 Nvivo's Top 25 Word Frequency Query Results for CR\&S Goals - CRE Firms' CR\&S Reports

\begin{tabular}{|l|r|r|r|}
\hline Word & Count & Weighted Percentage (\%) \\
\hline energy & 64 & 1.63 \\
\hline 2011 & 60 & 1.53 \\
\hline properties & 38 & 0.97 \\
\hline water & 38 & 0.97 \\
\hline 2010 & 37 & 0.94 \\
\hline office & 36 & 0.92 \\
\hline waste & 34 & 0.86 \\
\hline retail & 31 & 0.79 \\
\hline sustainability & 30 & 0.76 \\
\hline buildings & 28 & 0.71 \\
\hline canadian & 27 & 0.69 \\
\hline 2008 & 25 & 0.64 \\
\hline environmental & 25 & 0.64 \\
\hline total & 25 & 0.64 \\
\hline performance & 24 & 0.61 \\
\hline portfolio & 22 & 0.56 \\
\hline year & 22 & 0.56 \\
\hline building & 20 & 0.51 \\
\hline intensity & 20 & 0.51 \\
\hline use & 19 & 0.48 \\
\hline leed & 18 & 0.46 \\
\hline canada & 17 & 0.43 \\
\hline emissions & 17 & 0.43 \\
\hline gas & 17 & 0.43 \\
\hline program & 17 & 0.43 \\
\hline
\end{tabular}


Table 23 Nvivo's Top 25 Word Frequency Query Results for CR\&S Goals - CRE Firms' Interview Segments

\begin{tabular}{|l|r|r|}
\hline Word & Count & Weighted Percentage (\%) \\
\hline sustainability & 6 & 4.29 \\
\hline think & 4 & 2.86 \\
\hline assets & 3 & 2.14 \\
\hline environmental & 3 & 2.14 \\
\hline social & 3 & 2.14 \\
\hline things & 3 & 2.14 \\
\hline brand & 2 & 1.43 \\
\hline building & 2 & 1.43 \\
\hline just & 2 & 1.43 \\
\hline long & 2 & 1.43 \\
\hline management & 2 & 1.43 \\
\hline obviously & 2 & 1.43 \\
\hline [NAME] & 2 & 1.43 \\
\hline perspective & 2 & 1.43 \\
\hline principles & 2 & 1.43 \\
\hline property & 2 & 1.43 \\
\hline put & 2 & 1.43 \\
\hline responsible & 2 & 1.43 \\
\hline term & 2 & 1.43 \\
\hline terms & 2 & 1.43 \\
\hline value & 2 & 1.43 \\
\hline additional & 1 & 0.71 \\
\hline also & 1 & 0.71 \\
\hline alternative & 1 & 0.71 \\
\hline approach & 1 & 0.71 \\
\hline
\end{tabular}


Table 24 Nvivo's Top 25 Word Frequency Query Results for CR\&S Motivators CRE Firms' CR\&S Entire Reports

\begin{tabular}{|l|r|r|}
\hline Word & Count & Weighted Percentage (\%) \\
\hline energy & 296 & 1.11 \\
\hline building & 258 & 0.97 \\
\hline 2011 & 242 & 0.91 \\
\hline sustainability & 224 & 0.84 \\
environmental & 197 & 0.74 \\
\hline (NAME) & 189 & 0.71 \\
\hline management & 184 & 0.69 \\
\hline Waste & 179 & 0.67 \\
\hline Green & 168 & 0.63 \\
\hline Water & 163 & 0.61 \\
\hline sustainable & 161 & 0.61 \\
\hline LEED & 160 & 0.60 \\
\hline Program & 157 & 0.59 \\
\hline 2010 & 154 & 0.58 \\
\hline performance & 150 & 0.56 \\
\hline Properties & 150 & 0.56 \\
\hline Property & 142 & 0.53 \\
\hline canada & 133 & 0.50 \\
\hline canadian & 124 & 0.47 \\
\hline Employees & 123 & 0.46 \\
\hline Buildings & 121 & 0.45 \\
\hline Best & 118 & 0.44 \\
\hline practices & 102 & 0.38 \\
\hline Office & 92 & 0.35 \\
\hline programs & 89 & 0.33 \\
\hline & & \\
\hline
\end{tabular}


Table 25 Nvivo's Top 25 Word Frequency Query Results for CR\&S Motivators CRE Firms' Interview Segments

\begin{tabular}{|l|r|r|}
\hline Word & Count & Weighted Percentage (\%) \\
\hline think & 17 & 5.67 \\
\hline piece & 6 & 2.00 \\
\hline sustainability & 6 & 2.00 \\
\hline clients & 5 & 1.67 \\
\hline employees & 5 & 1.67 \\
\hline tenants & 5 & 1.67 \\
\hline important & 4 & 1.33 \\
\hline really & 4 & 1.33 \\
\hline also & 3 & 1.00 \\
\hline assets & 3 & 1.00 \\
\hline better & 3 & 1.00 \\
\hline big & 3 & 1.00 \\
\hline business & 3 & 1.00 \\
\hline existing & 3 & 1.00 \\
\hline factor & 3 & 1.00 \\
\hline kind & 3 & 1.00 \\
\hline obviously & 3 & 1.00 \\
\hline one & 3 & 1.00 \\
\hline part & 3 & 1.00 \\
\hline sort & 3 & 1.00 \\
\hline tenant & 3 & 1.00 \\
\hline terms & 3 & 1.00 \\
\hline third & 3 & 1.00 \\
\hline value & 3 & 1.00 \\
\hline ability & 2 & 0.67 \\
\hline
\end{tabular}


Table 26 Nvivo's Top 25 Word Frequency Query Results for Implementation and Tracking Methods- CRE Firms' CR\&S Reports

\begin{tabular}{|l|r|r|}
\hline Word & Count & Weighted Percentage (\%) \\
\hline energy & 42 & 1.60 \\
\hline sustainability & 38 & 1.44 \\
\hline properties & 32 & 1.22 \\
\hline water & 29 & 1.10 \\
\hline building & 27 & 1.03 \\
\hline green & 25 & 0.95 \\
\hline also & 24 & 0.91 \\
\hline best & 24 & 0.91 \\
\hline [NAME] & 23 & 0.87 \\
\hline management & 21 & 0.80 \\
\hline program & 19 & 0.72 \\
\hline waste & 18 & 0.68 \\
\hline office & 16 & 0.61 \\
\hline performance & 16 & 0.61 \\
\hline initiatives & 15 & 0.57 \\
\hline real & 15 & 0.57 \\
\hline tenants & 15 & 0.57 \\
\hline boma & 14 & 0.53 \\
\hline property & 14 & 0.53 \\
\hline 2011 & 13 & 0.49 \\
\hline buildings & 13 & 0.49 \\
\hline consumption & 13 & 0.49 \\
\hline environmental & 13 & 0.49 \\
\hline industry & 13 & 0.49 \\
\hline sustainable & 13 & 0.49 \\
\hline
\end{tabular}


Table 27 Nvivo's Top 25 Word Frequency Query Results for Implementation and Tracking Methods - CRE Firms' Interview Segments

\begin{tabular}{|l|r|r|}
\hline Word & Count & Weighted Percentage (\%) \\
\hline energy & 5 & 3.38 \\
\hline like & 4 & 2.70 \\
\hline sort & 4 & 2.70 \\
\hline data & 3 & 2.03 \\
\hline really & 3 & 2.03 \\
\hline terms & 3 & 2.03 \\
\hline waste & 3 & 2.03 \\
\hline water & 3 & 2.03 \\
\hline built & 2 & 1.35 \\
\hline clients & 2 & 1.35 \\
\hline going & 2 & 1.35 \\
\hline guess & 2 & 1.35 \\
\hline impact & 2 & 1.35 \\
\hline look & 2 & 1.35 \\
\hline manage & 2 & 1.35 \\
\hline management & 2 & 1.35 \\
\hline mean & 2 & 1.35 \\
\hline measure & 2 & 1.35 \\
\hline might & 2 & 1.35 \\
\hline primary & 2 & 1.35 \\
\hline system & 2 & 1.35 \\
\hline target & 2 & 1.35 \\
\hline targets & 2 & 1.35 \\
\hline think & 2 & 1.35 \\
\hline tool & 2 & 1.35 \\
\hline
\end{tabular}


Table 28 Nvivo's Top 25 Word Frequency Query Results for Barriers across CRE Firms' Interview Segments

\begin{tabular}{|l|c|c|}
\hline Word & Count & Weighted Percentage (\%) \\
\hline think & 13 & 3.33 \\
\hline challenge & 8 & 2.05 \\
\hline still & 6 & 1.54 \\
\hline tenant & 6 & 1.54 \\
\hline engagement & 5 & 1.28 \\
\hline just & 5 & 1.28 \\
\hline really & 5 & 1.28 \\
\hline sometimes & 5 & 1.28 \\
\hline business & 4 & 1.03 \\
\hline clients & 4 & 1.03 \\
\hline difficult & 4 & 1.03 \\
\hline going & 4 & 1.03 \\
\hline sort & 4 & 1.03 \\
\hline also & 3 & 0.77 \\
\hline building & 3 & 0.77 \\
\hline case & 3 & 0.77 \\
\hline certain & 3 & 0.77 \\
\hline completely & 3 & 0.77 \\
\hline energy & 3 & 0.77 \\
\hline goals & 3 & 0.77 \\
\hline impact & 3 & 0.77 \\
\hline kind & 3 & 0.77 \\
\hline sustainability & 3 & 0.77 \\
\hline tenants & 3 & 0.77 \\
\hline understanding & 3 & 0.77 \\
\hline
\end{tabular}


Table 29 Nvivo 10's Top 25 Word Frequency Query Results for CR\&S Definition Corporate Tenants' CR\&S Report

\begin{tabular}{|l|r|r|}
\hline Word & Count & Weighted Percentage (\%) \\
\hline energy & 64 & 1.63 \\
\hline 2011 & 60 & 1.53 \\
\hline properties & 38 & 0.97 \\
\hline water & 38 & 0.97 \\
\hline 2010 & 37 & 0.94 \\
\hline office & 36 & 0.92 \\
\hline waste & 34 & 0.86 \\
\hline retail & 31 & 0.79 \\
\hline sustainability & 30 & 0.76 \\
\hline buildings & 28 & 0.71 \\
\hline canadian & 27 & 0.69 \\
\hline 2008 & 25 & 0.64 \\
\hline environmental & 25 & 0.64 \\
\hline total & 25 & 0.64 \\
\hline performance & 24 & 0.61 \\
\hline portfolio & 22 & 0.56 \\
\hline year & 22 & 0.56 \\
\hline building & 20 & 0.51 \\
\hline intensity & 20 & 0.51 \\
\hline LEED & 18 & 0.46 \\
\hline canada & 17 & 0.43 \\
\hline emissions & 17 & 0.43 \\
\hline program & 17 & 0.43 \\
\hline green & 15 & 0.38 \\
\hline management & 15 & 0.38 \\
\hline
\end{tabular}


Table 30 Nvivo 10's Top 25 Word Frequency Query Results for CR\&S Definition Corporate Tenants' Interview Segments

\begin{tabular}{|l|r|r|}
\hline Word & Count & Weighted Percentage (\%) \\
\hline business & 14 & 2.60 \\
\hline environmental & 13 & 2.42 \\
\hline social & 10 & 1.86 \\
\hline responsible & 8 & 1.49 \\
\hline governance & 7 & 1.30 \\
\hline communities & 5 & 0.93 \\
\hline corporate & 5 & 0.93 \\
\hline people & 5 & 0.93 \\
\hline bank & 4 & 0.74 \\
\hline community & 4 & 0.74 \\
\hline conduct & 4 & 0.74 \\
\hline customer & 4 & 0.74 \\
\hline economic & 4 & 0.74 \\
\hline future & 4 & 0.74 \\
\hline impacts & 4 & 0.74 \\
\hline long & 4 & 0.74 \\
\hline manage & 4 & 0.74 \\
\hline must & 4 & 0.74 \\
\hline responsibility & 4 & 0.74 \\
\hline risks & 4 & 0.74 \\
\hline term & 4 & 0.74 \\
\hline understand & 4 & 0.74 \\
\hline value & 4 & 0.74 \\
\hline vision & 4 & 0.74 \\
\hline actions & 3 & 0.56 \\
\hline
\end{tabular}


Table 31 Nvivo 10's Top 25 Word Frequency Query Results for CR\&S Goals Corporate Tenant's CR\&S Reports

\begin{tabular}{|l|r|r|}
\hline Word & Count & Weighted Percentage (\%) \\
\hline corporate & 7 & 2.83 \\
\hline environment & 7 & 2.83 \\
\hline sustainability & 7 & 2.83 \\
\hline communities & 6 & 2.43 \\
\hline healthy & 6 & 2.43 \\
\hline people & 6 & 2.43 \\
\hline responsibility & 6 & 2.43 \\
\hline organization & 5 & 2.02 \\
\hline really & 4 & 1.62 \\
\hline services & 4 & 1.62 \\
\hline society & 4 & 1.62 \\
\hline think & 4 & 1.62 \\
\hline business & 3 & 1.21 \\
\hline community & 3 & 1.21 \\
\hline economy & 3 & 1.21 \\
\hline engaging & 3 & 1.21 \\
\hline looking & 3 & 1.21 \\
\hline office & 3 & 1.21 \\
\hline subscribe & 3 & 1.21 \\
\hline view & 3 & 1.21 \\
\hline within & 3 & 1.21 \\
\hline area & 2 & 0.81 \\
\hline called & 2 & 0.81 \\
\hline carbon & 2 & 0.81 \\
\hline definition & 2 & 0.81 \\
\hline
\end{tabular}


Table 32 Nvivo 10's Top 25 Word Frequency Query Results for CR\&S Goals Corporate Tenants' Interview Segments

\begin{tabular}{|l|r|r|r|}
\hline Word & Count & Weighted Percentage (\%) \\
\hline goal & 12 & 1.92 \\
\hline paper & 12 & 1.92 \\
\hline reduction & 10 & 1.60 \\
\hline water & 10 & 1.60 \\
\hline carbon & 9 & 1.44 \\
\hline energy & 8 & 1.28 \\
\hline baseline & 6 & 0.96 \\
\hline neutral & 6 & 0.96 \\
\hline community & 5 & 0.80 \\
\hline emissions & 5 & 0.80 \\
\hline estate & 5 & 0.80 \\
\hline priority & 5 & 0.80 \\
\hline real & 5 & 0.80 \\
\hline really & 5 & 0.80 \\
\hline think & 5 & 0.80 \\
\hline three & 5 & 0.80 \\
\hline 2011 & 4 & 0.64 \\
\hline around & 4 & 0.64 \\
\hline corporate & 4 & 0.64 \\
\hline greenhouse & 4 & 4 & 0.64 \\
\hline increase & 4 & 0.64 \\
\hline next & 4 & 0.64 \\
\hline organization & 4 & 0.64 \\
\hline piece & 4 & 0.64 \\
\hline reduce & & 0.64 \\
\hline & & 5 & \\
\hline
\end{tabular}


Table 33 Nvivo 10's Top 25 Word Frequency Query Results for CR\&S Motivators Corporate Tenants' CR\&S Reports

\begin{tabular}{|l|r|r|}
\hline Word & Count & Weighted Percentage (\%) \\
\hline 2012 & 1275 & 0.95 \\
\hline canada & 830 & 0.62 \\
\hline report & 817 & 0.61 \\
\hline environmental & 722 & 0.54 \\
\hline business & 717 & 0.53 \\
\hline corporate & 675 & 0.50 \\
\hline employees & 666 & 0.49 \\
\hline public & 510 & 0.38 \\
\hline financial & 496 & 0.37 \\
\hline responsibility & 478 & 0.35 \\
\hline energy & 475 & 0.35 \\
\hline management & 448 & 0.33 \\
\hline services & 445 & 0.33 \\
\hline social & 428 & 0.32 \\
\hline life & 414 & 0.31 \\
\hline risk & 397 & 0.29 \\
\hline performance & 385 & 0.29 \\
\hline governance & 378 & 0.28 \\
\hline global & 372 & 0.28 \\
\hline information & 372 & 0.28 \\
\hline clients & 367 & 0.27 \\
\hline year & 360 & 0.27 \\
\hline community & 357 & 0.26 \\
\hline also & 342 & 0.25 \\
\hline employee & 334 & 0.25 \\
\hline
\end{tabular}


Table 34 Nvivo 10's Top 25 Word Frequency Query Results for CR\&S Motivators Corporate Tenants' Interview Segments

\begin{tabular}{|l|r|r|}
\hline Word & Count & Weighted Percentage (\%) \\
\hline environmental & 7 & 1.58 \\
\hline business & 6 & 1.35 \\
\hline Firm & 6 & 1.35 \\
\hline footprint & 6 & 1.35 \\
\hline Good & 6 & 1.35 \\
\hline actually & 5 & 1.13 \\
\hline Better & 5 & 1.13 \\
\hline communities & 4 & 0.90 \\
\hline community & 4 & 0.90 \\
\hline Customers & 4 & 0.90 \\
\hline Employee & 4 & 0.90 \\
\hline Energy & 4 & 0.90 \\
\hline Know & 4 & 0.90 \\
\hline Make & 4 & 0.90 \\
\hline operational & 4 & 0.90 \\
\hline perspective & 4 & 0.90 \\
\hline Things & 4 & 0.90 \\
\hline Also & 3 & 0.68 \\
\hline Areas & 3 & 0.68 \\
\hline Blah & 3 & 0.68 \\
\hline Focus & 3 & 0.68 \\
\hline Four & 3 & 0.68 \\
\hline Goals & 3 & 0.68 \\
\hline High & 3 & 0.68 \\
\hline Just & 3 & 0.68 \\
\hline
\end{tabular}


Table 35 Nvivo 10's Top 25 Word Frequency Query Results for CR\&S Implementation and Tracking Methods - Corporate Tenants' CR\&S Reports

\begin{tabular}{|l|r|r|}
\hline Word & Count & Weighted Percentage (\%) \\
\hline Energy & 21 & 1.66 \\
\hline Things & 13 & 1.03 \\
\hline Going & 10 & 0.79 \\
\hline Lighting & 10 & 0.79 \\
\hline Make & 9 & 0.71 \\
\hline process & 9 & 0.71 \\
\hline Actually & 8 & 0.63 \\
\hline Building & 8 & 0.63 \\
\hline Plan & 7 & 0.55 \\
\hline environmental & 6 & 0.47 \\
\hline Just & 6 & 0.47 \\
\hline Much & 6 & 0.47 \\
\hline package & 6 & 0.47 \\
\hline Risk & 6 & 0.47 \\
\hline Terms & 6 & 0.47 \\
\hline vancouver & 6 & 0.47 \\
\hline Audit & 5 & 0.39 \\
\hline Build & 5 & 0.39 \\
\hline Capital & 5 & 0.39 \\
\hline Carbon & 5 & 0.39 \\
\hline Credit & 5 & 0.39 \\
\hline efficient & 5 & 0.39 \\
\hline employee & 5 & 0.39 \\
\hline Every & 5 & 0.39 \\
\hline gone & 5 & 0.39 \\
\hline
\end{tabular}


Table 36 Nvivo 10's Top 25 Word Frequency Query Results CR\&S Implementation and Tracking Methods - Corporate Tenants' Interview Segments

\begin{tabular}{|l|r|r|}
\hline Word & Count & Weighted Percentage (\%) \\
\hline procurement & 16 & 4.49 \\
\hline environmental & 13 & 3.65 \\
\hline Policy & 9 & 2.53 \\
\hline energy & 6 & 1.69 \\
\hline lighting & 5 & 1.40 \\
\hline services & 5 & 1.40 \\
\hline responsible & 4 & 1.12 \\
\hline supply & 4 & 1.12 \\
\hline sustainability & 4 & 1.12 \\
\hline 2012 & 3 & 0.84 \\
\hline achieve & 3 & 0.84 \\
\hline engagements & 3 & 0.84 \\
\hline ensure & 3 & 0.84 \\
\hline party & 3 & 0.84 \\
\hline priorities & 3 & 0.84 \\
\hline products & 3 & 0.84 \\
reflect & 3 & 0.84 \\
\hline step & 3 & 0.84 \\
\hline systems & 3 & 0.84 \\
\hline third & 3 & 0.84 \\
\hline water & 3 & 0.84 \\
\hline 2010 & 2 & 0.56 \\
\hline accent & 2 & 0.56 \\
\hline action & 2 & 0.56 \\
\hline assess & 2 & 0.56 \\
\hline
\end{tabular}


Table 37 Nvivo 10's Top 25 Word Frequency Query Results CR\&S Barriers Corporate Tenants' Interview Segments

\begin{tabular}{|l|r|r|}
\hline Word & Count & Weighted Percentage (\%) \\
\hline Energy & 11 & 1.34 \\
\hline things & 8 & 0.98 \\
\hline challenge & 7 & 0.85 \\
\hline kind & 7 & 0.85 \\
\hline much & 7 & 0.85 \\
\hline organization & 7 & 0.85 \\
\hline building & 6 & 0.73 \\
\hline just & 6 & 0.73 \\
\hline really & 6 & 0.73 \\
\hline stock & 6 & 0.73 \\
\hline always & 5 & 0.61 \\
\hline barrier & 5 & 0.61 \\
\hline boma & 5 & 0.61 \\
\hline business & 5 & 0.61 \\
\hline efficient & 5 & 0.61 \\
\hline estate & 5 & 0.61 \\
\hline everybody & 5 & 0.61 \\
\hline going & 5 & 0.61 \\
\hline know & 5 & 0.61 \\
\hline real & 5 & 0.61 \\
\hline think & 5 & 0.61 \\
\hline able & 4 & 0.49 \\
\hline acquisitions & 4 & 0.49 \\
\hline also & 4 & 0.49 \\
\hline anything & 4 & 0.49 \\
\hline
\end{tabular}


Table 38 Nvivo 10's Top 25 Word Frequency Query Results CR\&S Definitions Construction Firms' CR\&S Reports

\begin{tabular}{|l|r|r|}
\hline Word & Count & Weighted Percentage (\%) \\
\hline sustainability & 14 & 2.88 \\
\hline business & 11 & 2.26 \\
\hline sustainable & 10 & 2.06 \\
\hline environmental & 7 & 1.44 \\
\hline positive & 7 & 1.44 \\
\hline social & 7 & 1.44 \\
\hline strategy & 7 & 1.44 \\
\hline [NAME] & 6 & 1.23 \\
\hline environment & 5 & 1.03 \\
\hline impact & 5 & 1.03 \\
\hline make & 5 & 1.03 \\
\hline projects & 5 & 1.03 \\
\hline support & 5 & 1.03 \\
\hline 2020 & 4 & 0.82 \\
\hline across & 4 & 0.82 \\
\hline [NAME] & 4 & 0.82 \\
\hline communities & 4 & 0.82 \\
\hline company & 4 & 0.82 \\
\hline leading & 4 & 0.82 \\
\hline outcomes & 4 & 0.82 \\
\hline vision & 4 & 0.82 \\
\hline businesses & 3 & 0.62 \\
\hline change & 3 & 0.62 \\
\hline clients & 3 & 0.62 \\
\hline climate & 3 & 0.62 \\
\hline
\end{tabular}


Table 39 Nvivo 10's Top 25 Word Frequency Query Results CR\&S Definitions Construction's Interview Segments

\begin{tabular}{|l|r|r|}
\hline Word & Count & Weighted Percentage (\%) \\
\hline sustainability & 14 & 2.88 \\
\hline business & 11 & 2.26 \\
\hline sustainable & 10 & 2.06 \\
\hline environmental & 7 & 1.44 \\
\hline positive & 7 & 1.44 \\
\hline social & 7 & 1.44 \\
\hline strategy & 7 & 1.44 \\
\hline [NAME] & 6 & 1.23 \\
\hline environment & 5 & 1.03 \\
\hline impact & 5 & 1.03 \\
\hline make & 5 & 1.03 \\
\hline projects & 5 & 1.03 \\
\hline support & 5 & 1.03 \\
\hline 2020 & 4 & 0.82 \\
\hline across & 4 & 0.82 \\
\hline [NAME] & 4 & 0.82 \\
\hline communities & 4 & 0.82 \\
\hline company & 4 & 0.82 \\
\hline leading & 4 & 0.82 \\
\hline outcomes & 4 & 0.82 \\
\hline vision & 4 & 0.82 \\
\hline businesses & 3 & 0.62 \\
\hline change & 3 & 0.62 \\
\hline clients & 3 & 0.62 \\
\hline climate & 3 & 0.62 \\
\hline
\end{tabular}


Table 40 Nvivo 10's Top 25 Word Frequency Query Results CR\&S Goals Construction Firms' CR\&S Reports

\begin{tabular}{|l|r|r|r|}
\hline Word & Count & Weighted Percentage (\%) \\
\hline [NAME] & 24 & 1.55 \\
\hline emissions & 23 & 1.48 \\
\hline environmental & 18 & 1.16 \\
\hline sustainability & 14 & 0.90 \\
\hline business & 12 & 0.77 \\
\hline 2011 & 11 & 0.71 \\
\hline data & 11 & 0.71 \\
\hline projects & 11 & 0.71 \\
\hline sustainable & 11 & 0.71 \\
\hline company & 10 & 0.65 \\
\hline construction & 10 & 0.65 \\
\hline project & 10 & 0.65 \\
\hline waste & 10 & 0.65 \\
\hline performance & 9 & 0.58 \\
\hline water & 9 & 0.58 \\
\hline energy & 8 & 0.52 \\
\hline environment & 8 & 0.52 \\
\hline reduce & 8 & 0.52 \\
\hline corporate & 7 & 0.45 \\
\hline people & 7 & 0.45 \\
\hline practices & 7 & 0.45 \\
\hline recycling & 7 & 0.45 \\
\hline report & 7 & 0.45 \\
\hline site & 7 & 0.45 \\
\hline building & 6 & 0.39 \\
\hline
\end{tabular}


Table 41 Nvivo 10's Top 25 Word Frequency Query Results CR\&S Goals Construction Firms Interview Segments

\begin{tabular}{|l|r|r|}
\hline Word & Count & Weighted Percentage (\%) \\
\hline things & 7 & 1.91 \\
\hline measure & 6 & 1.63 \\
\hline really & 6 & 1.63 \\
\hline think & 5 & 1.36 \\
\hline trying & 5 & 1.36 \\
\hline across & 4 & 1.09 \\
\hline company & 4 & 1.09 \\
\hline different & 4 & 1.09 \\
\hline employee & 4 & 1.09 \\
\hline environmental & 4 & 1.09 \\
\hline initiatives & 4 & 1.09 \\
\hline just & 4 & 1.09 \\
\hline right & 4 & 1.09 \\
\hline side & 4 & 1.09 \\
\hline social & 4 & 1.09 \\
\hline business & 3 & 0.82 \\
\hline economic & 3 & 0.82 \\
\hline focus & 3 & 0.82 \\
\hline goal & 3 & 0.82 \\
\hline goals & 3 & 0.82 \\
\hline going & 3 & 0.82 \\
\hline kind & 3 & 0.82 \\
\hline measures & 3 & 0.82 \\
\hline people & 3 & 0.82 \\
\hline provide & 3 & 0.82 \\
\hline
\end{tabular}


Table 42 Nvivo 10's Top 25 Word Frequency Query Results CR\&S Motivators Construction Firms' CR\&S Reports

\begin{tabular}{|l|r|r|}
\hline Word & Count & Weighted Percentage (\%) \\
\hline sustainability & 6 & 3.03 \\
\hline Business & 4 & 2.02 \\
\hline Clients & 3 & 1.52 \\
\hline company & 3 & 1.52 \\
\hline employees & 3 & 1.52 \\
\hline social & 3 & 1.52 \\
\hline sustainable & 3 & 1.52 \\
\hline accountability & 2 & 1.01 \\
\hline aspects & 2 & 1.01 \\
\hline Efforts & 2 & 1.01 \\
\hline emissions & 2 & 1.01 \\
\hline Future & 2 & 1.01 \\
\hline governments & 2 & 1.01 \\
\hline initiatives & 2 & 1.01 \\
\hline Leading & 2 & 1.01 \\
\hline [NAME] & 2 & 1.01 \\
\hline Quality & 2 & 1.01 \\
\hline regulations & 2 & 1.01 \\
\hline responsibility & 2 & 1.01 \\
\hline Risks & 2 & 1.01 \\
\hline stakeholders & 2 & 1.01 \\
\hline Support & 2 & 1.01 \\
\hline Ability & 1 & 0.51 \\
\hline account & 1 & 0.51 \\
\hline Accurate & 1 & 0.51 \\
\hline
\end{tabular}


Table 43 Nvivo 10's Top 25 Word Frequency Query Results CR\&S Motivators Construction Firms' Interview Segments

\begin{tabular}{|l|r|r|}
\hline Word & Count & Weighted Percentage (\%) \\
\hline company & 13 & 3.39 \\
\hline sustainability & 11 & 2.87 \\
\hline green & 9 & 2.35 \\
\hline buildings & 8 & 2.09 \\
\hline advantage & 5 & 1.31 \\
\hline competitive & 5 & 1.31 \\
\hline well & 5 & 1.31 \\
\hline construction & 4 & 1.04 \\
\hline related & 4 & 1.04 \\
\hline right & 4 & 1.04 \\
\hline services & 4 & 1.04 \\
\hline thing & 4 & 1.04 \\
\hline want & 4 & 1.04 \\
\hline becoming & 3 & 0.78 \\
\hline cases & 3 & 0.78 \\
\hline clients & 3 & 0.78 \\
\hline framework & 3 & 0.78 \\
\hline instance & 3 & 0.78 \\
\hline know & 3 & 0.78 \\
\hline make & 3 & 0.78 \\
\hline management & 3 & 0.78 \\
\hline risk & 3 & 0.78 \\
\hline terms & 3 & 0.78 \\
\hline things & 3 & 0.78 \\
\hline background & 2 & 0.52 \\
\hline
\end{tabular}


Table 44 NVivo 10's Top 25 Word Frequency Query Results Implementation and Tracking Methods - Construction Firms' CR\&S Reports

\begin{tabular}{|l|r|r|}
\hline Word & Count & Weighted Percentage (\%) \\
\hline employees & 6 & 2.06 \\
\hline [NAME] & 5 & 1.72 \\
\hline Reduction & 5 & 1.72 \\
\hline 2010 & 4 & 1.37 \\
\hline Fuel & 4 & 1.37 \\
\hline measure & 4 & 1.37 \\
\hline baseline & 3 & 1.03 \\
\hline emissions & 3 & 1.03 \\
\hline Natural & 3 & 1.03 \\
\hline performance & 3 & 1.03 \\
\hline Vehicles & 3 & 1.03 \\
\hline Waste & 3 & 1.03 \\
\hline Across & 2 & 0.69 \\
\hline Always & 2 & 0.69 \\
\hline Building & 2 & 0.69 \\
\hline Business & 2 & 0.69 \\
\hline communities & 2 & 0.69 \\
\hline Corporate & 2 & 0.69 \\
\hline environmental & 2 & 0.69 \\
\hline Future & 2 & 0.69 \\
\hline increase & 2 & 0.69 \\
\hline landfill & 2 & 0.69 \\
\hline North & 2 & 0.69 \\
\hline Pass & 2 & 0.69 \\
\hline platinum & 2 & 0.69 \\
\hline
\end{tabular}


Table 45 NVivo 10's Top 25 Word Frequency Query Results Implementation and Tracking Methods - Construction' Firms' Interview Segments

\begin{tabular}{|l|r|r|}
\hline Word & Count & Weighted Percentage (\%) \\
\hline well & 17 & 1.77 \\
\hline sustainability & 12 & 1.25 \\
\hline company & 11 & 1.14 \\
\hline things & 11 & 1.14 \\
\hline like & 10 & 1.04 \\
\hline going & 9 & 0.94 \\
\hline also & 8 & 0.83 \\
\hline just & 8 & 0.83 \\
\hline kind & 8 & 0.83 \\
\hline many & 8 & 0.83 \\
\hline think & 8 & 0.83 \\
\hline type & 8 & 0.83 \\
\hline look & 7 & 0.73 \\
\hline right & 7 & 0.73 \\
\hline specific & 7 & 0.73 \\
\hline sure & 7 & 0.73 \\
\hline construction & 6 & 0.62 \\
\hline everybody & 6 & 0.62 \\
\hline health & 6 & 0.62 \\
\hline initiatives & 6 & 0.62 \\
\hline make & 6 & 0.62 \\
\hline management & 6 & 0.62 \\
\hline metrics & 6 & 0.62 \\
\hline policies & 6 & 0.62 \\
\hline policy & 6 & 0.62 \\
\hline
\end{tabular}


Table 46 NVivo 10's Top 25 Word Frequency Query Results for CR\&S Barriers Construction Firms' Interview Segments

\begin{tabular}{|l|r|r|}
\hline Word & Count & Weighted Percentage (\%) \\
\hline think & 13 & 3.44 \\
\hline people & 10 & 2.65 \\
\hline sustainability & 9 & 2.38 \\
\hline well & 7 & 1.85 \\
\hline challenges & 6 & 1.59 \\
\hline means & 6 & 1.59 \\
\hline sometimes & 6 & 1.59 \\
\hline different & 5 & 1.32 \\
\hline always & 4 & 1.06 \\
\hline another & 4 & 1.06 \\
\hline business & 4 & 1.06 \\
\hline complex & 4 & 1.06 \\
\hline going & 4 & 1.06 \\
\hline right & 4 & 1.06 \\
\hline working & 4 & 1.06 \\
\hline Awareness & 3 & 0.79 \\
\hline building & 3 & 0.79 \\
\hline care & 3 & 0.79 \\
\hline categories & 3 & 0.79 \\
\hline challenge & 3 & 0.79 \\
\hline grow & 3 & 0.79 \\
\hline information & 3 & 0.79 \\
\hline make & 3 & 0.79 \\
\hline organization & 3 & 0.79 \\
\hline sectors & 3 & 0.79 \\
\hline
\end{tabular}




\section{Appendix G Environmental Resource Management Data-CRE Firms ENERGY}

\begin{tabular}{|c|c|c|c|c|c|c|c|c|}
\hline & Reporting Year & Baseline & $\begin{array}{c}\text { Energy } \\
\text { Consumption } \\
\text { Reduction as } \\
\text { of } 2011\end{array}$ & $\begin{array}{c}\text { Energy } \\
\text { Reduction } \\
\text { Target }\end{array}$ & $\begin{array}{c}\text { Energy Reduction } \\
\text { Target Year }\end{array}$ & \begin{tabular}{|l} 
Energy \\
Intenstities \\
(ekWh/ft2/yr)
\end{tabular} & $\begin{array}{l}\text { Average } \\
\text { Intensity }\end{array}$ & $\begin{array}{l}\text { BOMA BESt } \\
\text { Average }\end{array}$ \\
\hline Company 1 & - & - & - & - & - & - & \multirow{7}{*}{29.542} & - \\
\hline Company 2 & $2012-2011$ & 2011 & $-3.2 \%$ & - & - & 30 & & Lowest Performing \\
\hline Company 3 & $2011-2010$ & 2010 & $-1.63 \%$ & & & 27.61 & & Lower Middle \\
\hline Company 4 & $2011-2010$ & 2010 & $-2.0 \%$ & & & 37.6 & & - \\
\hline Company 5 & 2011 & 2008 & $-12.0 \%$ & $15.0 \%$ & 2014 & 21 & & Top Performing \\
\hline Company 6 & - & - & - & - & - & - & & - \\
\hline Company 7 & $2011-2010$ & 2010 & $-1.0 \%$ & $10.0 \%$ & 2014 & 31.5 & & Lower Middle \\
\hline
\end{tabular}

\section{WATER}

\begin{tabular}{|l|c|c|c|c|c|c|c|c|}
\hline & $\begin{array}{c}\text { Reporting } \\
\text { Baseline }\end{array}$ & $\begin{array}{c}\text { Water } \\
\text { Consumption } \\
\text { Reduction }\end{array}$ & $\begin{array}{c}\text { Water } \\
\text { Reduction } \\
\text { Targets }\end{array}$ & Average & $\begin{array}{c}\text { Target } \\
\text { Baseline }\end{array}$ & $\begin{array}{c}\text { Water } \\
\text { Intensity } \\
\text { (It/sqf/yr) }\end{array}$ & $\begin{array}{c}\text { Average } \\
\text { Intensity } \\
\text { (It/sqf/yr) }\end{array}$ \\
\hline Company 1 & & - & - & $5 \%$ & - & - & - & 88.3133333 \\
\hline Company 2 & 2009 & $-1.0 \%$ & - & $5 \%$ & - & - & 75 & \\
\hline Company 3 & 2008 & $-3.1 \%$ & - & $5 \%$ & - & - & 78.94 & \\
\hline Company 4 & 2009 & $-3.0 \%$ & $15.0 \%$ & $5 \%$ & 2008 & 2014 & $220 \mathrm{ML}$ & \\
\hline Company 5 & 2007 & $-0.7 \%$ & - & $5 \%$ & - & - & $4.85 \mathrm{m3}$ & - \\
\hline Company 6 & - & - & - & $5 \%$ & - & - & - & - \\
\hline Company 7 & 2005 & $-11.2 \%$ & $10.0 \%$ & $5 \%$ & 2010 & 2015 & 111 & \\
\hline
\end{tabular}

\section{GHG}

\begin{tabular}{|c|c|c|c|c|c|c|c|c|}
\hline & $\begin{array}{l}\text { Reporting } \\
\text { Baseline }\end{array}$ & $\begin{array}{c}\text { GHG } \\
\text { Reduction }\end{array}$ & GHG Targets & Average & Baseline & Goal & $\begin{array}{c}\text { Total GHG } \\
\text { Emission } \\
\text { Savings } \\
\text { (tCO2e) }\end{array}$ & $\begin{array}{c}\text { LEED } \\
\text { Average }\end{array}$ \\
\hline Company 1 & - & - & - & $10 \%$ & - & - & - & - \\
\hline Company 2 & 2009 & $-9.7 \%$ & - & - & & - & $21,508.00$ & \\
\hline Company 3 & 2008 & $-1.7 \%$ & - & - & - & - & $17,242.00$ & \\
\hline Company 4 & 2008 & $-5.0 \%$ & - & - & - & - & $4,828.00$ & \\
\hline Company 5 & 2007 & $-1.2 \%$ & - & - & 2007 & 2011 & $77,819.00$ & \\
\hline Company 6 & - & - & - & - & - & - & - & \\
\hline Company 7 & 2005 & $-1.0 \%$ & $10 \%$ & - & 2010 & 2014 & - & \\
\hline
\end{tabular}

\section{WASTE}

\begin{tabular}{|l|c|c|c|c|c|c|c|c|}
\hline & $\begin{array}{c}\text { Reporting } \\
\text { Baseline }\end{array}$ & $\begin{array}{c}\text { Waste Diversion } \\
(2010)\end{array}$ & $\begin{array}{c}\text { Waste Diversion } \\
(2011)\end{array}$ & $\begin{array}{c}\text { Waste } \\
\text { Divesion } \\
\text { Improvement } \\
\text { Rate }\end{array}$ & $\begin{array}{c}\text { Waste } \\
\text { Diversion } \\
(2011 \text { vs } \\
\text { Baseline) }\end{array}$ & $\begin{array}{c}\text { Waste } \\
\text { Targets }\end{array}$ & $\begin{array}{c}\text { Targets Goal } \\
\text { Year }\end{array}$ \\
\hline Company 1 & - & - & - & - & - & - & & \\
\hline Company 2 & 2009 & $45.00 \%$ & $49.0 \%$ & $3.0 \%$ & $-2.2 \%$ & - & - \\
\hline Company 3 & 2008 & $66.90 \%$ & $71.4 \%$ & $4.5 \%$ & $-11.9 \%$ & - & - \\
\hline Company 4 & 2010 & $69.30 \%$ & $74.80 \%$ & $5.50 \%$ & $-5.5 \%$ & - & $-6.9 \%$ \\
\hline Company 5 & 2009 & $69.00 \%$ & $70 \%$ & $1.0 \%$ & $-10.0 \%$ & $65.0 \%$ & 2011 \\
\hline Company 6 & - & - & - & - & - & - & \\
\hline Company 7 & 2006 & $68.00 \%$ & $65.0 \%$ & $-3 \%$ & $-5.0 \%$ & $60.0 \%$ & - \\
\hline
\end{tabular}


Appendix H - Environmental Resource Management Data- Tenants ENERGY

\begin{tabular}{|c|c|c|c|c|c|c|}
\hline & Reporting Year & Baseline & $\begin{array}{c}\text { Energy } \\
\text { Consumption } \\
\text { Reduction as } \\
\text { of } 2011 \\
\end{array}$ & $\begin{array}{c}\text { Energy } \\
\text { Reduction } \\
\text { Target }\end{array}$ & $\begin{array}{c}\text { Energy Reduction } \\
\text { Target Year }\end{array}$ & Goal \\
\hline Company 1 & 2012 & 2011 & $-6.99 \%$ & - & - & $1,337,650.00$ \\
\hline Company 2 & 2012 & 2011 & $-4.62 \%$ & - & NA & $920,898.00$ \\
\hline Company 3 & 2012 & 2011 & $-1.36 \%$ & - & NA & $2,966,975.00$ \\
\hline Company 4 & 2012 & 2011 & $0.82 \%$ & - & NA & $1,483,492.00$ \\
\hline Company 5 & 2012 & 2011 & $-4.04 \%$ & - & NA & $1,360,490.00$ \\
\hline Company 6 & - & - & - & - & - & - \\
\hline Company 7 & - & - & - & - & - & - \\
\hline Company 8 & 2012 & 2011 & 8.77 & - & NA & $670,000.00$ \\
\hline Company 9 & 2012 & 2011 & $28.49 \%$ & $-2.0 \%$ & Annual & $136,230.00$ \\
\hline
\end{tabular}

\section{WATER}

\begin{tabular}{|l|c|}
\hline & COMMENTS \\
\hline Company 1 & - \\
\hline Company 2 & water reduction strategies 27\% reduction compared to plumbing code \\
\hline Company 3 & discloses consumption in M3) and represents 46\% of portfolio. Will work withlandlords to obtain data \\
\hline Company 4 & focus on gaining data but no direct commentments to targets and goals \\
\hline Company 5 & low-flow models for water fixtures \\
\hline Company 6 & mention of water and consumtpion reduction but its at the refinery stage but have a goal of 12\% byt 2015 \\
\hline Company 7 & no direct measures or goals \\
\hline Company 8 & - \\
\hline Company 9 & - \\
\hline Company 10 & - \\
\hline GHG & \\
\hline
\end{tabular}

\section{GHG}

\begin{tabular}{|l|c|c|c|c|c|c|}
\hline & $\begin{array}{c}\text { Reporting } \\
\text { Year }\end{array}$ & Baseline & $\begin{array}{c}\text { Total GHG } \\
\text { Reduction }\end{array}$ & $\begin{array}{c}\text { GHG } \\
\text { Reduction } \\
\text { Targets }\end{array}$ & Goal Year & $\begin{array}{c}\text { Total GHG } \\
\text { Emission } \\
\text { (tCO2e) }\end{array}$ \\
\hline Company 1 & 2012 & 2011 & $-11.82 \%$ & - & - & 159491 \\
\hline Company 2 & 2012 & 2011 & $-9.1 \%$ & - & - & 2842 \\
\hline Company 3 & 2012 & 2011 & $9.15 \%$ & $10 \%$ & 2016 & 220427 \\
\hline Company 4 & - & - & - & - & - & - \\
\hline Company 5 & 2012 & 2011 & $8.15 \%$ & 1 tCO2e/FTE & 2015 & 129391 \\
\hline Company 6 & 2011 & 2010 & $-4 \%$ & $15 \%$ & 2015 & 402973 \\
\hline Company 7 & 2012 & 2011 & $4.20 \%$ & - & - & 101427 \\
\hline Company 8 & 2012 & 2011 & $-3.61 \%$ & $2 \%$ & Annual & 6992 \\
\hline Company 9 & 2012 & 2011 & $10.80 \%$ & - & - & 25602 \\
\hline
\end{tabular}




\section{References}

AltusInSite. 2013.Research Report: Q3 2013 Quarterly Highlights. http://www.altusinsite.com/index_en.php?page=research_report. June 2013.

Azapagic, A., Perdan, S., 2005. An Integrated Sustainability Decision-Support Framework Part I: Problem Structuring. International Journal of Sustainable Development and World Ecology; Vol. 12, No. 2, pp. 98 - 111.

Azapagic, A., Perdan, S., 2005. An Integrated Sustainability Decision-Support Framework Part II: Problem Analysis. International Journal of Sustainable Development and World Ecology; Vol. 12, No. 2, pp. 98 - 111.

Backhouse, R.E., Medema, S. G., 2009. Retrospectives on the Definition of Economics. Journal of Economic Perspectives, Vol. 23, No. 1, 221 - 233.

BOMA Canada. 2011. BOMA BESt Energy and Environmental Report 2011 (BBEER).

BOMA International. 2013. Building Class Definitions. http://www.boma.org/research/pages/building-class-definitions.aspx. October 2013.

Bonda, P., Sosnowchik, K. 2007. Sustainable Commercial Interiors. John Wiley \& Sons. New York.

Brooks, M., Capanelli, R., 2011. Evidence Backs Green Business Case. Canadian Property Management. Toronto.

Buhr, N. 2007. Sustainability Accounting and Accountability. Unerman, E, Bebbington, J \& O'Dwyer, B (eds) pp. 57-69.

Canadian Property Management. 2012. Who's Who 200 Companies in Canadian Real Estate. Vol. 26.

CaGBC. 2013. LEED Commercial / Institutional. http://www.cagbc.org/Content/NavigationMenu/Programs/LEED/Commerciallnstit utional/default.htm. April 2013.

Chen, Z., Khumpaisal, S. 2009. An Analytical Network Process for Risk Assessment in Commerical Real Estate Development. Journal of Property Investment \& Finance. Vol. 27, No. 3, pp.238 - 258

Corporate Knights. 2012. The Global 100: World Leaders in Clean Capitalism. http://www.corporateknights.com/report/8th-annual-global-100. February 2012.

Crane, A., McWilliams, A., Matten, D., Moon, J., Stegel, D., 2008. The Oxford Handbook of Corporate Social Responsibility. Oxford University Press, Oxford. 
Dahir, A. 2006. Realigning the Corporate Building Blocks: Shareholder Proposals as Vehicle for Achieving Corporate Social and Human Rights Accountability. American Business Law Journal. Vol. 43, No. 2 pp., 365 - 412.

Dodd, M.E. Jr. 1932. For Whom are Corporate Managers Trustees? Harvard Law Review Vol. 45, No. 7, pp., 1145-1163.

Dunlavy, C. 2006. Social Conceptions of the Corporation: Insights from the History of Shareholder Voting Rights. 63 Wash Lee L. Rev. 1347

Eichholtz, P., Kok, N., Yonder, E., 2012. Portfolio Greeness and the Finanial Performance of REITS. Journal of Internal Money and Finance. pp. 1 - 19.

Environmental Protection Agency. EPA's Greenhouse Gas Emission Reductions. http://www.epa.gov/greeningepa/ghg. August 2013.

Ellison, L., Brown, P. 2011. Sustainability metrics for commercial real estate assets establishing a common approach. Journal of European Real Estate Research, Vol. 4, No. 2, pp. $113-130$.

Freeman, I., and Hasnaoui, A. 2010. The meaning of corporate social responsibility: The vision of four nations. Journal of Business Ethics. pp. 1-25.

Friedman, M. 1970. The Social Responsibility of Business Is to Increase Its Profits. New York Times Magazine. pp.32-33, 122, 126.

GRESB, 2012. 2012 GRESB Report. http://gresb.com/content/2012_GRESB_Report.pdf. June 2012

GRI, 2011. Annual Report 2011/2012.

https://www.globalreporting.org/resourcelibrary/GRI-Annual-Report-2011-2012.pdf

September 2012.

Hebb, T., Hamilton, A., Hachigian, H. 2010. Responsible Property Investing in Canada: Factoring Both Environmental and Social Impacts in the Canadian Real Estate Market. Journal of Business Ethics. Vol. 90, pp. 99 - 115.

Jones Lang LaSalle. 2013. Global Market Perspective. First Quarter. http://www.joneslanglasalle.com/GMP/en-gb/Documents/Third-quarter-

2013/pdf/Global\%20Market\%20Perspective-Q3-2013.pdf. September 2013.

Kolluru, R. 1996. Risk Assessment and Management Handbook. N.Y McGraw-Hill. pp. $3.3-4.68$

Krippendorff, K. 1980. Content analysis: an Introduction to its Methodology. Sage Publications. Beverly Hills. 
Krumwiede, D., Hackert A.M., Tokle J., Vokurka, R., 2012. The Practice of Corporate Social Responsibility in Different Countries: A Study of Firms in Canada, Hungary, Italy, Lebanon, Taiwan and the United States. International Journal of Management, Vol. 29, No. 1, Part 2, pp. $389-402$.

Kvale, S., 1996. InterViews: An Introduction to Qualitative Research Interviewing. Sage Publications. Thousand Oaks.

Linkedln. 2005. http://www.LinkedIn.com. October 2012.

Maclean's. 2012. Top 50 Socially Responsible Corporations - 2012. http://www2.macleans.ca/canada-top-50-socially-responsible-corporations-2012/.

October 2012.

Mateus, R., Braganca, L., 2011. Sustainability Assessment and Rating of Buildings: Developing the methodology SBtool ${ }^{P T}-H$. Building and Environment Vol. 46. Pp. 1962 $-1971$.

Mayring, P. 2000. Qualitative Content Analysis. Forum Qualitative Social Research. Vol. 1, No. 2.

McDonough, W. 1992. The Hannover Principles. Design for Sustainability. William McDonough Architects. Charlottesville.

Miles, M. B., Huberman, A. M. (1994) Qualitative data analysis: A sourcebook of new methods. Thousand Oaks, CA: Sage.

Monks, R., Miller, A., Cook, J. 2004 Shareholder activism on environmental issues: A study of proposals at large US Corporations (2000 - 2003). Natural Resources Forum 28, $317-330$.

Morrison Hershfield, 2005 A Business Case for Green Buildings in Canada. Ottawa.

NAIOP "NAIOP Terms \& Definition: U.S. Office and Industrial Market", https://www.naiop.org/en/Research/Terms-and-Definitions.aspx. November 2013.

Network for Sustainable Business. 2010. Embedding Sustainability in Organizational Culture. A How-to Guide for Executives. University of Western Ontario. London.

NVivo 10. 2013. "Using NVivo for Qualitative Research". http://helpnv10.qsinternational.com/desktop/concepts/using_nvivo_for_qualitative_research.htm\# MiniTOCBookMark4http://help-

nv10.qsrinternational.com/desktop/concepts/using_nvivo_for_qualitative_research.htm\# MiniTOCBookMark4. November 2013.

O'Connor, M., Spangenberg, J.H. 2008. A methodology of CSR reporting: assuring a representative diversity of indicators across stakeholders, scales, sites and performance issues. Journal of Cleaner Production Vol. 16, pp. $1399-1415$. 
Persram, S., Lucuik, M., and Larsson, N. 2007. Marketing Green Buildings to Tenants of Leased Properties. Morrison Hershfield. Toronto.

Pivo, G. 2008. Responsible Property Investing: what the leaders are doing. Journal of Property Investment \& Finance. Vol. 26, No. 6, Pp. 562 - 576.

Prakash, P., and Rappaport, A. 1977. Information Inductance and its Significance for Accounting. Accounting, Organizations and Society. Vol 2, No. 1, pp. 29 - 38.

REALpac and Jantzi-Sustainalytics. 2010. Canadian Commercial Real Estate Sustainability Performance Report. Toronto

Schilling, J. 2006. On the pragmatics of qualitative assessment: Designing the process for content analysis. European Journal of Psychological Assessment. Vol. 22, No. 1, pp. 28-37.

Schumann , B. 2010. Impact of Sustainability on Property Values. University of Regensburg. Regensburg.

Searcy, C. and Buslovich, R. 2013. Corporate Perspectives on the Development and Use of Sustainability Reports. Journal of Business Ethics (In press).

Government of Canada. 2002. Public Accountability Statements (Banks, Insurance Companies, Trust and Loan Companies) Regulations. SOR/2002 - 133. Justice Laws Website. http://laws-lois.justice.gc.ca/eng/regulations/SOR-2002-133/FullText.html October.

The Leaders. 2012. Canadian Top General Contractors. Reed Construction Data. http://www.dcnonl.com/images/leaders/leaders2012.pdf. August 2012.

UNEP, 2010. Guidelines on Education Policy for Sustainable Built environments. South Wales.

Van den Hoonaard, D. K. 2012. Qualitative Research in Action. A Canadian Premier. Oxford University Press.

Warren, C., 2009. Measures of environmentally sustainable development and their effect on property asset value. An Australian perspective. Property Management Vol. 28, No. 2, pp. $68-79$.

Waitzer, E. and Jaswal, J., 2009. Peoples, BCE, and the Good Corporate "Citizen". Osgoode Hall Law School and Schulich School of Business, Toronto.

Wenhao, C. and Kaufman, K., 2011. Corporate social responsibility in fortune magazine's top 50 companies: State of action and salient trends. African Journal of Business Management Vol. 5, pp. 11636 - 11651. 